University of San Diego

Digital USD

1990

\title{
The Effects of Collaboration, Organizational Climate, and Job Stress on Job Satisfaction and Anticipated Turnover in Nursing
}

Jaynelle F. Stichler DNSc

University of San Diego

Follow this and additional works at: https://digital.sandiego.edu/dissertations

Part of the Nursing Commons

\section{Digital USD Citation}

Stichler, Jaynelle F. DNSc, "The Effects of Collaboration, Organizational Climate, and Job Stress on Job Satisfaction and Anticipated Turnover in Nursing" (1990). Dissertations. 222.

https://digital.sandiego.edu/dissertations/222

This Dissertation: Open Access is brought to you for free and open access by the Theses and Dissertations at Digital USD. It has been accepted for inclusion in Dissertations by an authorized administrator of Digital USD. For more information, please contact digital@sandiego.edu. 
THE EFFECTS OF

COLLABORATION, ORGANIZATIONAL CLIMATE, AND JOB STRESS

ON JOB SATISFACTION AND

ANTICIPATED TURNOVER IN NURSING

by

Jaynelle F. Stichler

A dissertation presented to the

FACULTY OF THE PHILIP Y. HAHN SCHOOL OF NURSING UNIVERSTITY OF SAN DIEGO

In partial fulfillment of the requirement for the degree DOCTOR OF NURSING SCIENCE

Spring 1990 


\section{ABSTRACT}

THE EFFECTS OF COLTABORATIVE BEHAVIOR, ORGANIZATIONAL CLIMATE, AND JOB STRESS ON JOB SATISFACTION

AND̄ Z̈NTICIPATED TURNOVER IN NURSING

The purpose of this study was to examine the effects of collaborative behavior, organizational climate, and job stress on job satisfaction and anticipated turnover in nursing. The path analytic model of anticipated turnover was temporally ordered with all exogenous variables proposed to directly effect job satisfaction and anticipated turnover and indirectly effect anticipated turnover through job satisfaction. Subjects $(N=188)$ were female Registered Nurses from six hospitals in Southern Califurnia. The majority of the respondents were clinical nurses who worked full time on the day shift, although a significant percentage of the sample also worked part-time or perdiem and were assigned to evening, nights, or rotating shifts. The mean age of the sample was 39 years of age with 6 years of seniority in their current position. Collaborative behavior between nurses arid physicians and between nurses and managers, organizational climate, and job stress had significant predictive validity with job satisfaction and explained $41 \%$ of the variance in job satisfaction. organizational climate and job stress were the strongest predictors of job satisfaction. Age, nurse-manager collaborative behavior and job satisfaction had predictive validity with anticipated turnover and accounted for $31 \%$ of the explained variance in anticipated turnover. Job 
satisfaction was the strongest predictor of anticipated turnover. A post hoc regression analysis of the dimensions of each exogenous variable with the endogenous variables supported the earlier findings. The post hoc model explained $44 \%$ of the variance in job satisfaction and $31 \%$ of the variance in anticipated turnover. Post hoc araiysis of variance revealed several significant group differences in the study variables. Overall job satisfaction scores between evening and night nurses differea significantly ( $\underline{p} \leq .02$ ) with night nurses reporting higier mean scores than evening nurses. Night nurses also reported the lowest mean scores for anticipated turnover with significant group differences related to the assigned shift reported for anticipated turnover. The current study supported the findings of other researchers related to job satisfaction and anticipated turnover. 
Copyright by Jaynelle F. Stichler 1990

All Rights Reserved

V

Reproduced with permission of the copyright owner. Further reproduction prohibited without permission. 


\section{DEDICATION}

This dissertation, one of the more significant accomplishments of my life, is dedicated to several significant persons in my life:

Todd and Ryan, my dear sons, who give me GREAT JOY;

Ronald, my husband, who provides continuous encouragement;

Lillian, my mother, who is a constant stability;

$$
\text { and to }
$$

Marion Hubbard, a dear friend, who helped to make this dream come true. 


\section{ACKNOWILEDGEMENTS}

These years of doctoral study have been a period of transition in my life with a blend of joy and sorrow, success and failure which has rasulted in significant personal and professional growth and accomplishment. For the strength, tenacity, and resolution which often carried me through difficult times, I thank my parents, Lillian Flowers and the late Thomas B. Flowers, who always espoused such beliefs. I am also deeply grateful to my sons, Todd and Ryan, who have also grown and changed through this experience. They were the only boys on the team(s) whose mother sat in the stands reading a book on research, theory, or statistics. I never doubt that you both will also accomplish your dreams one day! My husband, Ronald, deserves acknowledgement for his unending support, encouragement, and assistance through these years of doctoral study and the completion of this dissertation.

These four years have offered the opportunity for me to study with and to meet a number of outstanding professionals. Special thanks is extended to Dr. Rita Snyder-Halpern, Chair of the Disseration Committee, for her guidance, support, and direction; Drs. Mary Quayhagen and Janet Harrison, Dissertation Committee members, for their precious time and commitment to my learning; and other esteemed members of the faculty and staff of University of San Diego, who have been most supportive. My colleagues at Sharp Memorial Hospital, Sharp HealthCare, and fellow 
doctoral students are also to be acknowledged for their continual concern, support, and encouragement.

I am deeply grateful to several who have served as significant mentors in my professional life and through this educational process. Dr. Timothy Porter-o'Grady has been a great inspiration to me and has taught me the essence of collaborative management in sharing his beliefs and philosophy of Shared Governance. Dr. Gloria Bader has been a champion in supporting my progress in climbing the challenging mountain of doctoral study. Janet Cetti has been an inspirational role model often causing me to reflect on the inner core of my beliefs about many issues. special thanks are extended to the executive nurses, managers, secretaries, and nursing staff at Sharp Memorial Hospital, Sharp Cabrillo Hospital, Community Hospital at Chula Vista, Pomerado Hospital, Palomar Hospital, and Grossmont Hospital who assisted in this research. Dr. Michael Beebe has been most helpful in assisting with the computer programming for statistical analysis.

Some very special people are also thanked for the times that they helped in ways that went unnoticed, unmeasured, but were not forgotten: Jill, Mary, Donna, Willa, Merry, Marianne, Nancy, and Lyn. Most of all, I am deeply grateful to Marion Hubbard, who established the Marion Hubbard Scholarship, for making this accomplishment possible. Thanks to you all!

viii 
ABSTRACT . . . . . . . . . . . . . . . . . iii

DEDICATION . . . . . . . . . . . . . . . . . . vi v vi

ACKNOWLEDGEMENTS . . . . . . . . . . . . • . . . . vii

IIST OF TABLES . . . . . . . . . . . . . . . . . . xiii

LIST OF FIGURES. . . . . . . . . . . . . . . . . . xiv CHAPTER

I. INTRODUCTION. . . . . . . . . . . . . . . . 1

Problem . . . . . . . . . . . . . . . 3

Purpose . . . . . . . . . . . . . . . . 5

Theoretical Framework . . . . . . . . . 5

Research Hypotheses . . . . . . . . . . . . . 9

Theoretical Definitions of Terms . . . . . . 10

Collaborative Behavior. . . . . . . . . . 10

Organizational climate. . . . . . . . . . 11

Job stress . . . . . . . . . . . . . . 11

Job Satisfaction. . . . . . . . . . . . 12

Anticipated Turnover. . . . . . . . . . 12

Summary . . . . . . . . . . . . . . . . 12

II. REVIEW OF THE LITERATURE. . . . . . . . . . . . 13

Job Satisfaction. . . . . . . . . . . . 13

Collaborative Behaviors . . . . . . . . . . 18

Nurse-Physician Collaboration and Job
Satisfaction. . . . . . . . . . . . 18

Nurse-Management Collaboration and Job
Satisfaction. . . . . . . . . . . . 20

Organizational climate and Job Satisfaction . . . 24

Job Stress and Job Satisfaction . . . . . . . 29 
Page

Multivariate Studies of Job Satisfaction. . . . 30

Job Satisfaction and Anticipated Turnover . . . 32

Collaborative Behavior and Anticipated Turnover . 34

Organizatioral Climate and Anticipated Turnover • 36

Job Stress and Anticipated Turnover . . . . . . . 37

Personal Characteristics, Job Satisfaction and

Anticipated Turnover . . . . . . . . . . 39

Summary . . . . . . . . . . . . . . 41

III. METHODOLOGY . . . . . . . . . . . . . . . . 49

Research Design . . . . . . . . . . . . . 49

Structural Equations. . . . . . . . . . . 49

Sample. . . . . . . . . . . . . . . . 50

Instruments . . . . . . . . . . . . . . . 52

Weiss and Davis Collaborative Practice Scale. • 52

Stichler Collaborative Behavior Scale . . . . 53

Dieterly and Schneider Organizational

Climate Measure . . . . . . . . . . 55

Gray-Toft and Anderson Nursing Stress Scale . . 56

Stamps and Piedmonte Index of Work Satisfaction . . . . . . . . . 58

Hinshaw and Atwood Anticinated Turnover Scale . so

Demographic Questionnaire . . . . . . . . . 61

Data Collection . . . . . . . . . . . 61

Data Analysis . . . . . . . . . . . . . 63

Assumptions . . . . . . . . . . . . . . 64

Summary . . . . . . . . . . . . . 64

IV. RESULTS . . . . . . . . . . . . . . . 68

Data Reduction. . . . . . . . . . . . 68

$\mathrm{x}$ 
Page

Examination of Bivariate Correlations . . . . . 68

Correlations between Demographics and study

variables . . . . . . . . . . . . 75

Hypotheses Testing. . . . . . . . . . . . 76

Regression Analysis . . . . . . . . . . . 76

Collective Model. . . . . . . . . . . 78

Results of Each Hypothesis. . . . . . . . . 81

Testing the Assumptions . . . . . . . . . . 87

Post-Hoc Analysis . . . . . . . . . . . . 87

Regression Analysis Using Dimensions of Study

Variables . . . . . . . . . . . . 87

Analysis of Variances between Groups. . . . . 89

summary . . . . . . . . . . . . . . 94

V. DISCUSSION AND RECOMMENDATIONS. • • • • . • • • . 95

Discussion. . . . . . . . . . . . . . 95

Anticipated Turnover. . . . . . . . . . 95

Job Satisfaction. . . . . . . . . . . . 97

Post-Hoc Analysis . . . . . . . . . . . 101

Limitations . . . . . . . . . . . . . 109

Internal Validity (IP). . . . . . . . . . 109

External Validity (GP) . . . . . . . . . . 110

Implications and Recommendations. . . . . . . 110

Nursing Research . . . . . . . . . . . 111

Nursing Services/Administration. . . . . • . 113

Implications and Recommendations for Nursing 120

Summary. . . . . . . . . . . . . . 123

REFERENCES . . . . . . . . . . . . . . . 124

$x i$ 
APPENDICES . . . . . . . . . . . . . . . . . 136

APPENDIX A: COLLABORATIVE PRACTICE SCALE . • • 137

APPENDIX B: COLLABORATIVE BEHAVIOR SCALE - A • 139

APPENDIX C: COLIÄBORATIVE BEHAVIOR SCALE - B • 142

APPENDIX D: ORGANIZATIONAL CLIMATE MEASURE • • 145

APPENDIX E: NURSING STRESS SCALE . • • . • • • 148

APPENDIX F: INDEX OF WORK SATISFACTION . . . . 151

APPENDIX G: ANTICIPATED TURNOVER SURVEY • • • 155

APPENDIX H: DEMOGRAPHIC QUESTIONNAIRE. • . • • 157

APPENDIX I: DISCLAIMER LETTER. . • • . . • . 159

APPENDIX J: RESEARCH BILL OF RIGHTS. • . . . . 161

APPENDIX K: UNIVERSITY OF SAN DIEGO COMMITTEE

ON PROTECTION OF HUMAN SUBJECTS . . . . . 163

APPENDIX L: INDIRECT EFFECTS OF NURSE-PHYSICIAN COLLABORATIVE BEHAVIOR ON ANTICIPATED

TURNOVER. . . . . . . . . . . . 165

APPENDIX M: INDIRECT EFFECTS OF NURSE-MANAGER COLLABORATIVE BEHAVIOR ON ANTICIPATED

TURNOVER. . . . . . . . . . . . . 167

APPENDIX N: INDIRECT EFFECTS OF ORGANIZATIONAL CLIMATE ON ANTICIPATED TURNOVER . . . . . 169

APPENDIX O: INDIRECT EFFECTS OF JOB SATISFACTION ON ANTICIPATED TURNOVER . . . . . . . . 171

APPENDIX P: ANALYSIS OF VARIANCE SUMMARY TABLES. 173 
Table

Page

1. Correlational studies Supporting Theoretical

Model . . . . . . . . . . . . . . .

2. Psychometric Properties of Instruments üseả in the Study... . . . . . . . . . . . . 66

3. Correlational Matrix for Study Variables. . . . 69

4. Correlational Matrix for organizational Climate Survey (OCS)............ . . . . . . 71

5. Correlational Matrix for Nursing Stress Scale (NSS) . . . . . . . . . . . . . . 72

6. Correlational Matrix for Index of Work Satisfaction (IWS). . . . . . . . . . . . . 73

7. Correlational Matrix for Anticipated Turnover (ATS). . . . . . . . . . . . . 74

8. Effects of Independent Variables on Job Satisfaction and Anticipated Turnover . . . . . 80

9. Regressions Used to Compute Path Coefficients for Simplified Model. . . . . . . . . . . . .

10. Analysis of Hypotheses. 
Figure

1. Theoretical path model of the effects of collaborative behavior, organizational climate, and job stress on job satisfaction and anticipated turnover in nursing. . . . . . . . . . . . . . .

2. Simplied Path Model Relating Anticipated Turnover With Predictor Variables . . . . . . . . . . 84

3. Post-Hoc Simplified Path Model Relating Anticipated Turnover with Dimensions of Predictor variables. . . . . . . . . . . . . . . . 90

xiv 
CHAPTER I

\section{INTRODUCTION}

Health care is experiencing the most severe Registered Nurse (RN) shortage in recent history. Although tine current supply of RNs is at an all time high with an estimated $80 \%$ of totai available RNs employed, only $68 \%$ of those employed work in acute care hospitals (Department of Human \& Health Services, 1988). The need for greater numbers of nurses has never been so intense. Increased acuities in hospitalized patients and increased technological interventions require continuous and sophisticated monitoring and assessment by professional nurses. Shorter lengths of stay, requiring intensive in-patient care regimens and excensive out-patient care, also increase the demand for nurses. Nurses provide the best coordination of patient care across the home-tohospital-to-home continuum. Yet at a time when the health care system needs the expertise of nurses the most, many nurses are leaving the profession disenchanted with the physical anā emotionaì demanàs piaceã on tinem in tine work environment. Long hours, low wages, increased patient assignments, and limited advancement opportunities have often been indicated as reasons for role dissatisfaction (Nursing Shortage Poll Report, 1988). Additionally, limited involvement in decisions affecting the professional practice of nursing, poor interpersonal relationships with management 
and other health care providers, and lack of recognition and reward for professional expertise and contributions have been cited as reasons for disillusionment with the nursing role (Bream \& Schapiro, 1989; Nursing Shortage Poll Report, 1988; Office of the Inspector General, 1989). With fewer students selecting nursing as a career option, a severe shortage of professional nurses can be expected over the next decade.

The American Hospital Association (AHA) in association with other commissions, associations, and foundations has reviewed the status and image of nursing for the past three decades (National Commission on Nursing, 1981). From the myriad of published public testimonials of nurses and the study findings of the Commissions, several recurrent themes have been cited as critical factors leading to role dissatisfaction. These factors include: 1) lack of participation in decisions affecting patient care and the practice of nursing; 2) inadequacy in the systems for delivery of care; and 3) negative interprofessional relationships, specificaliy with physicians and hospital administration. Publications from numerous groups commissioned to study nursing have recommended a spirit of collaboration and collegiality among health care providers and involvement of nurses in decisions affecting nursing practice and patient care in order to support the vital role of nurses as members of the health care team (Department of Health \& Human Services, 1988; Lysaught, 1970; National Commission on 
Nursing, 1982). Magnet hospitals and others who have been most successful in recruitment and retention efforts have facilitated development of organizational cultures and climates which fuster autonomy, accountability, and educational growth in professional practice (Department of Heaith \& Human Services, 1988). In a professional atmosphere of mutual trust and collegiality, nurses are active on multi-disciplinary committees, governance and planning councils, and career advancement programs. Many of these same hospitals encourage joint practice models as recommended by the ANA and the AMA as a method of enhancing nurse-physician relationships and improving the coordination of patient care (National Joint Practice Commission, 1981). Terms such as professional networks, partnerships, interdisciplinary teams and committees, and shared governance are the hallmarks of many health care organizational mission and value statements which encourages the development of a culture thi $t$ recognizes the unique and necessary contribution of each of its employees and professional groups. While nearly three decades have passed and progress has been made toward these goals in some health care settings, realization of collaborative practice in health care organizations has not become the norm.

\section{Problem}

Vacancy and turnover rates for nurses employed in hospitals are high with some hospitals reporting rates of 
approximately $40 \%$. According to Department of Health \& Human Services (DHHS) surveys (1988), RN vacancies in hospitals have more than doubled from $4.4 \%$ in 1983 to $11.3 \%$ in December 1987. The cost of turnover is extremely high with estimations of nearly $\$ 8,000$ per nurse. This figure does not include the indjrect emotional and physical cost of nurses working overtime to complete the work previously performed by the vacated nurse or to orient new employees. other factors associated with turnover are difficult to quantify but influence the overall effectiveness of the organization. These factors include: 1) the cost of diminished quality in patient care caused by vacancies and new employees not yet realizing full work potential; 2) the loss of potential physician clients who may fear to refer patients to hospitals staffed with a high percentage of registry personnel or new employees; and 3) the emotional cost to nurses who must work harder to fill staff: ng vacancies while orienting and socializing new employees. In this sense, nursing turnover becomes a threat to the hospital's fiscal integrity, culture, employee satisfaction and commitment, and clients.

It is critical to identiry detemuinants of job satisfaction for nurses in order to operationalize programs that will prevent turnover in nursing. In a time of scarce fiscal and human resources in health care, any study that provides information regarding variables that positively or negatively predict job satisfaction in nursing will provide 
rich information for the improvement of organizational relationships which have an impact on nurse satisfaction. Such information is critical to the alteration of organizational behaviors and interprofessional relationships in order to recruit new students into the profession, enhance future growth and development of the profession, and improve the effectiveness of our heath care organizations.

\section{Purpose}

The purpose of this study was to determine the effect of collaborative behavior, organizational climate, and job stress on job satisfaction and anticipated turnover in nursing. These phenomena are of primary concern to nurses and hospital administrators because of their impact on overall organizational effectiveness.

\section{Theoretical Framework}

The theoretical framework for this study was adapted from a model of organizational effectiveness developed by Lawler, Nadler, and Cammann (1980). This model suggests that a combination of the employees' personal characteristics and the characteristics of the organization effect the employee's affective reactions to the job. These affective reactions influence behaviors which can influence organizational effectiveness. Since organizational effectiveness is a multidimensional construct, there has been considerable research with different indicators of 
organizational effectiveness as the dependent variable; however, a common body of knowledge pertaining to the construct has not been developed (Campbell, 1977). The construct is important not only because of pragmatic considerations, but also because it is central to the existence of organizations and organizational theory.

Lawler et al. (1980) define organization effectiveness as an outcome or substantive dimension such as productivity, efficiency, profit, quality, morale, absenteeism, participation or shared influence, stability, conflict-cohesion, turnover, and job satisfaction. This study focused on two of these indicators, job satisfaction and anticipated turnover in nursing, because of their significance to the economic viability of health care organizations and their impact on the quality of patient care.

Using the Lawler et al. (1980) model of organizational effectiveness as a framework, this study focused on the interrelationships among collaborative behavior, organizational climate, and perceptions of job stress, and the effect of these variables on job satisfaction and anticipated turnover in nursing. A three stage theoretical path analytic model, as shown in Figure 1, outlined the predicted relationships among the variables described above and the predicted effects of these variables on job satisfaction and turnover in nursing. The model will be considered by stages, one through three, signifying the causal ordering. The theoretical rationale for the ordering 


$\begin{array}{lll}\text { ORGANIZATIONAT } & \text { AFFECTIVE } & \text { ORGANIZATIONAL } \\ \text { CHARACTERISSICS } & \text { REACTIONS } & \text { EFFECTIVENESS }\end{array}$

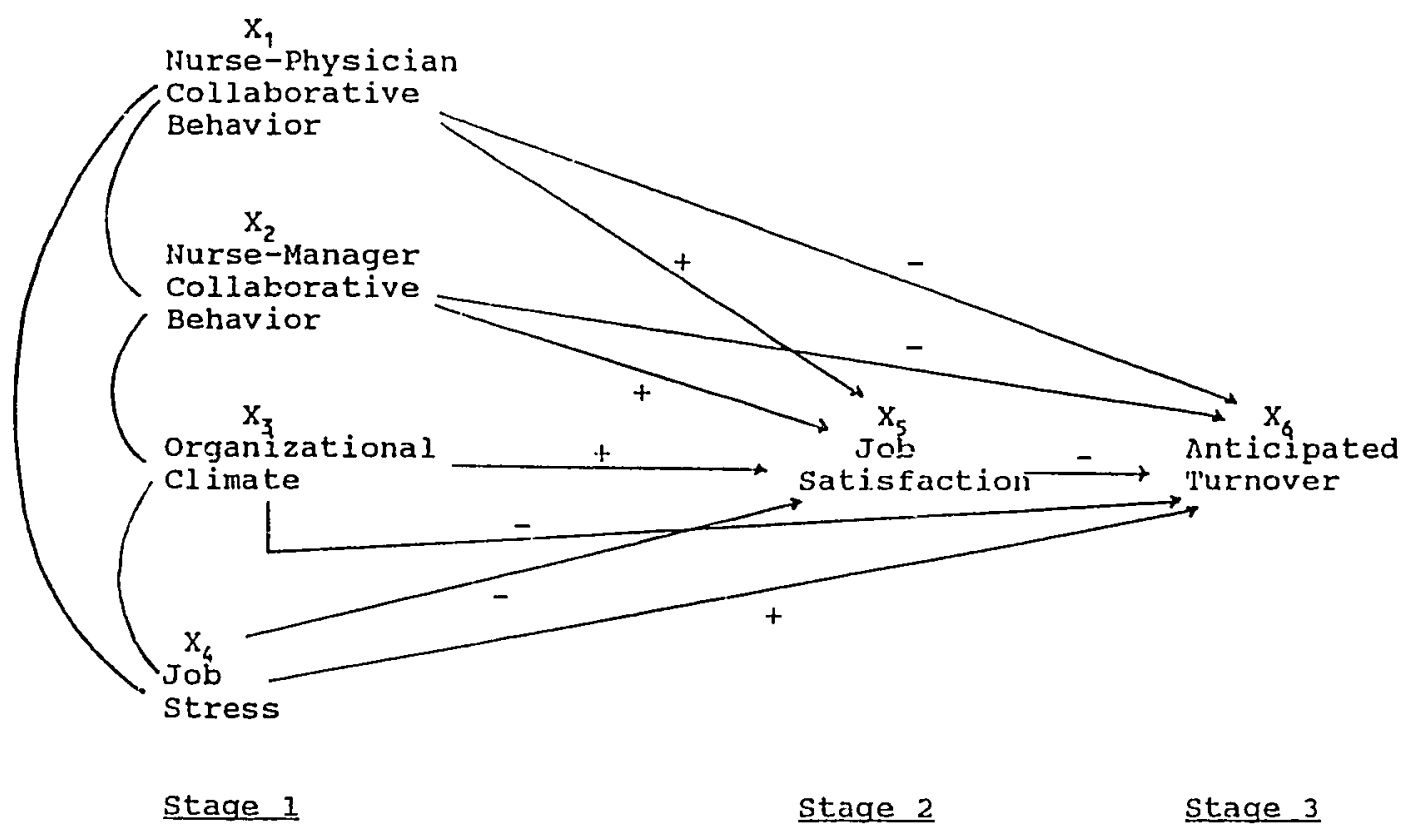

Figure 1. Theoretical Model Illustrating the Effects of Collaborative Behavior, organizational climate, and Job stress on Job Satisfaction and Anticipated 'Turnover in llursing. 
of the predictors will be discussed in the review of the literature.

stage 1. Consistent with the theoretical model of Lawler et al. (1980) describea earlier, four variables, representative of organizational characteristics, were considered in stage 1. These variables included: 1) nursephysician collaborative behavior; 2) nurse-manager collaborative behavior; 3) organizational climate; and 4) job stress. It was expected that these variables would be interrelated and would predict job satisfaction and anticipated turnover. Demographic variajles, representative of the personal characteristics described in the Lawler and Porter (1971) model were expected to be related to the study variables in stages 1,2 , and 3 .

Stage 2. Job satisfaction was considered to be an indicator of the employee's affective reaction which was predicted by personal and orsanizational characteristics described in stage 1. It was proposed that joo satisfaction would predict anticipated turnover.

stage 3. In concert with the theoretical underpinnings of the model, anticipated turnover was considered to be an indicator of organizational effectiveness and was predicted by job satisfaction, job stress, organizational climate, nurse-physician collaborative behaviors, and nurse-manager collaborative behaviors. 


\section{Research Hypotheses}

This study addressed the research question: What are the interrelationships among nurse-physician and nursemanager collaborative behavior, organizational climate, and job stress and the direct and indirect effects of these variables on job satisfaction and anticipated turnover in nursing? Nine direct hypotheses were generated for the study:

1. Nurse-physician collaborative behavior has a direct positive effect on job satisfaction.

2. Nurse-physician collaborative behavior has a direct negative effect on anticipated turnover.

3. Nurse-manager collaborative behavior has a direct positive effect on job satisfaction.

4. Nurse-manager collaborative behavior has a direct negative effect on anticipated turnover.

5. Organizational climate has a direct positive effect on job satisfaction.

6. Organizational climate has a direct negative effect on anticipated turnover.

7. Job stress has a direct negative effect on job satisfaction.

8. Job stress has a direct positive effect on anticipated turnover.

9. Job satisfaction has a direct negative effect on anticipated turnover. 
Four indirect hypotheses were developed for the study as follows:

10. Nurse-physician collaborative behavior has an indirect effect on anticipated turnover through job satisfaction.

11. Nurse-manager collaborative behavior has an indirect effect on anticipated turnover through job satisfaction.

12. Organizationa]. climate has an indirect effect on anticipated turnover through job satisfaction.

13. Job stress has an indirect effect on anticipated turnover through job satisfaction.

\section{Theoretical Definition of Terms}

Six major concepts and their interrelationships were the focus of this study: 1) nurse-physician collaborative behavior, 2) nurse-manager collaborative behavior, 3) organizational climate, 4) job stress, 5) job satisfaction, and 6) anticipated turnover. Theoretical definitions of these variables are as follows:

\section{Collaborative Behavior}

Collaborative behavior was defined as a cooperative process, characterized by interpersonal valuing, which synthesizes and integrates the talents of two or more interdependent persons to accomplish a common goal as operationalized by the Stichler collaborative Behavior Scale 
(CBS) - parts A and B (Stichler, 1989). Collaborative

behavior in nurse-physician interactions was operationalized

with the CBS-part A. The Collaborative Practice Scale (CPS)

Part A (Weiss \& Davis, 1985) which measures the assertion

and clarification of mutual responsibilities that exist in interactive relationships was added to test the concurrent validity of the CBS-A. Collaborative behavior in nursemanager relationships was operationalized with the Collaborative Behavior Scale-Part B (CBS-B).

\section{Organizational climate}

Organizational climate is the employee's perception of the nature of the organization (Gibson, Ivancevich, \& Donnelly, 1979; Lawler, Hall \& Oldham, 1974). The term refers to characteristics in the organization that are relatively stable over time, differentiate the organization from other organizations, and influence the behavior and attitudes of the organization's employees (Forehand \& Gilmer, 1964). In this study, organizational climate was defined as the nurse's perception of the amount of autonomy, structure, rewards, and warmth that exists in the organization as operationalized by the organizational Climate Measure (Dieterly \& Schneider, 1974).

\section{Job stress}

Nursing stress reflects situations or conditjons in the job that are stressful to the nurse. In this study, job stress was defined as the frequency that the nurse 
encounters death and dying, emotional demands of patient and families, inadequate staffing and work overload, and conflicts with other nurses, physicians, and administrators as operationalized by the Nursing stress Scale (Gray-Toft \& Anderson, 1981).

\section{Job Satisfaction}

Job satisfaction reflects the nurses' feelings of enthusiasm, enjoyment, contentment, and pleasure about employment in the present role and/or organization. In this study, job satisfaction was defined as the nurse's satisfaction with pay, the level of autonomy, task requirements, organizational requirements, job status, and interactions as operationalized by the Index of Work Satisfaction Survey (Stamps and Piedmonte, 1986).

\section{Anticipated Turnover}

Anticipated turnover was defined as the employee's anticipation or intent to leave the organization as operationaIizeả by the Ânticipated Turnover Scale (Hinshaw \& Atwood, 1982).

\section{Summary}

Chapter I introduced the study in terms of its purpose, theoretical framework, and operational definition of terms. Major concepts of interest were identified as collaborative behavior, organizational climate, job stress, job satisfaction, and anticipated turnover in nursing. 
CHAPTER II

REVIEW OF THE LITERATURE

The purpose of this chapter was to review literature relevant to the major concepts in the study. The studies cited supported the proposed relationships between the variables in the study as identified in the theoretical path analytic model in Figure 1. These studies and their relationship to study variables are summarized in Table 1 at the end of this chapter.

\section{Job Satisfaction.}

Many theorists have studied job satisfaction and contributed to a body of knowledge regarding variables that contribute to satisfaction. Very early in organizational research satisfaction was linked to both individual and organizational variables (Taylor, 1911). Maslow (1954) theorized that self-actualization, the highest level of fulfillment, could not be realized until other more basic needs were satisfied in hierarchical order. This theory is important to nursing because it recognizes that the advancement of the profession is first dependent on the satisfaction of more basic needs such as assuring appropriate work loads (physiological), providing job security (safety), promoting partnerships and team development (social), and demonstrating appreciation and 
recognition (esteem) for nursing's contribution to health care.

A two factor theory developed by Herzberg (1968) hypothesized that satisfaction was not the opposite of dissatisfaction on a single continuum, but rather that satisfaction was the result of motivational factors including recognition, advancement, achievement, the work itself, increased responsibility, and other such rewards. He further hypothesized that the absence of these factors did not cause dissatisfaction, but that dissatisfaction was caused by a different set of hygiene factors such as interpersonal relationships anong organizational members, work conditions, pay, and security. The two factors of Herzberg compare to the five hierarchical needs described by Maslow. The motivators relate to Maslow's higher order needs, and the hygiene factors relate to the lower order needs. These theories would support a positive relationship between collaborative behavior and job satisfaction and a positive relationship between organizational climate and job satisfaction as proposed in this study. Using this framework, collaborative behavior and organizational climate could be considered as hygiene factors that would need to be satisfied before job satisfaction could be realized. Lawler and Porter (1971) described a similar theory of satisfaction suggesting that satisfaction was related to extrinsic and intrinsic rewards. Extrinsic rewards referred to those given by the organization such as pay, promotions, 
job security, and status; whereas, intrinsic rewards were individual acknowledgements of worthwhile accomplishments (internal satisfaction). Building on this premise, Porter, Lawler, and Hackman (1975) suggested that a reciprocal relationship existed between the individual and the organization which effected the employee's level of satisfaction, behavior, and performance. Ultimately, the reciprocal relationship between the individual and the organization affected organizational effectiveness. These theorists purported that job satisfaction is affected by the individual's perception of rewards that should be received as a result of job performance. Satisfaction was defined as the difference between reward that the individual actually receives and the reward that was anticipated. The greater the discrepancy, the greater the dissatisfaction. Porter et al. (1975) summarized the reciprocal relationship between the organization and the individual by stating that "organizations tend to motivate the kind of behavior they reward" (p. 343). These theories provide support to the theoretical model (see Figure 1) predicting relationships among organizational characteristics (collaborative behavior, organizational climate, job stress), individual characteristics (demographics), and job satisfaction. studies linking satisfaction and dissatisfaction to performance and productivity have not been consistent or conclusive. In an analysis of early research on the subject, Vroom (1964) found only mild to moderate 
correlations between worker satisfaction and productivity. Recent studies are more likely to view job satisfaction as the outcome variable rather than as a predictive or intervening variable. In a review of current literature, Tauskey (1978) purported that stronger relationships were seen between dissatisfaction and absenteeism or turnover, which are often cited as behavioral outcomes which reduce organizational eifectiveness, than hypothesized relationships between satisfaction and productivity. This notion supports the hypothesis that job satisfaction and anticipated turnover are directly and negatively related.

Job satisfaction is a concept that has been widely studied in nursing. From a survey of the literature, Hinshaw and Atwood (1984) identified multiple variables directly related to job satisfaction in nursing. The variables were categorized as personal characteristics, i.e., age, education, experience, and position in the hierarchy; the environment, i.e., nursing care delivery model, specialty area, organizational climate, supervision, and interpersonal relationships; and the job itself, i.e., status, autonomy, repetitiveness, pay, and work load. While Hinshaw and Atwood (1984) suggested there are numerous studies demonstrating the relationship of one or two of these variables with job satisfaction at a time, the impact of these variables acting "simultaneously and conditionally is unknown" (p. 147). 
In a subsequent study to determine the effect of multiple variables on joh satisfaction, Hinshaw, Smeltzer, and Atwood (1987) reported ( $\underline{\mathbb{N}}=1597$ ) that organizational job satisfaction $\left(R^{2}=.57\right)$ was predicted for baccalaureate prepared nurses $(\underline{\mathrm{N}}=261)$ by group cohesion $(\underline{\mathrm{B}}=.27)$ supporting the collaborative behavior to job satisfaction linkage, by job stress $(\underline{B}=-.34)$ supporting the job stress to job satisfaction linkage, and control over practice $(\underline{B}=.17)$ and autonomy $(\underline{B}=.13)$ supporting the organizational climate to job satisfaction linkage. Professional satisfaction was also strongly predicteā $\left(\mathrm{R}^{2}=.49\right)$ by group cohesion $(\underline{B}=.17)$, autonomy $(\underline{B}=.18)$, and job stress $(\underline{B}=-.47)$ supporting the theoretical model proposed in this study. Similar findings were reported for diploma prepared nurses $(\underline{N}=297$ ) with organizational satisfaction $\left(\mathrm{R}^{2}=.50\right)$ predicted by group cohesion $(\underline{B}=.24)$, job stress $(\underline{B}=.16)$, and autonomy $(\underline{B}=.16)$. Professional satisfaction $\left(R^{2}=.38\right)$ was predicted only by job stress $(\underline{B}=-.45)$. Hinshaw's et al. (1987) findings support the negative and direct relationship proposed in this study between job stress and job satisfaction. Although group cchesion is not synonymous with collaborative behavior, the positive relationship between group cohesion and job satisfaction lends support to the positive relationship between collaborative behavior and job satisfaction hypothesized in this study. 


\section{Collaborative Behaviors}

Collaborative behaviors refer to assertive and cooperative behaviors which promote a feeling of mutuality, partnership or teamwork (Deutsch, 1973; Kilmann \& Thomas, 1977). Coilaborative behaviors are characterized by a reciprocal exchange or integration of expertise or information for the purpose of accomplishing a common goal. Recognition and acknowledgement of interdependence precedes the onset of collaborative behavior (Gray, 1985). Interpersonal valuing occurs during and as a result of the collaborative process promoting a "win-win" condition for those involved (Stichler, 1989). Conversely, organizational climate can either encourage or inhibit collaborative behaviors among members. Nurses have independent, dependent, and interdependent roles with physicians and hospital management. It is proposed that collaborative behavior between nurses and physicians and nurses and managers has a positive effect on job satisfaction and a negative effect on anticipated turnover as supported by the research findings described in the following sections.

Nurse-Physician Collaboration and Job Satisfaction.

It has been stated that nurse-physician relationships are related to job satisfaction in nursing (Nursing shortage Poll Report, 1988). In a qualitative study to determine variables cited by RNs and other nursing personnel as satisfiers, Floyd and Smith (1983) reported that 
communication between nurses and physicians was a critical variabie. Other studies demonstrated a negative relationship to job satisfaction when there was a lack of collaborative interaction between nurses and physicians and nurses and management (Clark \& Lenburg, 1980; National Commission on Nursing, 1981) - Clark and Lenburg documented that nurses were least able to use their knowledge base in areas of 1) nurse-physician interaction, 2) mutual decision making, and 3) interprofessional monitoring leading to frustration and dissatisfaction in their roles. In a case study of one hospital's experience in developing guidelines for collaborative relationships between emergency medical technicians, nurses, and physicians, Coburn (1988) reported multiple benefits including an increased team identity and positive relationships after the guidelines were implemented.

In a study comparing satisfaction scores of the nursing staff on two units before, during, and after the implementation of primary nursing, Blenkarn, D'Amico, and Virtue (1988) reported that the satisfaction scores improved in all categories in the first year and the third year post-test periods. Nurse-physician collaboration was significantly related to job satisfaction in the third year for both units (Unit $1 ; \underline{\underline{r}}=.87 . \underline{\mathrm{p}} \leq .25$ for a one-tailed test; Unit $2 ; \underline{\underline{r}}=.92, \underline{\underline{ }} \leq .01$ for a one-tailed test). While this research supported the linkage between nursephysician collaboration and job satisfaction, the sample 
size was extremely small (less than 10 in each group) which may have affected the study's validity.

Stephen and Bailey (1979) reported that in a sample of nurses polled at a meeting of the American Association of Critical Care Nurses $(\underline{N}=556)$, more than half indicated that direct patient care was their greatest source of satisfaction. Positive nurse-physician interaction was also cited as a source of satisfaction, but interpersonal conflicts between nurses and physicians and nurses and supervisors was considered to be the greatest source of job stress leading to job dissatisfaction. supporting this report, Norbeck (1985) stated that stressful factors including communication problems with physicians were related to job satisfaction $(\underline{\underline{x}}=-.11)$. These findings support the positive linkage between collaborative behaviors and job satisfacicion and the negative linkage between job stress and job satisfaction as presented in theoretical model.

Nurse-Management Collaboration and Job Satisfaction. In early research in decision making, Vroom and Yetton (1973) indicated that there was often a relationship between the leadership style and decision making style, although there was a wide variance across problems or situations. Correlational studies were performed to determine the relationship between levels of subordinate participation, problem attributes, and decision making styles used by 
leaders. These studies resulted in a normative model which indicated paths that the leader should take in decision making and a descriptive analysis which demonstrated that leaders actually adapt their roie in decision-making depending on the demands of the situation. The early studies of Vroom and Yetton (1973) and Stogdill (1974) indicated a positive relationship between participation in decision making by subordinates and job satisfaction.

McKay (1983) posited that the professional's autonomy in situations where there is shared accountability is related more to interdependent decision making than independent styles and that the nurse administrator can play a major role in determining the extent in which nurses participate in interdependent decision making. These studies discussing the positive effect of employee participation in decision making on job satisfaction support the notion that an organizational climate that promotes a supportive and open relationship between the nurse and manager will be positively related to job satisfaction.

In a similar study using a two group experimental design to test the effects of participation in decision making on worker satisfaction and productivity in a sample of 128 male undergraduates, Vanderslice, Rice, and Julian (1987) reported that high levels of participation in decision making had a significantly positive effect on satisfaction ( $\underline{\underline{v}}=.56, \underline{\underline{p}} \leq .01)$, and a stronger effect on perceived influence $(\underline{\underline{r}}=.68, \underline{\underline{p}} \leq .01)$. Even though these 
findings are not specific to nursing, they are important since they support the linkage between collaborative behavior and job satisfaction.

Similarly in a multivariate analysis of role conflict and role ambiguity on dimensions of job satisfaction in faculty members $(\underline{\mathrm{N}}=285)$, Fain (1987) found that role conflict and ambiguity were negatively related to work satisfaction $(\underline{\underline{y}}=-.47$ and $\underline{\underline{I}}=-.36, \underline{p}=\leq .01$ respectively) and satisfaction with the supervisor $(\underline{\underline{r}}=.39, \underline{\underline{p}} \leq .01)$. This study supported other research which demonstrated that employees were more satisfied with their work when performance expectations were clear and non-conflicting. As mentioned earlier, collaborative behavior in interdependent relationships is characterized by role negotiation and clarification making this study significant to the current study by potentially supporting a relationship between nurse- manager collaborative behavior and job satisfaction. Blegen and Mueller (1987) in a path analysis $(\underline{N}=370)$ of the effect of multiple variables on nurses' job satisfaction found that job satisfaction was significantly related ( $p \leq .05$ ) to lower opportunity for jobs outside of the hospital, job communication $(\underline{\underline{x}}=.21)$, "routinization" $(\underline{\underline{x}}=-.34)$, higher autonomy $(\underline{\underline{r}}=.37)$, promotional opportunity $(\underline{\underline{r}}=.36)$, social integration $(\underline{r}=.17)$, fairness in pay $(\underline{r}=.13)$ and distribution justice $(\underline{r}=.32)$, and workload $(\underline{r}=.13)$. The study was $a$ longitudinal design with data collected at two times 8 
months apart. Satisfaction at the time 1 measurement was correlated with the second measurement ( $\underline{r}=.75)$ which reflected the stability of the concept of satisfaction over time. Blegen and Mueller's model accounted for $39 \%$ of the explained variance in job satisfaction. The positive and direct relationship of job communication and social integration supported the relationships proposed in this study which suggested that personal and organizational characteristics are directly related to job satisfaction. A study with similar findings was conducted by Buccheri (1986) who used a cross-sectional survey to examine perceived levels of job satisfaction and supervisor support for nurses working on adult, inpatient psychiatric units. While the findings of this study may not be particularly generalizable to other nursing specialties, this study indicated a significant correlation between the overall job satisfaction and supervisor support. Another finding of this study was that nurses in top management were significantly more satisfied than staff because of participation in decision-making and with the recognition that they received. In general, this study indicated that sharing information which affects the staff, providing support for their needs for infiuence, recognition, and communication, and allowing participation in decision making is related to job satisfaction. These same factors can be interpreted as descriptive of a collaborative style of management supporting the focus of this study relating 
collaboration between nurses and management with job satisfaction.

Role negotiation and clarification, identification of mutual goals, reciprocal exchanges of expertise, information, and resources, and interpersonal valuing were cited as essential elements to a collaborative relationship (Stichler, 1989). Several of the studies cited above reference behaviors between nurses and physicians and nurses and management. These behaviors were labeled as supportive behaviors, interaction and communication, team spirit, and participation in decision making. While not directly labeled as collaborative behaviors, these variables lend support to the notion that collaborative behavior has a direct effect on job satisfaction and anticipated turnover.

\section{Organizational climate and Job Satisfaction}

organizational climate reflects a reciprocal relationship between organizational member behavior, the structure of the organization, and organizational processes. The climate of an organization differentiates it from all others and is a relatively stable characteristic over time. The amount of structure or autonomy that is afforded the employees, the reward systems inherent in the organization, and the amount of support and warmth that is felt by employees reflects the organizational climate (Dieterly \& Schneider 1974; Schein, 1985). 
While the congruence between nurses and organizational climate has been linked theoretically to job satisfaction (Lyon \& Ivancevich, 1974), other researchers argue that job satisfaction and organizational climate refer to the same variable (Porter et al., 1975). Payne, Fineman, and Wall (1976) differentiated concepts of job satisfaction and organizational climate through application of factor analysis. They postulated that job satisfaction is a concept reflective of a particular job and a person's affective response to his/her job, whereas organizational climate reflects the organization as a whole and a person's description of what the organization is like.

Hinshaw et al. (1987) reported a significant relationship ( $\underline{Q} \leq .05$ ) between cortrol over practice and organizational job satisfaction in Diploma-prepared Registered Nurses. Specific subdimensions of control over practice and related beta weights included: 1) committee control $(\underline{B}=.23) ; 2)$ access to ideas $(\underline{B}=.20)$; and 3) personal resources $(\underline{B}=.21)$. Autonomy was also related to job satisfaction $(\underline{B}=.1 .6)$. With Baccalaureate-prepared Registered Nurses, control over practice $(\underline{B}=.17)$ and autonomy $(\underline{B}=.13$ ) were also related to organizational job satisfaction. These moderately positive relationships supported the linkage between organizational climate and job satisfaction, since organizational climate in this study was defined as the degree of autonomy and structure afforded by the organization. 
In a study by Duxbury, Henley, and Armstrong (1982) an analysis of the relationship between the organizational climate of Neonatal Intensive Care Units (NICUs) and nurse satisfaction revealed that there was a statistioally significant relationship between climate and satisfaction. The dimensions demonstrating the highest correlations with job satisfaction were humanistic thrust measuring leadership behavior ( $\underline{r}=.52, \underline{p} \leq .02$ ) and esprit measuring group morale $(\underline{r}=.71, \underline{p} \leq .005)$. Disengagement by the leader was also correlated with job satisfaction ( $\underline{r}=-.47, \underline{p} \leq .05$ ). The authors acknowledged the limited generalizability of the study and suggested further studies to validate the findings.

Using the same instrument to measure organizational climate to study nursing faculty's perceptions of organization climate and the relationship to job satisfaction, Donohue (1986) discovered that the dean's behavior does influence perceptions of organizational climate and job satisfaction among faculty. Primary correlates of job satisfaction pertaining to the work itself were esprit $(\underline{\underline{x}}=.41, \underline{\underline{x}} \leq .01)$, disengagement $(\underline{\underline{x}}=-.36$, $\underline{p} \leq .01)$ and humanistic thrust $(\underline{r}=.35$, $\underline{p} \leq .01)$. Job satisfaction pertaining to supervision was correlated with the organizational climate dimensions of thrust ( $\underline{\underline{r}}=.55$, $\mathrm{p} \leq .01)$, consideration $(\underline{\mathrm{r}}=.44, \underline{\mathrm{p}} \leq .01)$ and esprit $(\underline{\underline{r}}=.40, \underline{\underline{p}} \leq .001)$. The organizational climate dimensions which were significantly correlated to job satisfaction 
included: 1) disengagement ( $\underline{\mathrm{r}}=-.40, \underline{\mathrm{p}} \leq .01), 2$ ) esprit $(\underline{\underline{x}}=.41, \underline{p} \leq .01), 3)$ thrust $(\underline{\underline{r}}=.30, \underline{\mathrm{p}} \leq .01)$, and 4) intimacy $(\underline{\underline{r}}=.27, \underline{p} \leq .01)$. Donohue's findings validated Duxbury's et al. (1982) research and supported the linkage between organizational climate and job satisfaction proposed in this study. organizational climates perceived as supportive and positive in socio-emotional relations were positively related to job satisfaction. Donohoe's findings suggested that those in the role of dean should be cognizant of managerial behaviors that promote a positive organizational climate and the need to maintain open and interactive communication styles which correlates with job satisfaction. Although not directly labeling open, interactive, and supportive communication as collaboration, these findings lend theoretical support to the positive and direct relationship between collaboration and job satisfaction, since the style of communication reported in this study is characteristic of a collaborative relationship.

Several studies demonstrated a relationship between primary nursing and nursing job satisfaction. Alexander, Weisman, and Chase (1981) reported no significant differences in job satisfaction between primary $(\underline{N}=31)$ and non-primary $(\underline{N}=20)$ care units, but data revealed significantly ( $\mathrm{p} \leq .01)$ lower resignation and absenteeism rates in primary care units versus the non-primary care units. While the sample was extremely small in this study 
limiting the generalizability, the study supported a potential relationship between individual and organizational variables and turnover. In contrast, Sellick, Russell, and Beckmann (1983) demonstrated significant differences in satisfaction between nurses on primary care and non-primary care units. The groups differed significantly on items which were of specific interest to the current study including opportunity to voice opinions ( $\underline{p} \leq .025)$,

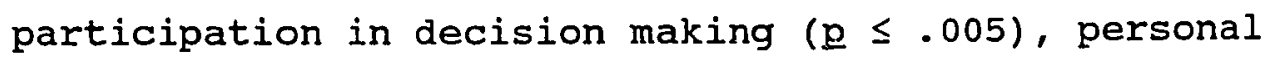
accomplishment $(\underline{p} \leq .01)$, and the ability to set the work pace $(\underline{\underline{p}} \leq .05)$.

Marram, Barrett, and Bevis (1979) also reported that nurses working in a primary care delivery system scored higher in job satisfaction as compared to other types of delivery systems. Several explanations for this relationship were offered including: 1) the in-depth relationship that was established between the nurse and patient: 2) a sense of accomplishment due to their personal contribution to patient care; and 3) interpersonal interactions with peers, supervisors, and physicians. Other studies by Carlsen and Malley (1981) and Blenkarn et al. (1988) also supported earlier research linking primary nursing and job satisfaction. These researchers suggested that primary nursing offered more opportunity for autonomy: accountability, and fulfillment social and esteem needs, since the nurse in a primary care system functions collaboratively with other professionals in the 
accomplishment of patient care goals. These studies supported the direct and positive linkage of collaborative behavior and the organizational climate dimensions of autonomy and structure with job satisfaction as proposed in the theoretical path analytic model for this study.

\section{Job Stress and Job Satisfaction}

In a study $(\underline{N}=148)$ investigating the relationship of role stress conflict, role stress ambiguity, participation in decision-making, and perceived social support to job satisfaction and organizational commitment, Feltham (1983) reported that significant relationships were found between role stress conflict $(\underline{\mathrm{r}}=-.26, \underline{\mathrm{p}} \leq .001)$ and role stress ambiguity $(\underline{\underline{x}}=-.49, \underline{\underline{p}} \leq .001)$ and job satisfaction. Role stress ambiguity accounted for $24 \%$ of the explained variance in job satisfaction; however, role stress conflict did not explain additional variance in the determination of job satisfaction in this study.

Norbeck (1985) studied the relationship between job stress, job satisfaction, and the incidence of psychological symptoms in critical care nursing. Job stress was found to be negatively related to job satisfaction $(\underline{r}=-.24$, $\underline{p} \leq .002$ ). Item analysis indicated that the factors which were most frequently ranked by nurses as the most stressful were not those that were significantly related to job satisfaction or symptom levels. Interpersonal communication problems were ranked less frequently as stressors but were 
most often related to the incidence of psychological symptoms and job dissatisfaction. These findings confirmed Feltham's (1983) findings and supported the need for open styles of communication and conflict resolution by nurse leaders.

\section{Multivariate Studies of Job Satisfaction}

Several studies reported multiple variables which correlated with job satisfaction and are discussed in the following section. The relationship between job satisfaction and twelve variables supported theoretically by Maslow and Herzberg, was also supported in a study of hospital nurses by Stember, Ferguson, Conway, and Yingling (1978). This study $(\underline{\mathrm{N}}=221)$ demonstrated statistically sigrificant correlation coefficients between all 12 variables suggesting that administrative changes to effect worker satisfaction in one area are likely to effect other variables. Variables were rank ordered with those correlating the highest with satisfaction to the lowest as follows: job importance, interpersonal relations, supervision, job mechanics, job security, influence, salary and benefits, work conditions, achievement, recognition, communication, and organizational politics. The findings of this study supported the direct and positive relationship between variables describing personal characteristics (age and length of employment, interpersonal relationships, and communication) and organizational variables (work 
conditions, salary and benefits, and supervision) and job satisfaction.

In a national survey of nursing job satisfaction (Godfrey, 1978) conducted through a major nursing jourral, several interesting trenas were reported. Seventy-nine (79) percent of nurses reported that they were very to moderately satisfied, and $21 \%$ reported heing moderately to very dissatisfied. In this study, the most satisfied nurses were those who reported adequate staffing and work loads, had supportive relationships with administration, and enjoyed a high level of team spirit with co-workers and physicians. This report also linked specialty area with job satisfaction and ranked the clinical areas from highest to lowest mean scores for satisfaction as follows: emergency room, administration, education, pediatrics, intensive care, geriatrics, medical-surgical, obstetrics/gynecology, and psychiatric units. Greater satisfaction was reported by day nurses with diminishing levels reported by evening and night nurses respectively. Rotating nurses were the most dissatisfied of all. These findings were significant to this study, since both organizational and individual characteristics were correlated with job satisfaction. Many of the demographic variables reported in Godfrey's survey were similar to those examined in this study. Nearly a decade later, a similar survey was conducted by the editors of Nursing Shortage Poll Report (1988). In $1978,79 \%$ of respondents were moderately to very satisfied 
with their jobs, however in $1987(\underline{N}=8,024)$, only $34 \%$ were satisfied. Thirty-three (33) percent of the respondents indicated that they would not choose nursing again as a career choice and cited reasons such as: 1) poor staffing and frustration at not being able to properly care for patients; 2) lack of feedback, poúr communication, and lack of support from management; 3) poor nurse-physician relationships; 4) job stress; and 5) poor pay. A direct relationship between job stress and anticipated turnover was also reported. The negative relationsinips between poor nurse-physician relationships and lack of support from management with job satisfaction and the positive relationships between job stress, poor compensation, and work load with anticipated turnover supported the linkages proposed in this study.

\section{Job Satisfaction and Anticipated Turnover.}

Anticipated turnover is of major interest to organizational researchers and theorists, because of it's direct relationship to actual turnover which threatens organizational effectiveness. Although not included in the theoretical model analyzed in this study, several researchers have reported findings that anticipated turnover is predictive of actual turnover, and both variables have been reported to be inversely related to job satisfaction (Hinshaw et al., 1987; Prestholdt, Lane, \& Mathews, 1987; Price \& Mueller, 1981; Vroom, 1964; Wolf, 1981). 
In a study of critical care nurses $(\underline{\mathrm{N}}=214)$, Kosmoski and Calkin (1986) reported that greater satisfaction with work and satisfaction with pay were positively and directly related to intent to stay $(\underline{\underline{r}}=.14, \underline{\mathrm{p}} \leq .05)$; whereas, years of formal education ( $\underline{\underline{x}}=-.19 ; \underline{\underline{n}} \leq .05)$, efforts to further education ( $\underline{\underline{r}}=-.13, \underline{\underline{p}} \leq .05)$, and participation in work related educational offerings $(\underline{\underline{r}}=-.13, \underline{\underline{p}} \leq .05)$ were negatively correlated with intent to stay. These five variables in combination explained $28 \%$ of the total variance in intent to stay. The strongest predictor of intent to stay was satisfaction with work activities $(\underline{B}=.43, p=\leq$ .05) which explained $19 \%$ of the total variance. The findings supported the predicted relationship between job satisfaction and anticipated turnover.

A similar study $(\underline{N}=1597)$ by Hinshaw et al. (1987) reported that anticipated turnover was significantly $(\underline{p} \leq .05)$ predicted from the total sample by professional/occupational job satisfaction, although some differences were reported between baccalaureate and diploma prepared nurses. For baccalaureate prepared nurses $(\underline{\mathrm{N}}=261)$, anticipated turnover $\left(\mathrm{R}^{2}=.20\right)$ was moderately predicted by organizational $(\underline{B}=-.23)$ and professional job satisfaction $(\underline{B}=-.17)$ and group cohesion $(\underline{B}=-.18)$. For diploma prepared nurses ( $\underline{N}=297)$, organizational $(\underline{B}=-.27)$ and professional $(\underline{B}=-.16)$ job satisfaction predicted anticipated turnover $\left(R^{2}=.16\right)$. Group cohesion was not predictive of anticipated turnover with diploma 
nurses which suggested that this variable was more important. to baccalaureate nurses than diploma nurses.

Hinshaw et al. (1987) also reported group differences between critical care and medical-surgical nurses in the relationship between job satisfaction and anticipated turnover. Actual turnover was not predicted by anticipated turnover for critical care nurses, but anticipated turnover was predicted by organizational job satisfaction $(\underline{B}=-.33)$ and group cohesion $(\underline{B}=-.14)$. For medical-surgical nurses, anticipated turnover predicted actual turnover ( $\underline{B}=.17$; $\left.\mathrm{R}^{2}=.06\right)$. Anticipated turnover was predicted by organizational ( $\underline{B}=-.23$ ) and professional ( $\underline{B}=-.25$ ) job satisfaction and group cohesion ( $\underline{B}=-.13)$. The findings of the Hinshaw's at al. (1987) study supported the predicted negative effect of job satisfaction on anticipated turnover hypothesized in this study.

\section{Collaborative Behavior and Anticipated Turnover}

As previously discussed, Hinshaw et al. (1987) demonstrated a negative relationship between group cohesion and anticipated turnover and a positive relationship between group cohesion and job satisfaction which supported the proposed inverse relationship between collaborative behavior and anticipated turnover and the positive effect of collaboration on job satisfaction. Taunton, Krampitz, and Woods (1989) referenced the effect of nurse-manager collaboration on job satisfaction and anticipated turnover. 
These researchers reported that the leadership style was negatively correlated $(\underline{\underline{r}}=-.35, \underline{\underline{p}} \leq .01)$ with the nurses' intent to stay in a job, positively correlated with job satisfaction ( $\underline{\underline{x}}=.37, \underline{\underline{ }} \leq .01)$, and positively correlated to retention $(\underline{I}=.2 I)$. This study $(\underline{N}=71)$ demonstrated a positive correlation to a leadership style that fostered subordinate relations and sought employee opinions in important matters. These findings supported the positive relationship between collaborative management and job satisfaction and inverse relationship between collaborative management and anticipated turnover.

The findings of the Nursing Shortage Poll Report (1988), which suggested a negative relationship between collaborative behavior and anticipated turnover, was supported by a research project involving 15 hospitals in four western states (Hart, 1989). Project findings indicated several obstacles to nurse retention including: 1) failure of physicians to interact with nurses in a collaborative manner; 2) failure of the physician to value and respect nurses, 3) failure of the physician to perceive the nurse as having a body of knowledge on which to base her practice; and 4) failure of the physician to acknowledge the vital role that nurses play in the physicians' success with the patient. Findings suggested that spending significant amounts of money on recruitment and retention efforts may be ineffective unless the critical eiements of retention were addressed. Hart's findings are significant to this study, 
since they suggested a positive and direct relationship between nurse-physician collaborative behaviors and anticipated turnover.

\section{organizational climate and Anticipated Turnover}

The findings of Traunton, Krampitz, and Woods (1989) also supported the negative relationship between organizational climate and anticipated turnover. These researchers demonstrated that nurses who were employed in units with managers who exercised authoritative leadership styles and used coercive or reward power were less satisfied $(\mathrm{p} \leq .05)$ and less committed to staying in their jobs. These nurses reported centralized decision making, less autonomy, and less individual power than other units. Retention was actually lower in this group of nurses as well.

Prestholdt et al. (1988) reported similar findings in a two step longitudinal study $(\underline{\mathrm{N}}=941)$ in which nurses were questioned about potential causes of turnover. Approximately 6 months after the first wave of data collection, the participating hospitals identified which of the nurses in the sample had remained and which had actually resigned (approximately 14 percent). Those who had resigned indicated that they felt a lack of rewards in the organization for their work and a lack of support from administration. Those remaining believed that they were employed in an organizatis where there was a spirit of 
cooperation and teamwork and where their supervisor was considerate and responsive. Those who remained also believed that they had the autonomy and authority to make decisions regarding patient care. While these findings supported the indirect effects of organizational climate and collaborative behavior on anticipated turnover, they did not explain how these differences can exist in the same organization during the same time frame. The personal characteristics of the respondent, assigned work area, or alternative work outside of the hospital may have contributed to the decision to leave or stay and may explain these differences.

\section{Job Stress and Anticipated Turnover}

Jacobson (1988) studied the relationship between psychosocial, physical, and organizational factors associated with persistence, success, and turnover among neonatal intensive care unit (NICU) nurses. Of the original 357 nurses who began the study, only $40 \%$ completed the entire study with $56 \%$ leaving the NICU. Significant correlations at the $\leq .001$ level were reported between job stress, burnout, and low job satisfaction with intent to turnover. Significant correlations were also reported between job stress and burnout and between emotional exhaustion and low job satisfaction. The low correlation between high stress and positive performance was attributed to the nurses' professional orientation and commitment to 
perform well in spite of a negative work environment. Jacobson's findings and those reported in the Nursing Shortage Poll Report (1988) supported the positive and direct relationship between job stress and anticipated turnover and the negative and direct relationship between job satisfaction and anticipated turnover as proposed in this study.

In contrast, Hinshaw et al. (1987) reported a negative relationship between job stress and anticipated turnover for medical-surgical nurses $(\underline{B}=-.25)$ which did not support the theoretical model of their study. While an explanation for this finding or the contrast with other groups in the study was not offered, the researchers suggested that job satisfaction actually buffered the effects of job stress on anticipated turnover.

studying the relationship between role stress ambiguity $(\underline{r}=-.39)$, role stress conflict $(\underline{r}=-.34)$, and organizational commitment, Feltham (1983) reported the role stress variables to be inversely related to organizational commitment. Feltham's findings infer support for the predicted relationship between job stress and anticipated turnover in this study, since organizational commitment is the antithesis of anticipated turnover. 


\section{Personal Characteristics and Job Satisfaction and Anticipated Turnover}

Several studies demonstrated inconsistent relationships between personal characteristics, job satisfacticn, and anticipated turnover. Blegen and Mueller (1987) reported that higher levels of satisfaction were correlated with older age, advanced tenure, higher positions in the hospital, and day shift. Simpson (1985) reported differences in correlations between sex, marital status, tenure, and educational level with job satisfaction depending on the respondents' position in the organization. For staff nurses, sex $(\underline{r}=.11, \underline{p} \leq .001)$, year graduated $(\underline{\underline{r}}=.11, \underline{\mathrm{p}} \leq .001)$, area of practice $(\underline{\mathrm{r}}=.-07, \underline{\mathrm{p}} \leq .05)$ and work experience $(\underline{r}=.07, \underline{p} \leq .05)$ correlated significantly with joh satisfaction. Similarly, stember et al. (1978) reported that employees with more years of total working experience in their careers were more satisfied in specific aspects of their jobs. Signjficant correlations were demonstrated between years of experience and job influence (participation in decision making, $\underline{r}=.19$, $\underline{p} \leq .01)$, job importance $(\underline{r}=.24, \underline{p} \leq .01)$, and achievement $(\underline{r}=.23, \underline{p} \leq .01)$. Seniority in the organization was correlated with job importance $(\underline{r}=.26, \underline{p} \leq .001)$, job mechanics $(\underline{r}=.14, \underline{p} \leq .01)$, and job security $(\underline{\underline{r}}=.16$, $\underline{p} \leq .01)$. Conversely, Donohue (1986) reported an inverse relationship between length of employment and job satisfaction in a study of faculty members. As the age of 
faculty members increased, satisfaction with pay increased, but satisfaction with job supervision deceased. Other researchers have reported differences in RN job satisfaction depending on the nurses' specialty area and educational preparation. Hinshaw et al. (1987) reported differences in predictors of organizational and professional job satisfaction between baccalaureate and diploma prepared nurses and between nurses assigned to critical care or medical-surgical units as discussed previously in this study. Roedel and Nystrom (1988) reported statistically significantly differences in work satisfaction $(\underline{F}=2.01$, $\underline{p} \leq .06$ ) between nurses of different work areas. Similar findings were reported by Taunton et al. (1989). The researchers of these studies suggested that it may not actually be the assigned clinical area that causes dissatisfaction or anticipated turnover, but that differences in the task orientation, degree of autonomy, participation in decision making, or relationship with the supervisor and/or peers contribute to the differences in work satisfaction between groups.

The research studies cited in the literature review supported the hypothesized effects of collaborative behavior, organizational clir:ate, and job stress on job satisfaction and anticipated turnover in nursing. Table 1 , at the end of this chapter, summarizes the research discussed in the literature review which linked the study variables. 


\section{Summary}

Relevant research from business and nursing literature supported the hypothesized direct and indirect relationships among collaborative behaviors, organizational climate, job stress, job satisfaction, and anticipated turnover. Relationships between personal characteristirs of the respondents such as age, seniority, experience as a nurse, and specialt $\bar{y}$ area have also been demonstrated to be related to job satisfaction and anticipated turnover, although the findings have not been consistent across studies. 
Table 1

Sumlary of Studies Supportirg Linkages in Theoretical vodel

\begin{tabular}{|c|c|c|c|c|c|}
\hline Researcher (s) & $\begin{array}{l}\text { Outcame } \\
\text { Variable }\end{array}$ & Instrument(B) & Sample & $\begin{array}{l}\text { Pelational } \\
\text { Variables(s) }\end{array}$ & $\begin{array}{l}\text { Correlation } \\
\text { coefficient/ } \\
\text { Direction }\end{array}$ \\
\hline \multirow[t]{5}{*}{$\begin{array}{l}\text { llinshaw, } \\
\text { Smeltzer \& } \\
\text { Atwood (1987) }\end{array}$} & $\begin{array}{l}\frac{\text { Job }}{\text { Satisfaction }} \\
\text { ogganlzational } \\
\mathrm{R}^{2}=.57\end{array}$ & $\begin{array}{l}\text {-Group Oahesion } \\
\text { Scale (Byrnes), } \\
\text {-Job Stress Scale } \\
\text { (Bailey \& claus), }\end{array}$ & $\begin{array}{l}261 \text { Baoca- } \\
\text { laurate PNs }\end{array}$ & $\begin{array}{l}\text { Group cohesion } \\
\text { Job Stress } \\
\text { Dontrol over practice } \\
\text { Autonomy: Quality of }\end{array}$ & $\begin{array}{l}\mathrm{B}=+.27 \\
\mathrm{~B}=-.34 \\
\mathrm{~B}=.17\end{array}$ \\
\hline & & $\begin{array}{l}\text { - Work Satisfaction } \\
\text { - Scale (Slavitt et } \\
\text { al.), } \\
\text { - Professional Job } \\
\text { Satisfaction } \\
\text { Scale (Brayfleld } \\
\text { \& Rotho) }\end{array}$ & & employment & $B=.13$ \\
\hline & $\begin{array}{l}\text { Brofessional } \\
\frac{\text { Job }}{\text { Satisfaction }} \\
\mathrm{R}^{2}=.49\end{array}$ & & & $\begin{array}{l}\text { Shift } \\
\text { Unit (critical care) } \\
\text { Autonamy } \\
\text { Job Stress } \\
\text { Group Cahesion } \\
\text { Experienoe at hosilital }\end{array}$ & $\begin{array}{l}B=.13 \\
B=.12 \\
B=.18 \\
B=-.47 \\
B=.17 \\
B=-.15\end{array}$ \\
\hline & $\begin{array}{l}\frac{\text { Organizational }}{\text { Job }} \\
\frac{\text { Satisfaction }}{p^{6}}\end{array}$ & & $\begin{array}{l}226-280 \\
\text { Diplana PNs }\end{array}$ & $\begin{array}{l}\text { Group Cohesion } \\
\text { Job stress } \\
\text { Oontrol over practice }\end{array}$ & $\frac{\mathrm{B}}{\mathrm{B}}=.24$ \\
\hline & $\mathrm{K}=.50$ & & & $\begin{array}{l}\text { Comittioe } \\
\text { Aocess to ideas } \\
\text { Pertonal resourcer3 } \\
\text { Autonaly } \\
\text { Job Stress } \\
\text { Ob/Gyn }\end{array}$ & $\begin{array}{l}\mathrm{B}=.23 \\
\mathrm{~B}=.20 \\
\mathrm{~B}=.21 \\
\underline{B}=.16 \\
\mathrm{~B}=-.45 \\
\mathrm{~B}=.20\end{array}$ \\
\hline
\end{tabular}

Note: $\quad *=\underline{p}<<.05$

$\begin{aligned} \star \star & =\mathrm{p}<.01 \\ \star \star \star & =\mathrm{p}<.001\end{aligned}$ 


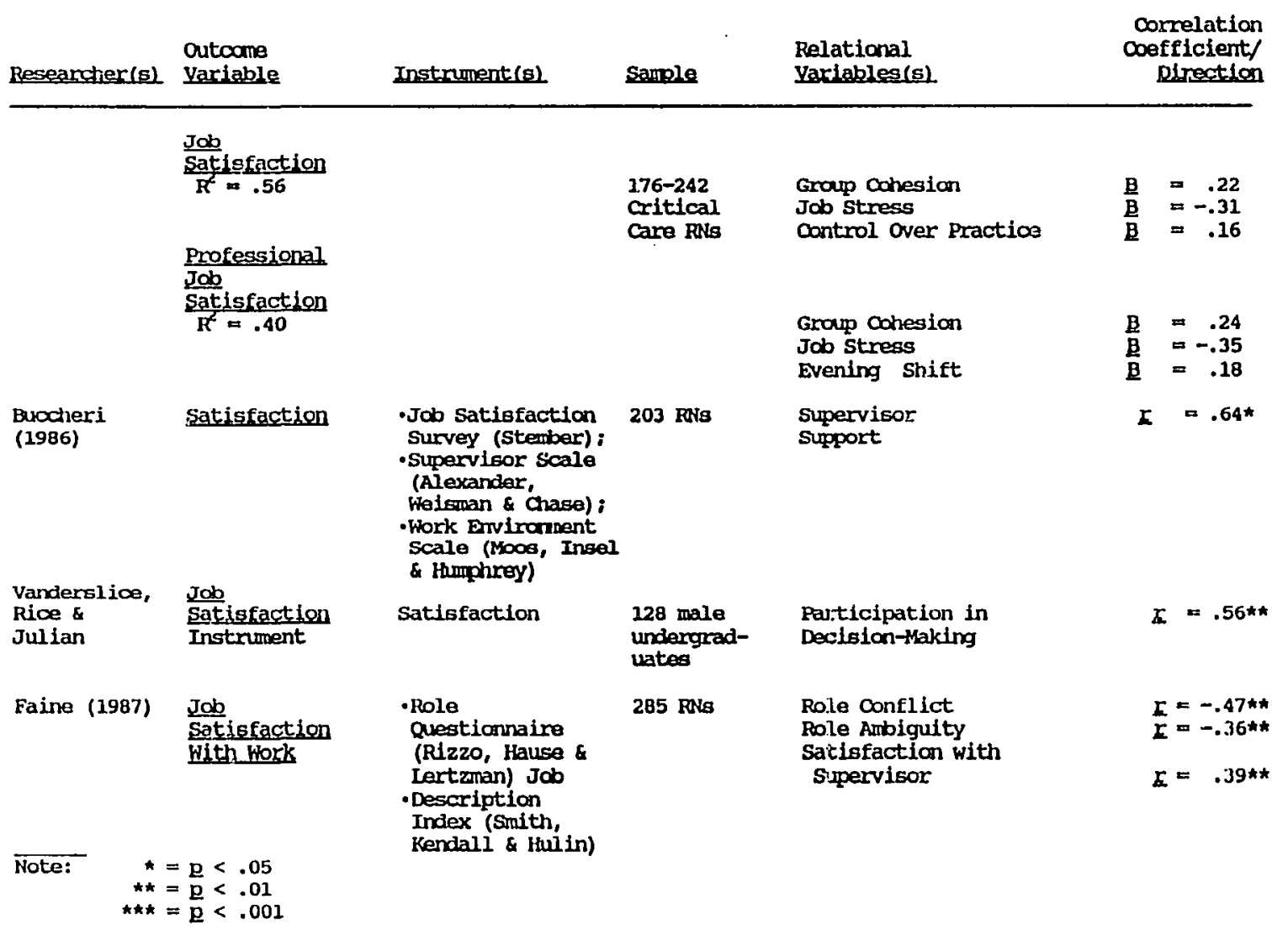




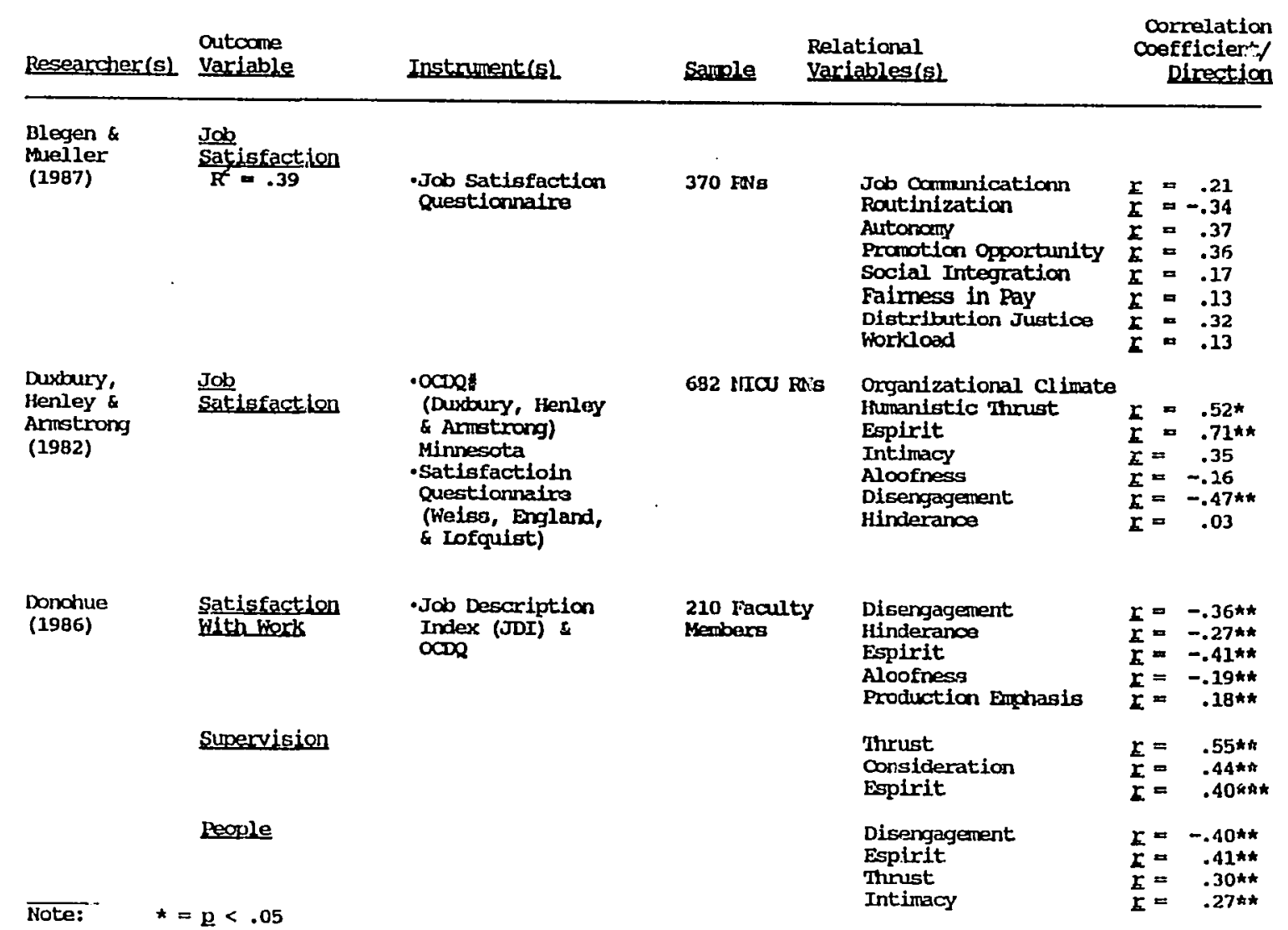




\begin{tabular}{|c|c|c|c|c|c|}
\hline Researcher (s). & $\begin{array}{l}\text { Outoame } \\
\text { Variable }\end{array}$ & Instrument(s) & Sample & $\begin{array}{l}\text { Relational } \\
\text { Yariables (g) }\end{array}$ & $\begin{array}{l}\text { Correlation } \\
\text { coefficient/ } \\
\text { Direction }\end{array}$ \\
\hline $\begin{array}{l}\text { Alexander, } \\
\text { Wiseman \& } \\
\text { Chase (1981) }\end{array}$ & $\begin{array}{l}\frac{\text { Job }}{\text { Satisfaction }} \\
\frac{\text { Anticipated }}{\text { Aunnorer }}\end{array}$ & $\begin{array}{l}\text { - Likert-type } \\
\text { Questionnaire } \\
\text { Nurstis Peroeptions } \\
\text { of Head Nunse }\end{array}$ & $\begin{array}{l}344 \text { staff } \\
\text { Hospital A }\end{array}$ & $\begin{array}{l}\text { Primary Care vs. } \\
\text { Non-Primary Care }\end{array}$ & $\begin{array}{l}\text { NS\#\# } \\
\text { Job } \\
\text { Satisfaction } \\
\text { p<.01 for } \\
\text { Anticipated } \\
\text { Turnover }\end{array}$ \\
\hline $\begin{array}{l}\text { Selick, } \\
\text { Pusseli \& } \\
\text { Beckman (1983) }\end{array}$ & $\frac{\text { Staff }}{\text { Satisfaction }}$ & $\begin{array}{l}\text {-Staff Satisfac- } \\
\text { tion Scale }\end{array}$ & 37 RNS & $\begin{array}{l}\text { Primary Care VE. } \\
\text { Non-Primary } \\
\text {-voice opportunitios } \\
\text {-practioe in decision- } \\
\text { making } \\
\text {-set pace of own work } \\
\text {-ctange to acoarpllsh } \\
\text { worthwhile work }\end{array}$ & $\begin{array}{l}\mathrm{p}<.025 \\
\mathrm{Q}<.005 \\
\mathrm{p}<.05 \\
\mathrm{p}<.01\end{array}$ \\
\hline $\begin{array}{l}\text { Carleon \& } \\
\text { Malley (1981) }\end{array}$ & Job & $\begin{array}{l}\text {-Job Satisfaction } \\
\text { Questionnaire }\end{array}$ & $180 \mathrm{FNB}$ & $\begin{array}{l}\text { Participation in } \\
\text { Decision-Haking } \\
\text { Using Skills \& } \\
\text { Abilities }\end{array}$ & $\begin{array}{l}\mathrm{D}<. .02 \\
\mathrm{D}<. .04\end{array}$ \\
\hline $\begin{array}{l}\text { Blenkarn, } \\
\text { d'Amico \& } \\
\text { Virtue ;1988) }\end{array}$ & $\frac{\text { Job }}{\text { Satisfaction }}$ & $\begin{array}{l}\text {-Job Satisfaction } \\
\text { Survey (Slavitt } \\
\text { ot al.) }\end{array}$ & $\begin{array}{l}\text { not } \\
\text { reported }\end{array}$ & $\begin{array}{l}\text { Murse/Physician } \\
\text { Relationships } \\
\text { Autonamy } \\
\text { Professional status }\end{array}$ & $\begin{array}{l}\mathbf{p}< \\
1-\text { tailed test } \\
\mathbf{p}<\quad .05 \\
\mathbf{p}<.05\end{array}$ \\
\hline $\begin{array}{l}\text { Feltham } \\
\text { (1983) }\end{array}$ & $\frac{\frac{\text { Job }}{\text { Satjisfaction }}}{\text { R }^{\prime}=.24}$ & & 148 RNB & $\begin{array}{l}\text { Role Stress Conflict } \\
\text { Role Stress Ambilguity }\end{array}$ & $\begin{array}{l}x=-.26 t k \hbar t \\
x=-.49\end{array}$ \\
\hline
\end{tabular}




\begin{tabular}{|c|c|c|c|c|c|}
\hline Resparatier(s) & $\begin{array}{l}\text { outcome } \\
\text { variable }\end{array}$ & Instrument(s) & Sample & $\begin{array}{l}\text { Ralational } \\
\text { Variables(s) }\end{array}$ & $\begin{array}{l}\text { correlation } \\
\text { coefficiclent/ } \\
\text { pinection }\end{array}$ \\
\hline $\begin{array}{l}\text { Norbeck } \\
\text { (1985) }\end{array}$ & $\frac{\frac{\text { Job }}{\text { Satisfaction }}}{\frac{k^{\prime}=.06}{=}=.06}$ & $\begin{array}{l}\text { - Questionnaire for } \\
\text { Stressful Factors } \\
\text { - Nurning Job } \\
\text { Satilafaction scale } \\
\text { (Atwood \& Hinshaw) } \\
\text { - Brief Symptom } \\
\text { Irventory }\end{array}$ & 180 RNs & Job Stress & $.24 \star \star$ \\
\hline $\begin{array}{l}\text { Godfrey } \\
\text { (1978) } \\
\text { Nursing } 88\end{array}$ & $\frac{\text { Job }}{\text { Satisfaction }}$ & $\begin{array}{l}\text { - Survey } \\
\text { survey }\end{array}$ & 8024 FNS & $\begin{array}{l}\text { Day Shift } \\
\text { Poor Staffing \& Workload } \\
\text { Iack of Support from } \\
\text { Management } \\
\text { Jab Stress } \\
\text { Poor Pay }\end{array}$ & $\begin{array}{l} \pm \\
\pm \\
=\end{array}$ \\
\hline $\begin{array}{l}\text { Traunton, } \\
\text { Krampitz \& } \\
\text { Woods (1989) }\end{array}$ & $\frac{\mathrm{Job}}{\text { Satisfaction }}$ & - Not Described & $\begin{array}{l}71 \text { Hospital } \\
\text { Professionals } \\
\text { Making }\end{array}$ & $\begin{array}{l}\text { Leadership Style } \\
\text { Centralized Declsion- }\end{array}$ & $\begin{array}{l}x=.37 \star k \\
x=-.42^{\star \star}\end{array}$ \\
\hline $\begin{array}{l}\text { Kosmoski } \\
\text { \& Calkin } \\
\text { (1986) }\end{array}$ & $\begin{array}{l}\frac{\text { Anticipated }}{\text { Tumpover }} \\
\mathrm{R}^{\mathrm{t}=287} \\
(1986)\end{array}$ & $\begin{array}{l}\text {-Job Description } \\
\text { Index } \\
\text { - Six Questions } \\
\text { fram an Intent } \\
\text { to Stay Question- } \\
\text { naire (Q }=.90) \\
\text { - Organizational } \\
\text { Assessment } \\
\text { - Instrument (Van } \\
\text { de Ven \& Ferry) }\end{array}$ & 214 RNE & $\begin{array}{l}\text { Pay } \\
\text { Yaars of Formal } \\
\text { Education } \\
\text { Work-Realted } \\
\text { Education } \\
\text { Further Education }\end{array}$ & $\begin{array}{l}.14 * \\
E=-.19 * \\
E=-.13 * \\
E=-.13 *\end{array}$ \\
\hline
\end{tabular}




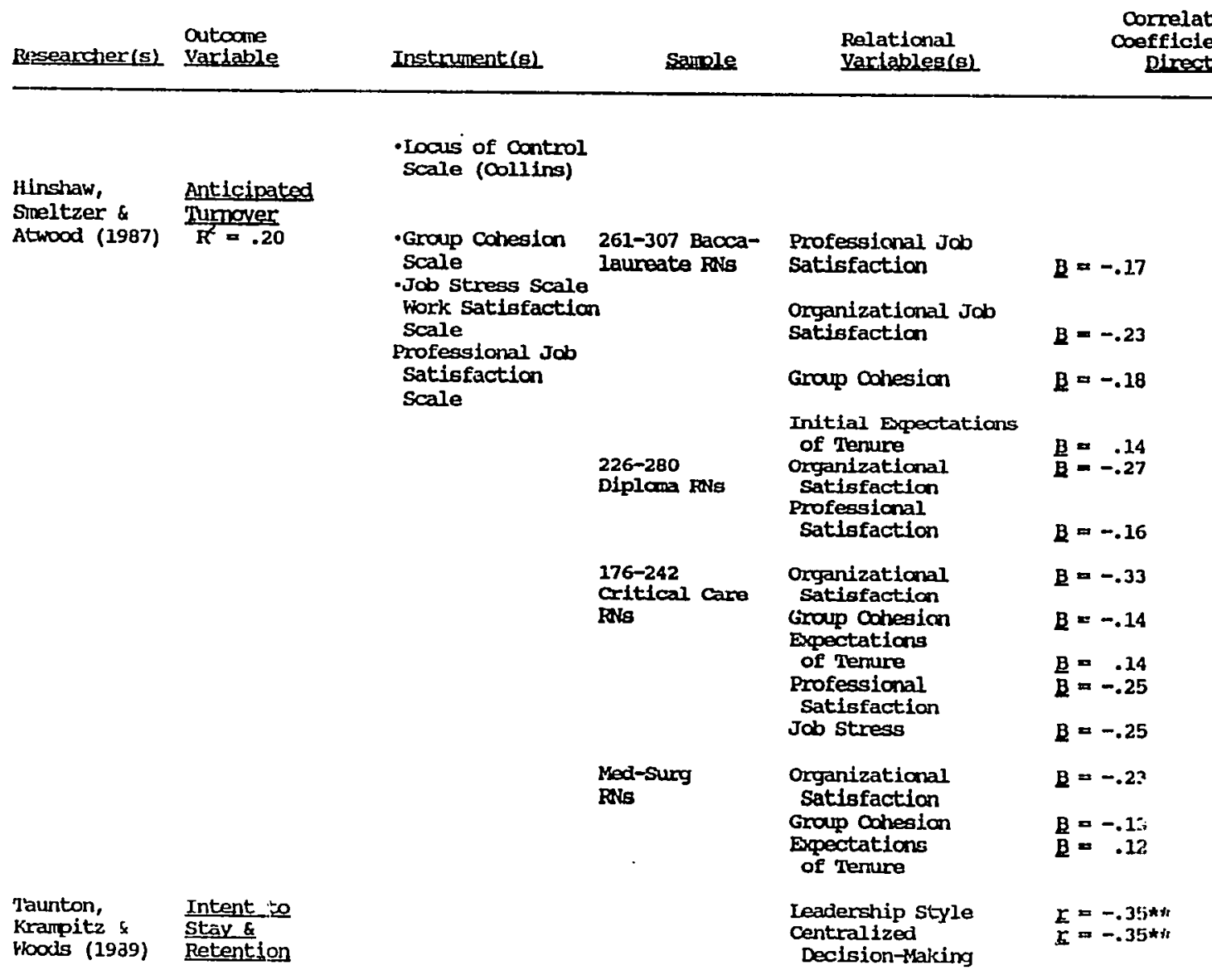


CHAPTER III

METHODOLOGY

Chapter III describes the research design, sample, instrumentation, data collection and analysis procedures used in the study. A summary section completes the chapter.

\section{Research Design}

The recursive theoretical model (see Figure 1) was tested using path analytic techniques. Collaborative behavior, organizational climate, and job stress were exogenous variables and were not influenced by other variables in the theoretical model. Job satisfaction and anticipated turnover were endogenous variables and were thought to be influenced by collaborative behavior, organizational climate, and job stress. Regression techniques provided an estimate of the separate effects of the exogenous variables on job satisfaction and anticipated turnover, and the extent to which these effects were transmitted indirectly through job satisfaction to anticipated turnover.

\section{Structural Equations}

Structural equations for the just-identified model, presented in Figure 1, were presented as follows: 
Nurse-Physician Collaborative Behavior

$$
x_{1}=e_{1}
$$

Nurse-Manager Collaborative Behavior

$$
x_{2}=e_{2}
$$

organizational climate

$$
x_{3}=e_{3}
$$

Job stress

$$
x_{4}=e_{4}
$$

Job Satisfaction

$$
x_{5}=P_{51} x_{1}+P_{52} x_{2}+P_{53} X_{3}+P_{54} X_{4}+e_{5}
$$

Anticipated Turnover

$$
x_{6}=P_{61} x_{1}+P_{62} x_{2}+P_{63} x_{3}+P_{64} x_{4}+P_{65} X_{5}+e_{6}
$$

\section{Sample}

This investigation utilized a total sample of 188

female Registered Nurses employed in six acute care hospital settings in Southern California. There were 194 responses with 188 usable data sets from a population sample of 366 subjects, indicating a 53\% response rate. Power analysis was performed according to the procedures described by Volicer (1984) and Cohen (1988) with a power greater than .995 obtained based on an effect size (L) of 81.77 , a probability level of .05, and five independent variables. A random sampling design was used. Because of the inability to obtain an adequate number of male participants to permit comparison of group responses between male and female respondents, males were excluded from the sample. 
The mean age of the respondents was 39 years $(\underline{S \underline{n}}=10$ ) with a mode of $3 I$ years and a range from 21 to 64 years. The mean years of education was 15.2 years $(\underline{S D}=1.1$ ) with $34.6 \%$ of the sample prepared at the Baccalaureate level, $25.5 \%$ prepared at the Diploma level, $32.4 \%$ prepared at the Associate level, and $7.5 \%$ prepared at the graduate or postgraduate level.

The mean years experience as a Registered Nurse was 13.3 years $(\underline{S D}=8.5)$ with an average of 6.3 years seniority in the current hospital and an average of 4.7 years in the present position. The majority (65\%) of the nurses worked full-time with an average of 38.6 hours ( $\underline{\underline{D}}=13.9$ ) worked per week. Seventeen percent $(17 \%)$ of the sample worked part-time, and $16 \%$ worked per diem. Fifty-five percent (55\%) of the nurses in the sample worked days; $22 \%$ worked evenings; $19 \%$ worked nights; and $4 \%$ rotated shifts.

The majority (81\%) of the respondents were clinical nurses, $9 \%$ charge nurses, $4 \%$ clinical nurse specialists, and $1 \%$ clinical educators. Five percent did not describe their position. Medical-surgical nurses represented $22 \%$ of the sample, with 11\% from critical care units, $10 \%$ from postpartum units, $8 \%$ from rehabilitation units, $7 \%$ from Labor and Delivery, and 6\% from the operating room. Several other units including nursery, emergency department, postanesthesia care unit, and neonatal intensive care were represented with each less than $5 \%$ of the total. 


\section{Instruments}

The instruments used to measure the study variables and their related psychometric properties are summarized in Table 2 at the end of this chapter. A description of each instrument and its related properties is presented in the following sections.

Weiss and Davis Collaborative Practice Scale.

The Collaborative practice scale (CPS) is a nine item scale developed by Weiss and Davis (1985). The CPS uses a six-point Likert-type scale with response options ranging from "never" to "always" that measures collaborative practice between nurses and physicians. The scale has a nurse and a physician version, but only the nurse version of the scale was used in this study. The insirument was developed using conflict resolution theory as prescribed by Kilmann and Thomas (1977).

Weiss and Davis (1985) reported Cronbach's alpha coefficients for internal consistency as .80 for the nurse CPS (NCPS) on initial testing and .83 on a subsequent test. The test-retest reliability was .79. Construct validity testing using factor analysis yielded two factors for the NCPS: 1) direct assertion of professional expertise and opinion and 2) active clarification of mutual responsibilities. Spearman correlations assessing the relationship between factors and to the total scale gave further support for the measure's internal consistency 
$(\underline{x}=.41)$. For this study, the cronbach's alpha coefficieit $(\mathrm{N}=188)$ was .91 with an inter-item correlation mean of $\underline{r}=.52$.

Convergent validity was investigated by correlating the initial sccres fromil the NCPS with the Health Role Expectations Index (HREI- Weiss \& Davis, 1983) and the "collaboration" mode of the Management of Differences Exercise (MODE) (Ruble \& Thomas, 1976). While the scores on the NCPS correlated significantly $(\underline{r}=.25, p \leq .01)$ with the HREI, the scores on the NCPS did not correlate with the scores on the collaboration mode of the MODE. The authors suggested that the absence of items pertaining to negotiation in the CPS may account for the lack of correlation with the collaboration mode of the MODE. While the MODE defines collaboration predominantly as a negotiation process, the CPS defines collaboration as the airect assertion ố professionaì expertise/opinion and active clarification of mutual responsibilities.

The CPS was administered to test the convergent validity of the collaborative Behavior scale (CBS-Part A, stichler, 1989) which is a new instrument. The Collaborative Practice Scale appears in Appendix A.

\section{Stichler Collaborative Behavior Scale} The Collaborative Behavior Scale (CBS)- Part $A$ and $B$ (Stichler, 1989) is a newly developed instrument. The CBS was designed as a self-report measure which is utilized to 
determine the extent of raspondents' collaborative behaviors in relationships. The CBS is a four point Likert-type scale with response options ranging from "rarely" to "nearly always". The 20 item CBS was developed using the theoretica! work of Deutsch (1973) and Homans (1950). The content validity index (CVI) for the instrument was reported as .91 (Stichler, 1989). Factoral validity was established using an alpha factoring technique. Varimax rotation yielded a simple structure with seventy-three percent (73\%) of the variance attributed to Factor 1. Factor loadings ranged from .79 to .92. Reliability was previously tested using Cronbach's alpha with item total correlations ranging from .78 to .90 and a standardized item alpha ô .98. For the current study ( $\mathbb{N}=188$ ), the CBS-A had a Cronbach's alpha of .96 with an inter-item correlation of .57. Reliability testing in the current study for the CBS-B revealed a Cronbach's alpha of .98 with an inter-item correlation of .68 .

Convergent and discriminate validity were initially established using the multitrait-multimethod approach which correlated the CBS-A with the MODE (Kilmann \& Thomas, 1977; Polit \& Hungler, 1987; Waltz, Strickland, \& Ienz, 1984). Although the correlation coefficient between the CBS-A and the collaboration MODE was low $\left(r_{x y}=.22\right)$, the coefficient was higher than for the other modes (competition, accommodation, avoidance, and cooperation), giving support for the convergent and discriminate validity of the 
instrument. Correlating the CBS-A and the CPS in this study provided further evidence of construct validity as described in Chapter IV of this study. The CBS-A appears in Appendix $B$, and the CBS-B appears in Appendix C.

Dieterly and Schneider organizational climate Measure.

The Organizational climate Measure (Dieterly \&

Schneider, 1974) consists of 28 items constructed along four dimensions which were theoretically supported by campbell, Dunnette, Lawler, and Weick (1970). These dimensions include: 1) individual autonomy (IA) - the nurses' feeling of self-directedness or feeling of responsibility for the outcomes of their work or contributions; 2) position structure (PS) - the nurses' feelings about the formal and informal lines of authority in the organization; 3) reward orientation (RO) - the nurses' feeling of being rewarded or recognized for one's contributions to the organizational goals; and 4) consideration and warmth (C)-the nurses' feeling of social integration, support, or camaraderie within the organization.

The instrument is a five point Likert-type scale with response options ranging from "strongly disagree" (1) to "strongly agree" (5). A summated score was obtained for each of the subscales and for the total instrument. Reliability coefficients for each sub-scale were reported as follows: 1) $\mathrm{IA}, \underline{\mathrm{a}}=.77 ; 2) \mathrm{PS}, \underline{\mathrm{a}}=.76 ; 3) \mathrm{RO}$, $\underline{\mathrm{a}}=.64 ;$ and 4) $\mathrm{C}$, $\underline{\mathrm{a}}=.87$. Several adaptations in wording of selected 
items were made for this study to make the items more appropriate for use in the hospital setting. For example, "company" was changed to "hospital", "employee(s)" was changed to "staff nurse(s)", "management" or "supervisor" was changed to "head nurse/nurse manager" or "administration", "output" was changed to "outcome", "objectives" was changed to "standards". The phrase "applications are done properly" was changed to "good care is given".

The reliability testing of the ocs in the current study $(N=188)$ yielded the following alpha coefficients for each subscale and total scale: 1) IA, $\underline{\mathrm{a}}=.72 ; 2)$ PS, $\underline{\mathrm{a}}=.40$; 3) $\mathrm{RO}, \underline{\mathrm{a}}=.73 ; 4) \mathrm{C}, \underline{\mathrm{a}}=.76$; and 5) total scale, $\underline{\mathrm{a}}=.85$. The organizational climate Instrument as adapted for this study appears in Appendix D.

\section{Gray-Toft and Anderson Nursing Stress Scale.}

The Nursing Stress Scale (NSS) developed by Gray-Toft and Anderson (1981) is a four point Likert-type scale with response categories ranging from "never" to "very frequently". The scale measures the frequency of situations which have been identified as stressors for nurses in the performance of their duties. It provides a total stress score as well as a score for each of seven scale dimensions. These dimensions which were identified by factor analysis include: 1) death and dying, 2) conflict with physicians, 3) inadequate preparation, 4) lack of support, 5) conflict with 
other nurses, 6) work load, and 7) uncertainty concerning treatment.

Previous reliability testing yielded the following reliability coefficients: a test-retest alpha coefficient of $\underline{r}=.81 ;$ a Spearman-Brown coefficient of $\underline{\underline{ }}=.79$; a Guttman split-half coefficient alphá of $\underline{a}=.79$; a coefficient alpha of .89; and a standardized alpha of .89. Reliability coefficients for each dimension were reported as follows: 1) Death, $\underline{\mathrm{a}}=.78 ; 2$ ) MD Conflict, $\underline{\mathrm{a}}=.68 ; 3$ ) Inadequate Preparation, $\underline{a}=.76 ; 4$ ) Lack of Support, $\underline{a}=.65$; 5) RN Conflict, $\underline{a}=.70 ; 6$ ) Workload, $\underline{a}=.77$; and 7 ) Uncertainty, $\underline{a}=.80$.

Convergent and discriminate validity were determined by correlating the total score from the NSS with measures of trait anxiety $(\underline{r}=.39)$, job satisfaction $(\underline{r}=-.15)$, and nursing turnover. In Gray-Toft and Anderson's study, the NSS was negatively correlated with Job Satisfaction and positively correlated to trait anxiety and nursing turnover.

In the current study, reliability testing yielded the following Cronbach's alpha coefficients for the subscales and total scale: 1) Death, $\underline{a}=.85 ; 2$ ) MD Conflict, $\underline{a}=.77$; 3) Inadequate Preparation, $\underline{a}=.82 ; 4$ ) Lack of Support, $\underline{\mathrm{a}}=.81 ; 5) \mathrm{RN}$ Conflict, $\underline{\mathrm{a}}=.84 ; 6$ ) Workload, $\underline{\mathrm{a}}=.78$; 7) Uncertainty, $\underline{a}=.88$; and 8 ) total NSS scale, $\underline{a}=.97$. The ins appears in Appendix $\mathrm{E}$. 
Stamps and Piedmonte Index of Work Satisfaction

The Index of Work Satisfaction (IWS), developed by Stamps and Piedmonte (1986), is a 44 item, Likert-type scale founded on the theoretical work of Maslow (1954) and Herzberg (1968). The instrument, which was adapted from a similar 48 item questionnaire originally developed by Slavitt, Stamps, Piedmonte, and Haase (1978), is intended to measure the occupational or work satisfaction of health care professionals. The seven point rating scale has response options which range from "Disagree" to "Agree". The instrument is comprised of seven dimensions of satisfaction which have been theoretically and empirically supported. The seven dimensions include: 1) job or professional status, defined as perception of importance of the job to the individual and to the organization or society at large; 2) task requirements, defined as duties required in the job; 3) pay, defined as financial remuneration and benefits received for work performed; 4) physician-nurse interaction (MDRN Interaction), defined as physician understanding and appreciation of the work of nursing; 5) nurse to nurse interaction (RNRN Interaction), defined as opportunities or requirements for formal and informal social and professional conduct while on duty; and 6) organizational requirements or policies, defined as constraints or limits imposed by management on work activities; and 7) autonomy, defined as independence in decision making or initiative related to work. 
The instrument is comprised of two parts. Part $A$ is a forced choice, paired comparison format in which respondents rank-ordered six components of satisfaction. Part $B$ is a seven point, Likert-type scale with seven response options ranging from "Disagree" to "Agree" that measures the level of satisfaction. The scores are summated for each of the seven dimensions and for the total scale. Since each part can be used singly or in combination, only Part B was used in this study.

Factor analysis using a varimax rotation procedure provided construct validity for the instrument with only one item (number 33 in organizational Policies) with a factor loading less than the .4 level (Nunnally, 1978). While reliability coefficients for each dimension were not delineated, the researcher's (Stamps \& Piedmonte, 1986) reported Cronbach's alpha coefficients ranging from .52 to .81 with a total scale alpha of .82 = Specific sub-scale alpha coefficients were not reported. Kendall's Tau, which measures the strength of correlation between the weighted score and the unweighted summed score of Part B (the attitude measure) was reported as .92. This high correlation supported the use of Part B only, since the focus of this study was to assess the current status of job satisfaction of the respondents rather than their expectation of satisfiers.

The instrument has been in development and revision for 10 years and has been usea in a number of studies (Blenkarn 
et al., 1989; Slavitt et al., 1979). 스though the scale has beer modified slightly in some studies, similarity in study results and consistency in instrument properties have been reported.

Reliability testing of the IWS in the current study yielded the following Cronbach's alpha coefficients for the subscales and the total scale: 1) Professional status, $\underline{\mathrm{a}}=.66$; 2) Task Requirements, $\underline{\mathrm{a}}=.78$; 3) Pay, $\underline{\mathrm{a}}=.90 ; 4$ ) MDRN Interaction, $\underline{a}=.86 ; 5)$ RNRN Interaction, $\underline{a}=.78$;

6) Organizational Policies, $\underline{\mathrm{a}}=.83$; 7) Autonomy, $\underline{\mathrm{a}}=.80$; and 8) totai IWS scale, $\underline{a}=.94$. The Index of Work Satisfaction appears in Appendix $F$.

\section{Hinshaw and Atwood Anticipated Turnover Scale.}

The Anticipated Turnover Scale (ATS) was developed by Hinshaw and Atwood (1982). The instrument is a 12 item self-report, Likert-type scale with seven response options ranging from "Disagree strongly" to "Agree strongly". The purpose of the instrument is to index the employee's perception of the possibility of voluntarily leaving his/her current position or job. The ATS was administered to 1,597 nursing staff members in a study to test a theoretical path model for job satisfaction and anticipated turnover of nursing staff (Hinshaw \& Atwood, 1985). The authors reported a standardized alpha of .84 for the total scale, but sub-scale alpha coefficients were not reported. Construct validity was estimated using principal components 
factor analysis and predictive modeling techniques. Two factors were identified which explained $54.9 \%$ of the variance. The order of the response options was modified for this study from a range of "Agree Strongly" to "Disagree strongly" to a range of "Disagree strongly" to "Agree strongly". This was done to provide consistency with the ordering of response options for other measures used in the study.

In this study, reliability testing revealed the following cronbach's alpha coefficients: 1) Time; $\underline{a}=.76$; 2) Certainty, $\underline{\mathrm{a}}=.81 ;$ and 3 ) total ATS, $\underline{\mathrm{a}}=.87$. The ATS appears in Appendix $G$.

\section{Demographic Questionnaire.}

Demographic data from individual respondents were requested via the Demographic Questionnaire to provide descriptive information about the sample and to permit comparisons of subsets within the sample. Representative items included age, years of education, type of education, years of experience as an $\mathrm{RN}$, seniority in the organization, specialty area, and position in the organization. The demographic questionnaire appears in Appendix $\mathrm{H}$.

\section{Data collection}

Data collection was accomplished with the instruments described above. In addition to the instruments two additional items were included in the data collection packet 
given to each subject: 1) a disclaimer letter (see Appendix I); and 2) a copy of the Research Bill of Rights (see Appendix J) .

Approval to conduct the research was obtained from each hospitals' administrative structure and/or research review committee and the University of San Diego Committee on Frotection of Human Subjects (see Appendix K). A pilot study was conducted with six managers and sixteen staff members in two clinical areas to test the clarity of the instructions for the data collection booklet. After permission was obtained to conduct the research, a list of registered nurses was obtained from each participating hospital. A number was drawn from a pool of numbers between one and ten and each "n-th" name was selected as a potential subject. Questionnaire packets were mailed to each subject which contained a self-addressed stamped envelope to facilitate return mailing. Since participation was voluntary, consent to participate in the study was assumed when the subjects returned the completed questionnaire. when the questionnaire packet was returned to the researcher, each questionnaire was coded with an identification number and separated from any identifying information which provided anonymity for the respondent. All response sheets were maintained in a locked file. 


\section{Data Analysis}

Correlations among the study variables and the demographic variables were computed with sPsS-X (1988) using Pearson Product Moment Correlations and multiple regression analysis as described in Munro, Visintainer, and Page (1986) - Descriptive statistics were utilized to analyze demographic data. Demographic variables having significant Pearson Product-Moment correlations with the study variables were included in the path moael. The bivariate correlation coefficients were examined for all variables with a level set at .60-.80 to rule out extreme multicollinearity (Asher, 1983; Munro et al., 1986). Those variables demonstrating high intercorrelation were either combined into one single variable or eliminated from the regression equation. All exogenous, endogenous, and demographic variables were entered into the regression analysis with each endogenous variable in a later time ordering. The output for the regression analysis was examined to determine:

a. Beta Weights (path coefficients) and their significance levels;

b. Amount of Variance $\left(R^{2}\right)$ accounted for by the variables in each equation;

A simplified causal model was developed to demonstrate those linkages that had significant correlations at the .05 level or greater, and/or saliency level of .io or greater (Munro et al. , 1986). 


\section{Assumptions}

The statistical tests were selected based on the assumptions of normality, linearity, and homoscedasticity (Verran \& Ferketich, 1987). The following assumptions were made: 1) a linear relationship existed between exogenous and endogenous variables; 2) the residuals were normally distributed with a mean equalling zero; 3 ) the residual variance was equal at all points of the preaicted dependent variable; 4) residuals were independent of one another; and 5) the indeperdent variables had a fixed distribution. A residual analysis procedure combining an analysis of graphic scatterplots and summary statistical tests as described by Verran and Ferketich (1987) was used to test the assumptions and the stability of the results of the analysis.

\section{Summary}

A path analytic design was used to test the proposed relationships illustrated in the theoretical model (Figure 1). It was hypothesized that the exogenous variables, collaborative behavior, organizational climate, and job stress have a direct effect on job satisfaction and anticipated turnover. Six instruments measuring the study variables were administered to a randomly selected sample of 188 female RNs from six acute care hospitals in southern California. A multiple regression procedure was used to determine path coefficients (suggested Beta weights) and 
their significance levels between the exogenous and endogenous variables. The amount of variance $\left(R^{2}\right)$ accounted for in each of the endogenous variables (job satisfaction and anticipated turnover) by each of the exogenous variables in the equation was obtained. A post hoc analysis of demographic variables was also conducted to determine significant correlations to be entered into the path model. 
Table 2

sumany of Psyctionetric Properties of_Study Instruments

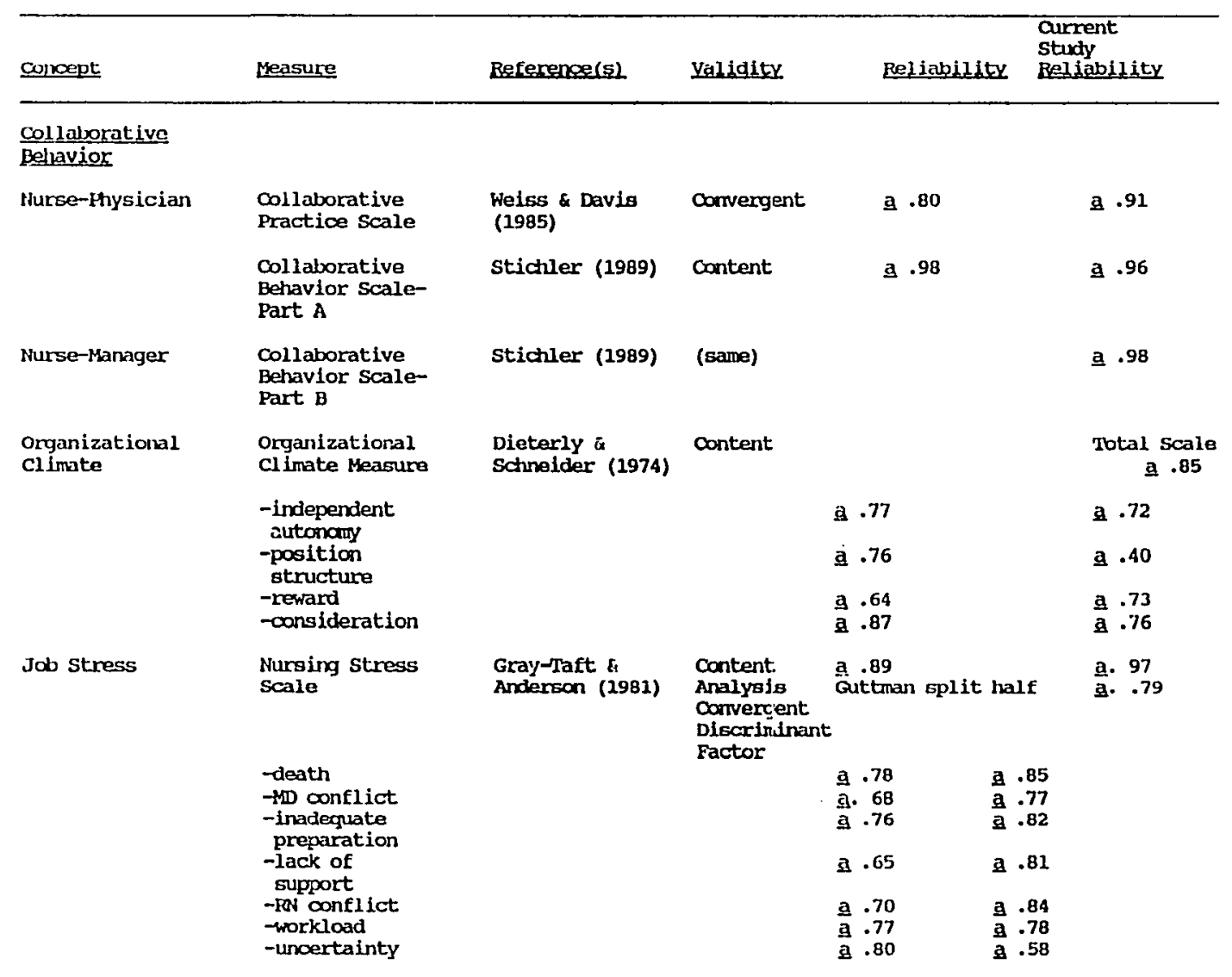




\begin{tabular}{|c|c|c|c|c|c|}
\hline concept & Masure & Beference(s) & Yalidity & Bellabllity & $\begin{array}{l}\text { Oprrent } \\
\text { Standy } \\
\text { Bellability }\end{array}$ \\
\hline \multirow[t]{2}{*}{ Job Satisfaction } & $\begin{array}{l}\text { Index of Work } \\
\text { Satisfaction }\end{array}$ & $\begin{array}{l}\text { Stamps \& } \\
\text { Pledtunte (1986) }\end{array}$ & $\begin{array}{l}\text { Factor } \\
\text { Analysis }\end{array}$ & a .82 & a $\cdot 94$ \\
\hline & & $\begin{array}{l}\text {-professicmal } \\
\text { status } \\
\text {-task requirements } \\
\text {-pay } \\
\text { - ND-FN interaction } \\
\text {-RN-FN interaction } \\
\text {-organizatianal } \\
\text { policies } \\
\text {-autoncmy }\end{array}$ & & & $\begin{array}{l}\text { E } .66 \\
\text { a } .78 \\
\text { a } .90 \\
\text { a } .86 \\
\text { a } .78 \\
\text { a } .83 \\
\text { a } .80\end{array}$ \\
\hline $\begin{array}{l}\text { Anticipated } \\
\text { Tumover }\end{array}$ & $\begin{array}{l}\text { Anticipated } \\
\text { Turnover Scale }\end{array}$ & $\begin{array}{l}\text { Hinshaw \& Atwood } \\
\text { (1982) }\end{array}$ & $\begin{array}{l}\text { Construct } \\
\text { Principal } \\
\text { Components } \\
\text { Analysis }\end{array}$ & a $\cdot 84$ & 3. .87 \\
\hline
\end{tabular}


CHAPTER IV

RESULTS

The data from the Demographic Questionnaire and instruments used to measure the study variables are presented in this chapter. The chapter will include the following sections and information: 1) data reauction -presenting correlational information for each of the instruments and subscales; 2) hypotheses testing -- results presented according to each hypothetical statement; 3) regression analysis -- results of the regression analysis; 4) assumption testing -- results of the residual analysis; and 5) post hoc analysis -- results of correlations of specific demographic variables with the predictor and outcome variables.

\section{Data Reduction}

\section{Examination of Bivariate Correlations}

Bivariate correlations using Pearson Product-Moment procedures were conducted on all study variables and the subscales to test for multicollinearity or interrelations among the independent variables prior to path analysis. A correlational matrix representing the intercorrelations among variables was developed and is presented in Table 3. All of the variables correlated significantly with Anticipated Turnover, but none of the bivariate correlations 
Table 3

Correlational Matrix for Study Variables

\begin{tabular}{|c|c|c|c|c|c|c|c|}
\hline variable & scale & CBSA & CBSB & $\infty$ & NSS & IWS & ATS \\
\hline $\begin{array}{l}\text { Collaborative } \\
\text { Behavior }\end{array}$ & $\begin{array}{l}\text { CBSA } \\
\text { CBSB }\end{array}$ & & $.21 * \star$ & $\begin{array}{l}.21 * \star \\
.40 * \star, k\end{array}$ & $\begin{array}{l}-.21 * * t \\
-.03\end{array}$ & $\begin{array}{l}.32 \star \star \star \\
.41 \star * \star\end{array}$ & $\begin{array}{l}-.16 \star * \\
-.38 * t *\end{array}$ \\
\hline $\begin{array}{l}\text { organizational } \\
\text { Climate }\end{array}$ & $\infty$ & & & & $-.17 *$ & 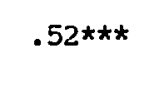 & $-.27 * * \star$ \\
\hline Job Stress & NSS & & & & & $-.43 \star \star \star$ & $.26 \star \star \star$ \\
\hline Job Satisfaction & IWS & & & & & & $-.52 * * *$ \\
\hline
\end{tabular}

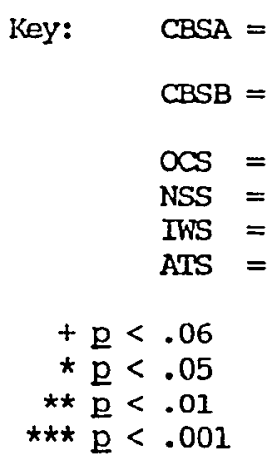


among the independent variables exceeded the .70 threshold described by Asher (1983) and Munro et al. (1986) . Higher correlation coefficients among the inciependent variables may have adversely affected the precision of the estimates of the regression coefficients and their standard errors and the tests of statistical significance and their confidence intervals (Pedhazur, 1982). Tables 4-7 outline correlations among the dimensions for each instrument and between the dimensions and the total scale of each instrument. The bivariate correlations between the collaborative Behavior scale -Part A (CBS-A) and the collaborative Practice Scale $(\underline{\underline{r}}=.4122, \underline{p}=\leq .001)$ supported the convergent validity of the CBS-A. Convergent validity was further substantiated with the bivariate correlations between $C B S-A$ and the Physician-Nurse interaction subscale of the IWS ( $\underline{r}=.5799, \underline{p}=\leq .001$ ) and the Consideration subscale of the OCS $(\underline{r}=.4832, \underline{p} \leq .001)$. Discriminate validity was further confirmed with the bivariate correlations between the CBS-A and the Physician-Nurse Conflict subscale of the Nursing Stress Scale ( $\underline{r}=-.2063$, $\underline{p} \leq .003)$ and the Nurse-Physician interaction subscale $(\underline{\underline{r}}=.0855, \underline{p} \leq .001)$ of the Index of Work Satisfaction. Because of the support for the concurrent validity for the CBS-A scale, the scale was entered into the path model without CPS to measure nurse-physician collaborative behavior. 
Table 4

Correlational Matrix for organizational climate Suniey (OCS)

\begin{tabular}{|c|c|c|c|c|c|}
\hline Scale & Indaut & Posstruc & Consid & Reward & Total oCs \\
\hline Indaut & & $.17 \star \star$ & $.47 \star \star \star$ & 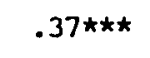 & $.73 \star \star \star \star$ \\
\hline Posstruc & & & $.14 \star \star$ & $.19 \star \star$ & $.42 \star \star \star \star$ \\
\hline Consid & & & & 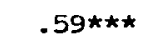 & 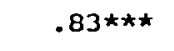 \\
\hline Reward & & & & & $.80 * \star \pi$ \\
\hline Key: & $\begin{array}{l}\text { Indaut }= \\
\text { Posstruc }= \\
\text { Consid }= \\
\text { IWS }= \\
\text { ATS }=\end{array}$ & $\begin{array}{l}\text { Individual Auto } \\
\text { Position Struct } \\
\text { Consideration } \\
\text { Index of Work } \\
\text { Anticipated Tu }\end{array}$ & $\begin{array}{l}\text { ion scale } \\
\text { ale }\end{array}$ & & \\
\hline $\begin{aligned}+\mathrm{p} & < \\
* \mathrm{p} & < \\
\star \star \mathrm{p} & < \\
\star \star \star \mathrm{p} & <\end{aligned}$ & $\begin{array}{l}.06 \\
.05 \\
.01 \\
.001\end{array}$ & & & & \\
\hline
\end{tabular}


Table 5

Correlational. Natrix for Nunsinz Stress Scale (NSS) subscales

\begin{tabular}{|c|c|c|c|c|c|c|c|c|}
\hline scale & Death & smonf & Inprep & Lacsup & Procont & Wrkload & Uncerty & Total \\
\hline Death & & $.51 \star \star \star$ & $.36 k \star \star$ & .02 & $.30 k k \star$ & $.43 \star \star \star$ & $.49 \hbar \hbar \star$ & $.66 k \star \hbar \hbar$ \\
\hline MDConf & & & $.42 \star \star \star$ & $.32 \star \hbar \hbar$ & $.45 \star \star \star \hbar$ & $.56 \star \star \star$ & $.58 \star \star \star$ & 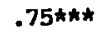 \\
\hline Inprep & & & & 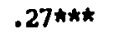 & $.33 * \star *$ & $.42 \star \star \star \star$ & $.48 * \hbar \hbar$ & $.61 \star \star \star$ \\
\hline Lacsup & & & & & $.36 \star \star \star$ & $.37 \hbar \star \star$ & $.31 * \star \star \star$ & $.4 B \star \star \star \hbar$ \\
\hline Ravconf & & & & & & $.60 \star \hbar \star$ & $.54 k \star \star *$ & 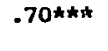 \\
\hline Horklod & & & & & & & $.59 \star \star \star$ & $.87 \hbar \star \star \star$ \\
\hline Uncerty & & & & & & & & $.82 \star \star \star \star$ \\
\hline
\end{tabular}

Key: Death $=$ Stress related to the suffering or death of patients

MDOonf $=$ Stress related to conflict with physiclans

Irprep families

Lacsup a Stress related to lack of staif support to share expervisors

RMoni - Stress related to workload, staffing prohlens

Uneerty = stress related to uncertainty conoeming treatment of patiente

NSS = Nursing Stress Scale (all subscales)

IWS $\quad=$ Index of Work Satisfaction Scale

ATS $=$ Anticipated Turmover scale

$+\mathbf{p}<.06$

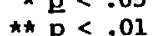

$\star \star \star \star \mathrm{B}<.001$ 
Table 6

Correlational Matrix for Index of Work Satisfaction (IWS) Subscales

\begin{tabular}{|c|c|c|c|c|c|c|c|c|}
\hline Scale & Profstat & Taskrg & Pay & MDFanInt & RNRRIInt & orgPol & Auton & Total \\
\hline Profstat & & 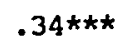 & .15 & $.37 * \star * *$ & $.38 * \star \star$ & $.30 * \star *$ & $.46 * \star \star \star *$ & $.61 * * *$ \\
\hline Taskrq & & & $.37 \star \star \star \star$ & $.30 \star \star \star \star$ & 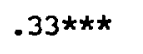 & $.57 \star \star \star$ & $.56 * * \star$ & $.74 \star \star \star \star$ \\
\hline Pay & & & & $.25 \star \star \star \star$ & $.11+$ & $.49 * * \star$ & $.23 * \star \star$ & $.58 * \star \star \star$ \\
\hline MDRNInt & & & & & $.18 * \star *$ & 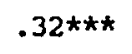 & $.29 * \star \star$ & $.55 * \star \star *$ \\
\hline RRRNInt & & & & & & $.37 * \star * \star$ & $.58 \star \star \star \star$ & $.59 * * *$ \\
\hline ORgPol & & & & & & & $.61 \star \star \star$ & $.80 * * *$ \\
\hline Auton & & & & & & & & $.80 * \star \star$ \\
\hline
\end{tabular}

定.

Profstat $=$ Professional Status

Taskra $=$ Task Requirements

MTRNInt $=$ Physician/Nurse Interaction

ATS = Anticipated Turnover Scale

orgpol = Organizational policies

Auton $=$ Autonomy

RNRNInt $=$ Nurse/Nurse Interaction

IWS $\quad=$ All subscales

$+\mathrm{p}<.06$

$\star \mathrm{p}<.05$

$\star \star \mathrm{p}<.01$

$\star \star \star x<.001$ 
Table 7

Correlational Matrix for Anticipated Tumover Scale (ATS)

\begin{tabular}{lcc}
\hline Time & Certainty & Total \\
\hline Time & $.81 \star \star$ & $.90 \star \star \star$ \\
certainty & $.96 * \star \star$ \\
\hline
\end{tabular}
$\begin{array}{lll}\text { Key: Time } & =\text { Anticipated length of time to leaving } \\ \text { Certainty } & =\text { certainty of leaving job }\end{array}$

$+\mathrm{p}<.06$

$\star \underline{p}<.05$

$* * \underline{p}<.01$

$\star \star \star \star \underline{\underline{D}}<.001$ 
Convergent validity of the Collaborative Behavior Scale Part-B (CBS-B) was demonstrated with the bivariate correlations between Reward ( $\underline{x}=.4309, \underline{p} \leq .001)$, a subscale of the organizational climate survey, and Organizational Policies ( $\underline{x}=.4469, \underline{p} \leq .001$ ), a subscale of the IWS. Mild support for discriminant validity was demonstrated with the bivariate correlation between the CBSB and Lack of Supervisor Support ( $\underline{\underline{r}}=-.1521, \underline{p} \leq .019)$, a subscale of the Nursing stress scale.

All of the exogenous variables in the first time ordering (nurse-physician and nurse-manager collaborative behavior, organizational climate, and job stress) were significantly correlated with the endogenous variable in the second time ordering, job satisfaction. All of the exogenous variables were also significantly correlated with the endogenous variable in the third time ordering, anticipated turnover.

Correlations between Demographics and Study Variables

Examination of bivariate correlations between demographic variables and the study variables revealed several significant correlations. Since four of the demographic variables (position, job status, shift, and clinical unit) did not yield continuous data, dumm codes were assigned to each response option and the data was considered as continuous data (Cohen \& Conen, 1983; Pedhazer, 1982; Volicer, 1984). 
Age was significantly correlated with job stress $(\underline{r}=-.14, \underline{p} \leq .05)$ and anticipated turnover $(\underline{r}=-.13$, $p \leq .05)$. Years of experience as a nurse was related to nurse-physician collaborative behavior ( $\underline{\underline{r}}=.14, \underline{\mathrm{p}} \leq .05)$. Years seniority in the current hospital demonstrated a trend of being inversely correlated with organizational climate $(\underline{x}=-.11, \underline{p} \leq .06)$. Position (staff nurse, charge nurse, clinical specialist, or staff educator) was significantly related to nurse-manager collaborative behavior $(\underline{r}=.15$, $\underline{p} \leq .05)$. Years in present position correlated to job stress $(\underline{r}=-.16, \underline{p} \leq .05)$ and nurse-physician collaborative behavior $(\underline{\mathrm{r}}=.14, \underline{\mathrm{p}} \leq .05)$. Job status (part-time, fulltime or per diem) was inversely related to job stress $(\underline{r}=-.20, \underline{p} \leq .01)$. Shift (days, evenings, nights, or rotating) demonstrated a trend with nurse-physician collaborative behavior ( $\underline{r}=-.11, \underline{p} \leq .06)$ and organizational climate $(\underline{\underline{x}}=.11, \underline{\mathrm{p}} \leq .06)$. Clinical unit assignment was significantly correlated with nurse-manager collaborative behavior $(\underline{x}=.16, \underline{p} \leq .01)$, job stress $(\underline{r}=-.14, \underline{p} \leq .05)$, job satisfaction $(\underline{r}=.14, \underline{p} \leq .03)$, and anticipated turnover $(\underline{\underline{r}}=-.13, \underline{\mathrm{p}} \leq .04)$.

\section{Hypotheses Testing}

Regression Analysis

Multiple regression analysis was performed to assess the strength and direction of the relationships between the exogenous variables and each of the subsequent endogenous 
variables in the path model. Because the two subscales for the ATS (Table 7) were highly correlated ( $\underline{x}=.81, \underline{p} \leq .01$ ), the total ATS scale was used in the path analysis. Although the IWS, NSS, and the ocs were multi-dimensional scales, a decision was made to enter the total scale scores into the path analysis rather than individual subscale scores for each instrument. One of the subscales for both the IWS (Professional Status, $\underline{a}=.66$ ) and the OCS (Fosition Structure, $\underline{a}=.40$ ) did not meet the pre-established criteria of .70 for the standardized alpha level giving justification for either dropping that subscale or using the total scale score. Gray-Toft and Anderson (1981) also suggested the use of the total instrument as a measure of Nursing stress, since intercorrelations among items and subscales in factor analysis confirmed a common stress factor. Two demographic variables were significantly correlated with the outcome variables. Age and anticipated turnover $(\underline{\underline{r}}=-.13, \underline{\underline{p}} \leq .05)$ and clinical unit assignment and job satisfaction $(\underline{\underline{x}}=.14, \underline{\underline{p}} \leq .03)$ and anticipated turnover ( $\underline{\underline{x}}=.13, \underline{\underline{p}} \leq .04$ ) were also entered into the regression analysis. Age was only included in the regression with anticipated turnover as the dependent variable, since the correlation between age and job satisfaction was not significant.

Using ordinary multiple regression techniques with simple inclusion, each of the exogenous variables were entered in a single step and were regressed with the 
earliest endogenous variable (job satisfaction) and the outcome variable (anticipated turnover). The regression output was reviewed to determine the beta coefficients and respective significance levels, the amount of variance $\left(R^{2}\right)$ accounted for by the model, the adjusted $\left(R^{2}\right)$ to adjust for the sample size and the number of variables (Munro et al., 1986), and the $\underline{F}$ value and significance level of the total regression.

Beta coefficients were used to determine the direct and indirect effects of each of the predictor variables on each of the dependent variables in the model. Predictive validity of each of the variables was determined by a significance level equal to or less than .05 and a saliency level of $\underline{B}=.10$ (Munro et al., 1986; Waltz \& Bausell, 1981).

\section{Collective Model}

Stage 1. All of the independent variables were entered into the regression, and nurse-physician collaborative behavior $(\underline{B}=.12, \underline{p} \leq .05)$, nurse-manager collaborative behavior ( $\underline{B}=.24, \underline{p} \leq .001$ ), organizational climate $(\underline{B}=.32, \underline{p} \leq .001)$, and job stress $(\underline{B}=-.31 \underline{p} \leq .001)$ had sufficient predictive validity with the first dependent variable to be retained in the first time-ordering of the simplified model. Neither of the two demographic variables, age nor clinical unit assignment, had surficient predictive validity to be retained in the first time ordering. This 
model accounted for $41 \%$ of the explained variance in job satisfaction $(F=26.53, \underline{p} \leqq .001)$.

Stage $2 \& 3$. Job Satisfaction, all previous endogenous variables, and age were entered into the regression with anticipated turnover as the dependent variable. Only job satisfaction $(\underline{B}=-.44, \underline{\mathrm{P}} \leq .001$ ) and nurse-manager collaborative behavior ( $\underline{B}=-.22 \mathrm{p} \leq .001$ ) had sufficient predictive validity to be retained in the model. Age $(\underline{B}=-.15, \underline{p} \leq .018)$ also had sufficient predictive validity to be retained in the simplified model. This model accounted for $31 \%$ of the explained variance in anticipated turnover $(F=12.94, \underline{p} \leqq .001)$.

The results of the path analysis reveal the direct, indirect, and total effects of age of the nurse, nursephysician collaborative behavior, nurse-manager collaborative behavior, organizational climate, and job stress on job satisfaction. Direct and indirect effects for each exogenous variable on the endogenous variables are outlined in Table 8 . Indirect effects were calculated by multiplying the beta coefficients of the pathways from each exogenous variable to the first endogenous variable and from the first endogenous variable to the outcome variable. The total effect represents the sum of the direct and indirect effects. The total effects of nurse-manager collaborative behavior, organizational climate, and job stress increased when both the indirect and direct effects were considered. Neither organizational climate nor job stress were 
Table 8

Effects of Independent Variables on Job Satisfaction and anticipated Tumover

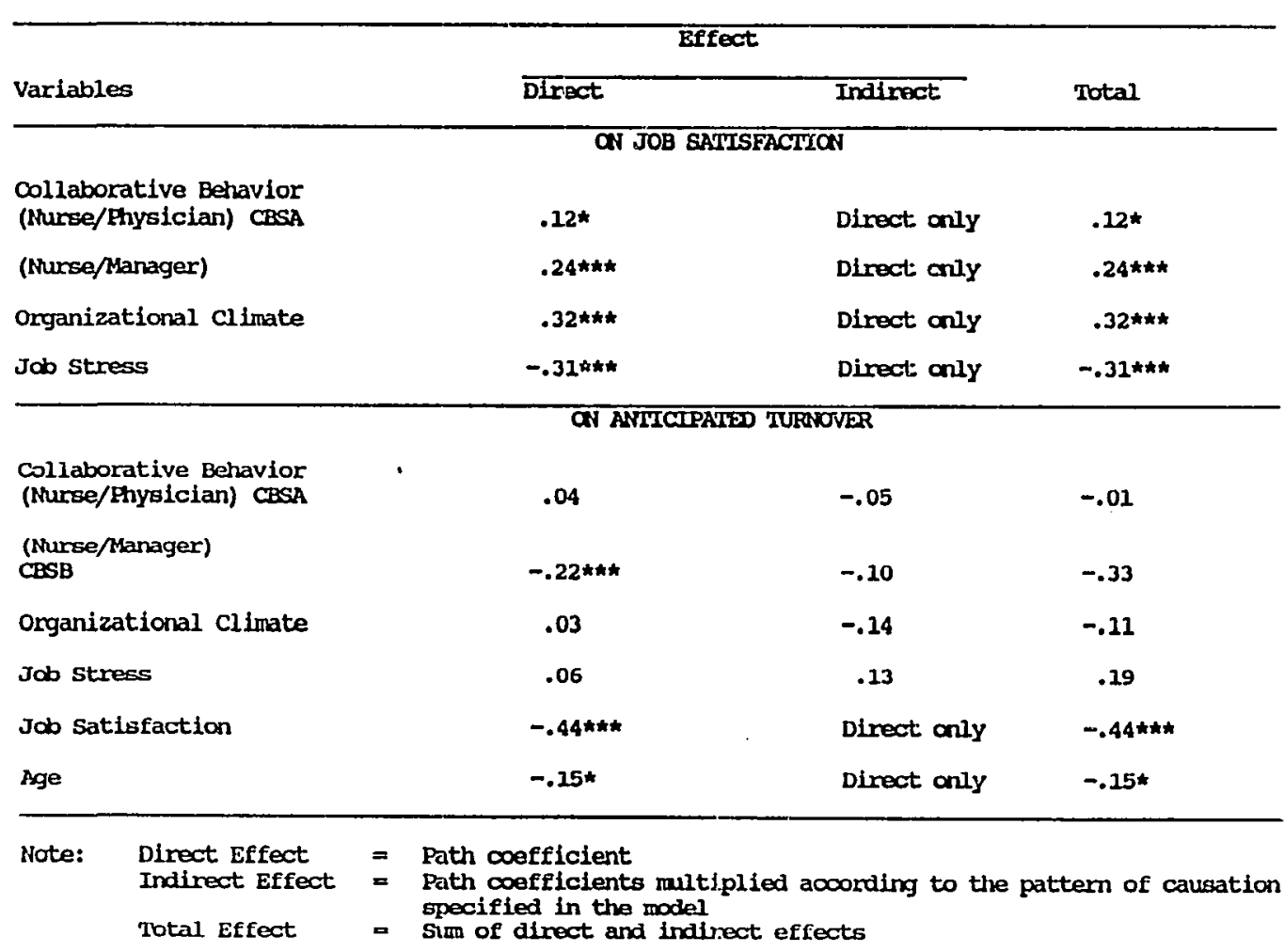


significantly predictive of anticipated turnover when only direct effects were considered; but when considering the total effect, both variables met the saliency level of .10 described by Munro et al. (1986) and Pedhazur (1982). The total effects of nurse-physician collaboration on anticipated turnover remained relatively unchanged from the direct effect. organizational climate and job stress were the strongest predictors of job satisfaction with all exogenous variables accounting for $41 \%$ of the explained variance in job satisfaction. Job satisfaction and nurse-manager collaborative behavior were the strongest predictors of anticipated turnover with all of the variables in previous time orderings accounting for $31 \%$ of the explained variance in anticipated turnover. Table 9 outlines the regressions used to compute path coefficients for the simplified model. Figure 2 represents the simplified model with the resultant beta coefficients for each path and the amount of explained variance $\left(R^{2}\right)$ for each endogenous variable.

\section{Results of each Hypothesis}

Table 10 outlines the results of analysis for each of the hypotheses. Examination of the results revealed that all of the research hypotheses were in the specified direction for the direct effect on the first endogenous variable (job satisfaction) and for the direct effect on the outcome variable (anticipated turnover). The effects of the 
Table 9

Regressions Used to Compute Path Coefficients for Simplified Model

\begin{tabular}{|c|c|c|c|c|}
\hline Regressioll & $\begin{array}{l}\text { Dependent } \\
\text { Variable }\end{array}$ & $\begin{array}{l}\text { Independent } \\
\text { Variable }\end{array}$ & $\begin{array}{c}\text { Correlation } \\
\text { (x) }\end{array}$ & Beta \\
\hline \multirow[t]{4}{*}{1} & $\begin{array}{l}\text { Job Satisfaction (X5) } \\
\text { (Adjusted } \mathrm{R}^{2}=.41 \text { ) }\end{array}$ & N-P Coll Behavior (XI) & $\underline{\underline{r}}_{15}=.32 \star *$ & $.12^{*}\left(p_{51}\right)$ \\
\hline & & N-M Coll Behavior (X2) & $\underline{r}_{25}=.41 * \star$ & $.24 * * *\left(P_{52}\right)$ \\
\hline & & org Clim (X3) & $\underline{\underline{r}}_{35}=.52 \star \star \star$ & $.32 \star \star \star\left(p_{53}\right)$ \\
\hline & & Job stress $(\mathrm{X} 4)$ & $\underline{r}_{45}=-.43 \star \star \star$ & $-.31 * \star *\left(p_{54}\right)$ \\
\hline \multirow[t]{6}{*}{2} & Anticipatsd Turnover & N-P Coll Behavior (X1) & $\underline{r}_{16}=-.16 * \star \star$ & $.04\left(p_{61}\right)$ \\
\hline & (Adjusted R2 = .31) & N-M coll Behavior (X2) & $\underline{\underline{r}}_{28}=-.38 * \star$ & $-.22 * x *\left(p_{62}\right)$ \\
\hline & - & Org clim (X3) & $\underline{1}_{36}=-.27 * \star \star$ & $.03\left(p_{63}\right)$ \\
\hline & & Job Stress (XA) & $\underline{E}_{46}=.26 * \hbar k$ & $-.22 \star \star \star *\left(p_{64}\right)$ \\
\hline & & Job Satisfaction (x5) & $\underline{\underline{r}}_{56}=-.52 k * *$ & $-.44 * * *\left(\mathrm{p}_{65}\right)$ \\
\hline & & Age $(X 7)$ & $.13 * \star$ & $-.15 *\left(p_{67}\right)$ \\
\hline
\end{tabular}


Table 10

Analysis of liypotheses

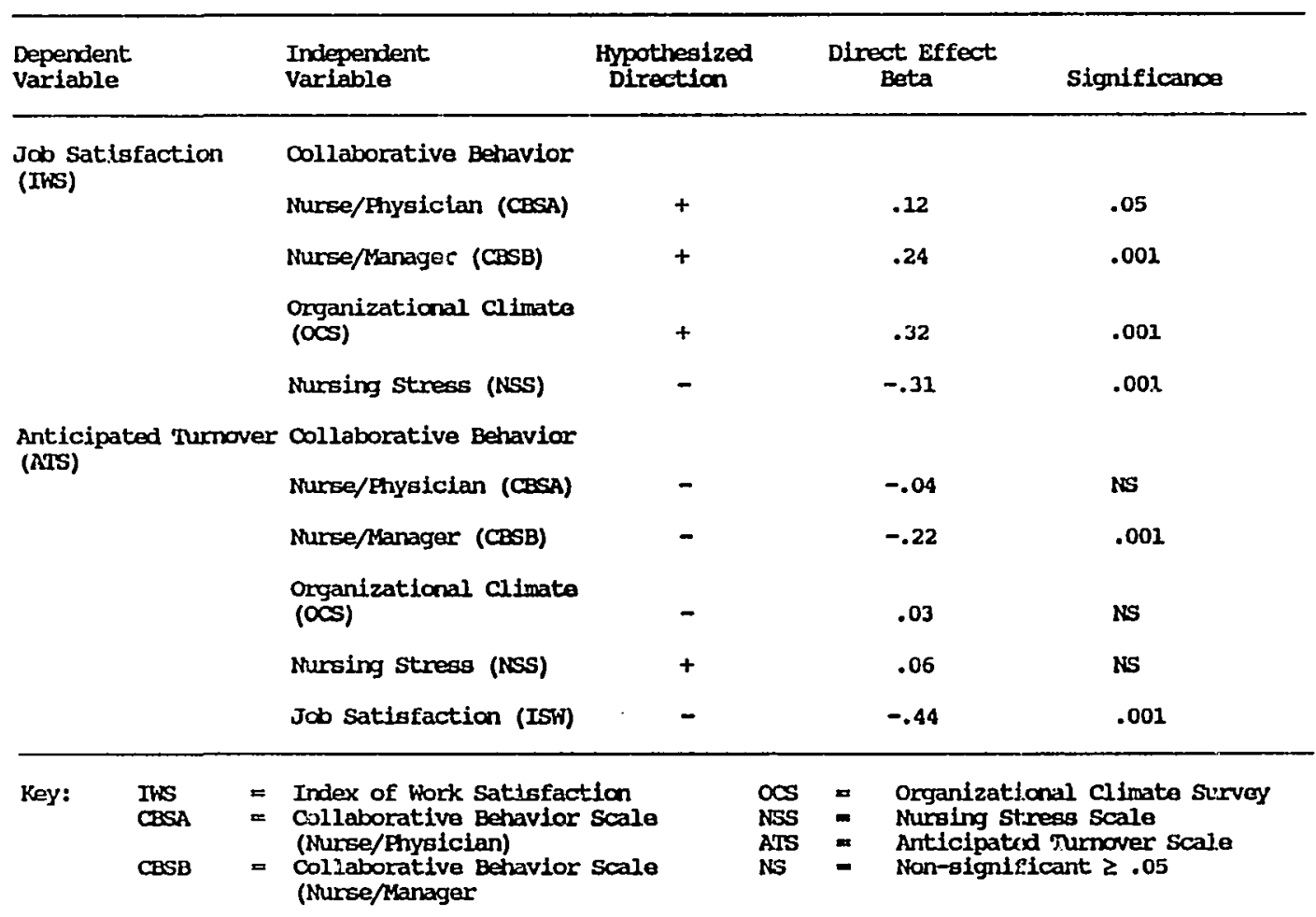




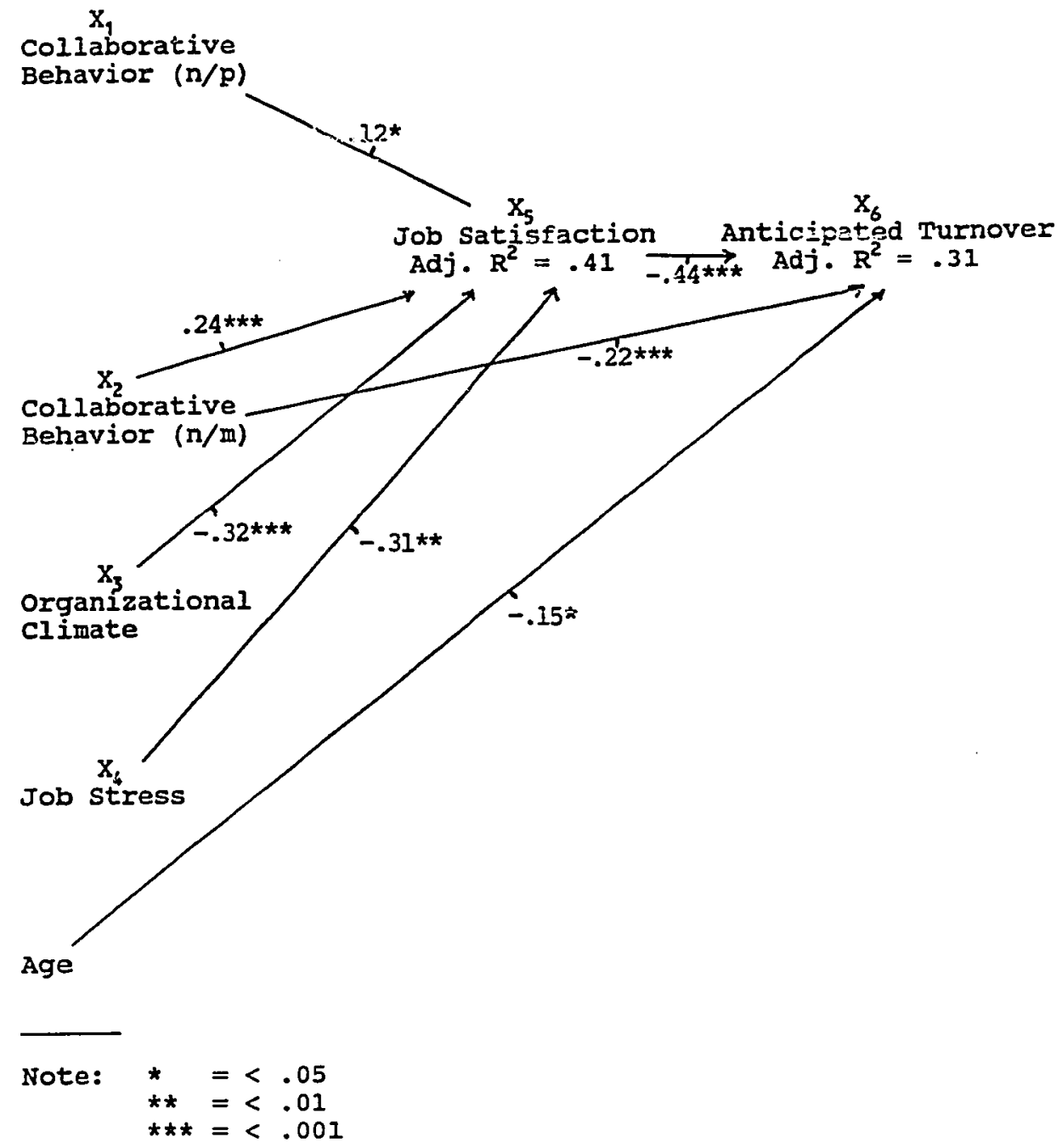

Fiqure 2. Simplified Path Model Relating Job Satisfaction and Anticipated Turnover Predictor Variables. 
predictor variables on the first endogenous variable (job satisfaction) were sufficient enough to be retained in the simplified model; however, the effects of nurse-physician collaborative behavior (CBS-A), organizational climate (OCS), and job stress (NSS) on anticipated turnover were not sufficient to be retained in the simplified model. Only age, job satisfaction, and nurse-manager collaborative behavior significantly predicted anticipated turnover and were retained in the simplified model (see Figure 2). Each of the hypothesis statements are reviewed below with the results of the path analysis. A summary of analysis by hypothesis is displayed in Table 10. Hypothesis 1, nurse-physician collaborative behavior has direct positive effect on job satisfaction, was supported ( $\mathrm{CBS}-\mathrm{A} ; \underline{\mathrm{B}}=.12, \underline{\mathrm{p}} \leq .05)$.

Hypothesis 2, nurse-physician collaborative behavior has a direct negative effect on anticipated turnover, was not supported.

Hypothesis 3, nurse-manager collaborative behavior has a direct positive effect on job satisfaction, was supported ( $\mathrm{CBS}-\mathrm{B} ; \underline{\mathrm{B}}=.24, \underline{\mathrm{p}} \leq .001)$.

Hypothesis 4, nurse-manager collaborative behavior has a direct negative effect on anticipated turnover, was supported ( $\underline{B}=-.22, \underline{p} \leq .001)$.

Hypothesis 5 , organizational climate has a direct positive effect on job satisfaction, was supported $(\underline{B}=.32$, $\underline{p} \leq .001)$. 
Hypothesis 6 , organizational climate has a direct negative effect on anticipated turnover, was not supported. Hypothesis 7 , job stress has a direct negative effect on job satisfaction, was supported ( $\underline{B}=-.31, \underline{p} \leq .001)$. Hypothesis 8 , job stress has a direct positive effect on anticipated turnover, was not supported.

Hypothesis 9, job satisfaction has a direct negative effect on anticipated turnover, was supported $(\underline{B}=-.44$, $\underline{p} \leq .001)$. Four indirect hypotheses were also tested using the regression analysis and revealed the following: Hypothesis 10, nurse-physician collaborative behavior has an indirect effect on anticipated turnover through job satisfaction was not supported.

Hypothesis 11, nurse-manager collaborative behavior has an indirect effect on anticipated turnover through job satisfaction was supported.

Hypothesis 12, organizational climate has an indirect effect on anticipated turnover through job satisfaction was supported.

Hypothesis 13, job stress has an indirect effect on anticipated turnover through job satisfaction was supported.

Appendix $L$ through 0 illustrate the indirect paths and the resultant beta coefficients. 
Testing the Assumptions

Residual analysis techniques described by Verran and Ferketich (1987) were employed to test the assumptions of the model. Scatterplots of standardized residuals and the predicted dependent variables yielded random and equal scatters of points about the zero line confirming equal variance. Linearity and fixed independence was also confirmed. Evidence of a linear relationship between the observed and expected residuals was demonstrated with normal probability scatterplots. Examination of the histograms revealed normal distributions of the residuals and zero means.

\section{Post Hoc Analysis}

Several statistical tests were conducted post hoc to analyze the data further and to determine clinical relevance. A multiple regression analysis using the same techniques described earlier was used to determine the predictive power of the dimensions of each instrument with the outcome variables. Analysis of variance was also used to determine group differences with the study variables.

\section{Regression Analysis Using Dimensions of Study Variables}

A regression analysis using ordinary multiple regression techniques with simple inclusion was conducted entering each subdimension for every exogenous variable study variable and one demographic variable (age) in a 
single step with the earliest endogenous variable (job satisfaction) and the outcome variaile (anticipated turnover). The regression output was reviewed to determine the significant $(\underline{p} \leqq .05)$ or salient $(\geq .10)$ Beta coefficients as described earlier. In the post hoc model, nurse-physician collaborative behavior ( $\underline{B}=.13, \underline{p} \leqq .03$ ), nurse-manager collaborative behavior ( $\underline{B}=.18, \underline{p} \leqq .006)$, lack of support (a subdimension of job stress; $\underline{B}=-.18$, $\mathrm{p} \leqq .006$ ), workload (a subdimension of job stress; $\underline{B}=-.22, \underline{\underline{ }} \leqq .006$ ), and consideration (a subdimension of organizational climate; $\underline{\mathrm{B}}=.18, \underline{\mathrm{p}} \leqq .05)$ had sufficient predictive validity with the first dependent variable to be retained in the first time-ordering of the simplified posthoc model. This model accounted for $44 \%$ of the variance in job satisfaction $(F=11.30, \underline{D} \leqq .001)$ as compared to the 41\% explained variance when the total scales wexe used in the regression analysis.

For the second and third time orderings of the posthoc model, all dimensions of the previous endogenous variables, the dimensions for job satisfaction, and age was regressed with anticipated turnover. In this model, age $(\underline{B}=-.12, \underline{p} \leqq .06)$, nurse-manager collaboration $(\underline{B}=-.21$, $\mathrm{p} \leqq .02$ ), consideration (a subdimension of organizational climate; $\underline{B}=.12, \underline{p} \leqq .22$ ), death (a subdimension of job stress; $\underline{B}=.19, \underline{\mathrm{p}} \leqq .02$ ), autonomy (a subdimension of job satisfaction; $\underline{\mathrm{B}}=-.11, \underline{\mathrm{p}} \leqq .30)$, and organizational policies (a subdimension of job satisfaction; $\underline{B}=-.21$, 
$\underline{p} \leqq .05)$ had sufficient predictive validity with anticipated turnover to be retained in the simplified post-hoc model. This model explained $31 \%$ of the variance in anticipated turnover $(F=5.09, \underline{p} \leqq .00 I)$ which was equal to the amount of explained variance described in the simplified model using the total scales. Figure 3 illustrates the post hoc simplified model. Assumptions for linearity, fixed independence, ranảom variance, and normal distribution of the residuals were met as described by Verran and Ferketich (1987). The post hoc regression analysis provided meaningful information about the predictive effect of the dimensions for each scale and supported the findings reported for the total scale predictive effects.

\section{Analysis of Variances Between Groups}

one-way analysis of variance (ANOVA) using the studentNewman-Keuls (SNK) procedure was performed to determine differences between grouped demographic data in relationship to the study variables. The SNK procedure accounts for unequal group sizes and is considered to be an appropriate test for the analysis of variance (Munro et al., 1986; Waltz \& Bausell, 1981). To test for the homogeneity of variance, the Bartlett-Box $F$ and Cochran's $C$ statistics were utilized (Hinkle, Wiersma, \& Jurs, 1979). The groups were mutually exclusive, continuous data was used for the dependent variable, and the dependent variable was normally 


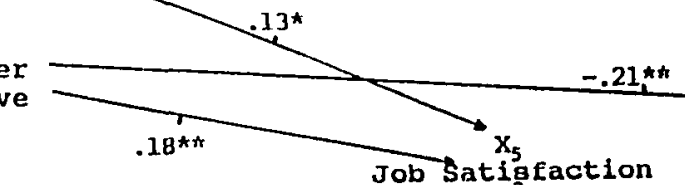
Job Satisafaction

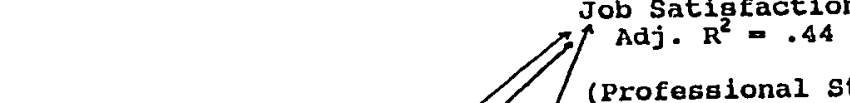

(organizational pol icles)

(Autonomy)

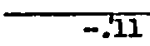

$x_{3}$

cimate

(Reward)
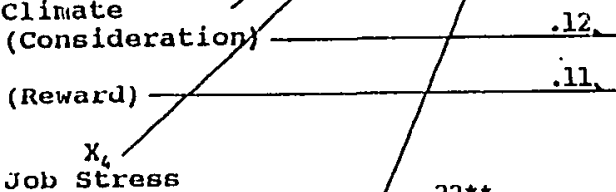

Lack of Suppor

(Workload)

(Nurse-Physician

Conflict)

(Death)

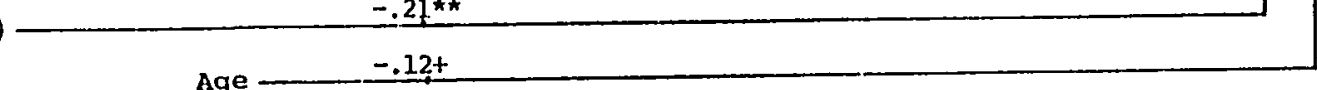

Age

Note: $\begin{aligned} t_{\star \star} & =<.05 \\ \star \star \star & =<.01 \\ & =<.001\end{aligned}$

Pigure 3. post lloc simplified path Model Relating Job Satisifaction and nnticipated Turnover to Dimensions of predictor variables. 
distributed which met the assumptions for ANOVA as described by Munro et al. (1986).

Nurse-physician collaborative behavior. Significant differences $(\underline{p} \leq .006)$ were demonstrated between clinical units in nurse-physician collaborative behavior. Emergency department rursas reported higher meañ scores for the CBS-A as compared to nurses assigned to postpartum and rehabilitation respectively. Significant differences were

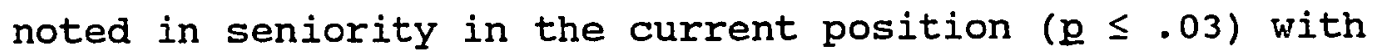
respect to nurse-physician collaborative behavior. Nurses with 1 year or less experience scored lower on the CBS-A than those with nine or more years. The same differences between these groups were noted in physician-nurse interaction (a subscale of the IWS, $\underline{p} \leq .03$ ). The shift assignment was also seen to significantly ( $\underline{\underline{1}} \leq .03)$ effect nurse-physician collaborative behavior with day nurses scoring higher on the CBS-A than evening nurses. Day nurses also reported higher mean scores $(\underline{M}=16)$ for assertiveness (subscale of CPS) which differed ( $\underline{\leq} .01$ ) from night $(\underline{M}=13.4)$ and evening $(\underline{M}=13)$ nurses. Significant differences $(p \leq .02)$ were also noted in the mean scores between day $(\underline{M}=22)$ and evening $(\underline{M}=18.6)$ nurses in job satisfaction related to physician-nurse interaction. Nurse-manager collaborative behavior. Significant differences $(\underline{p} \leq .007)$ were demonstrated between age groups in nurse-manager collaborative behavior. Subjects in group 3 (41 to 50 years) reported higher mean scores than subjects 
in group 2 (31 to 40 years) and group 4 (51 to 60 years) respectively. Nurses rotating their shift assignments scored significantly ( $\mathrm{p} \leq$.05) lower in nurse-manager collaborative behavior than working all other shifts. organizational climate. Significant differences were noted between baccalaureate prepared nurses and diploma prepared nurses in organizational climate ( $\underline{p} \leq .04)$, individual autonomy (a subscale of the organizational Climate Measure, $\mathrm{p} \leq .005$ ), and position structure ( subscale of the Organizational Climate Measure, $\mathrm{p} \leq .05$ ) . Mean scores for each of the organizational Climate Measure and the subscales were higher for the Baccalaureate prepared nurses than for the diploma nurses. Clinical specialists reported lower scores than staff nurses in individual autonomy (a subscale of the OCS, $\underline{p} \leq .05$ ). Differences in nurses working full-time, part-time or per diem existed for organizational climate scores with per-diem nurses differing from part-time nurses $(\mathrm{p} \leq .03)$. Similarly, per diem nurses differed from full and part-time nurses ( $p \leq .005)$ with respect to consideration or warmth (a subscale of the OCS) felt in the organization. Per diem nurses reported higher mean scores for the total ocs scale and the consideration subscale than both full and part-time nurses, and full-time nurses reported higher mean scores than part-time nurses. Job stress. Significant differences ( $\mathrm{p} \leq .002)$ between labor and delivery nurses and medical-surgical nurses were noted in job stress related to inadequate preparation with 
mean scores being higher for the medical-surgical nurses than their labor and delivery counterparts. Mean scores for overall job stress were significantly $(p \leq .01)$ higher for medical-surgical nurses than postpartum nurses. Clinical specialists reported lower mean scores for two job stress dimensions - death $(\underline{p} \leq .04)$ and inadequate preparation $(\underline{p} \leq .002)$ which differea significantiy from ail other groups (staff nurses, charge nurses, and clinical educators). Charge nurses reported higher mean stress scores in both of these dimensions than staff nurses. Evening nurses reported significantly ( $\underline{p} \leq .06)$ higher mean scores for job stress related to workload than night nurses. Job satisfaction. Significant differences ( $\underline{0} \leq .02)$ were noted between evening and night nurses in the task requirements dimension of the IWS with night nurses reporting higher mean satisfaction scores than evening nurses. Day nurses reported higher mean scores ( $\underline{.05}$ ) the autonomy dimension than their evening counterparts. Evening and night nurses differed ( $\underline{p} \leq .02)$ in overall job satisfaction with night nurses reporting higher mean scores than evening nurses.

Anticipated turnover. Evening nurses reported higher mean scores for anticipated turnover which differed significantly $(\underline{p} \leq .02)$ from day and night nurses. Night nurses reported the lowest mean scores for anticipated turnover. 


\section{Summary}

This chapter presented the results of correlations among study variables for data reduction and regression analyses to determine the direct and indirect effects and beta coefficients for the simplified path model. Each of the hypothesis statements were tested and reviewed with the results of the path analysis. A post hoc regression analysis using ali dimensions of the study variables was conducted. A series of one way analyses of variance was also conducted as a post hoc analysis of the data with resultant significant group differences reported. A residual analysis and results of tests of assumptions for the correlations and analysis of variances was also discussed. 
CHAPTER V

DISCUSSION AND RECOMMENDATIONS

This chapter presents a discussion of the findings of the study, the strengths and limitations of the study, and recommendations for future research. The study's findings will be compared and contrasted to previous research reported in the literature. Using path analytic techniques, this study lends further support to previously reported findings on the predictor variables for job satisfaction and anticipated turnover.

\section{Discussion}

\section{Anticipated Turnover}

In this study, job satisfaction emerged as the strongest predictor of anticipated turnover. Nurse-manager collaborative behavior remained in the simplified model as a significant predictor. one demographic variable, age, significantly predicted anticipated turnover, although less strongly than the other two predictor variables. The predictor variables accounted for $31 \%$ of the explained variance in anticipated turnover. The percentage of explained variance for turnover in this study was actually much higher than other studies. Hinshaw et al. (1987) reported an explained variance of $20 \%$ for Baccalaureateprepared nurses and $16 \%$ for Diploma-prepared nurses for similar predictor variables including professional and 
organizational job satisfaction. In another study, Choi, Jameson, Brekke, Anderson, and Podratz (1989) reported a path model in which job satisfaction was the strongest predictor of intent to leave explaining $31 \%$ and $22 \%$ of the variance in two intent to leave variables.

This study had similar findings to those of Wolf (1981) who reported that the primary causes of turnover are problems related to supervision and coordination, job dissatisfaction, and the administrative system. Prestholdt et al. (1988) also reported the importance of the interrelationships of job satisfaction and the work environment on the decision to leave or stay within an organization. Both of these studies citing the importance between the nurse-manager relationships and job satisfaction were similar to the findings of this study. The nurses in this study cited the necessity of working in an environment where there was a spirit of teamwork, a responsive and considerate management, and authority and autonomy to make decisions regarding patient care. Demonstrating an inverse relationship between job satisfaction and anticipated turnover, this study supported the findings of Kosmoski and Calkin (1986) and Price and Mueller (1981) who described satisfaction as a predictor of intent to leave.

Although not listed as an exogenous variable in the original theoretical model, this study demonstrated that age was inversely predictive of anticipated turnover. This finding supported the research of choi et al. (1989) who 
cited age as inversely predictive of intent to stay $(\underline{B}=-.16, \underline{\underline{1}} \leq .001)$.

The indirect effects of organizational climate and job stress on anticipated turnover in this study confirmed the findings from other research. Hinshaw et al. (1987) reported the significant indirect effects of job stress and control over practice and autonomy which were dimensions of organizational climate.

In summary, the findings of this study supported those of other research demonstrating job satisfaction as a strong predictor of anticipated turnover, intent to leave, or actual turnover. Secondly, this research supported the previous findings linking the nurse-manager relationship to anticipated turnover. The finding demonstrated that age was a predictor of anticipated turnover was supportive of previous research.

Job Satisfaction

organizational climate and job stress were the strongest predictors of job satisfaction in the present study. Nurse-manager and nurse-physician collaborative behavior were also significant as predictors of job satisfaction with nurse-manager collaborative behavior the stronger of the two variables. Together these four variables accounted for $41 \%$ of the explained variance in job satisfaction. These findings directly paralleled those reported by Hinshaw et al. (1987) who indicated the 
predictive validity of job stress, control over practice, autonomy, and group conesion for job satisfaction. In their study, these variables accounted for $56 \%$ of the explained variance in organizational job satisfaction and $40 \%$ of the explained variance in professional/occupational job satisfaction for the critical care nurses; $50 \%$ of the explained variance in organizational job satisfaction and $38 \%$ of the explained variance in professional job satisfaction for diploma-prepared nurses; and $57 \%$ of the explained variance in organizational job satisfaction and $49 \%$ of the explained variance for professional job satisfaction for the Baccalaureate-prepared nurses. This study demonstrated that organizational climate was the strongest determinant of job satisfaction. These findings supported previous research by Gray-Toft and Anderson (1985) and Duxbury et al. (1982). Donohue (1986) also reported that organizational climate was a primary predictor of job sutisfaction which was confirmed by this study.

Job stress was the second strongest predictor of job satisfaction in this study. This finding supported the findings Hinshaw et al. (1987), Norbeck (1985), and Cook and Mandrillo (1982). Norbeck reported that job stress accounted for $6 \%$ of the variance in job satisfaction $(\underline{\underline{r}}=-.24, \underline{\mathrm{p}}<.001)$ in a correlational study conducted in Critical Care $(\mathrm{N}=180)$. Similarly, Cook and Mandrillo determined that perceived stress was a significant 
determinant of job satisfaction for practicing Baccalaureate nurses $(\underline{r}=.58, \underline{p}<.05)$. The findings of the current study also supported those of Dolan (1987) who described burnout as an extension of job stress and reported a strong inverse relationship $(\underline{r}=.68, \underline{p}<.0001)$ between burnout and job satisfaction.

Research that reported a positive and interactive relationship between the nurse and management positively influenced worker satisfaction (Vanderslice et al., 1987) was validated by the findings in this study. Similarly, nurse-manager collaborative behavior as a significant predictor of job satisfaction supported the findings of Buccheri (1986), Taunton and Krampitz (1989), and Stember et al. (1978) who reported correlations between employee participation in decisions, the leadership style of the manager, and managerial support.

It was interesting to note the small, but significant, effect of nurse-physician collaboration on job satisfaction and the lack of a significant effect on anticipated turnover. Several researchers have described the positive effect of meaningful nurse-physician interaction on job satisfaction (Buccheri, 1986; Coburn, 1988; Floyd and Smith, 1983) which was supported by the findings of the current study. Similarly, Clark and Ienburg (1980) and Stephen and Bailey (1979) described the negative effects on job satisfaction when a positive nurse-physician relationship 
does not exist. These findings supported those in the current study.

A unique finding in the current study was the comparison of different effects of nurse-physician collaborative behavior and nurse-manager collaborative behavior on job satisfaction and anticipated turnover. An explanation for the difference in this effect could be the situational aspects of nurse-physician collaborative behavior, or the absence thereof, which could be indicative of conflict or absence of interaction, as compared to the long-term characteristics of the nurse-manager relationship. Situational relationships would not seem to have the same impact on job satisfaction or effect on the decision to leave an organization, as the long term effect of a positive or negative nurse-manager relationship.

stember et al. (1978) revealed that the more satisfying dimensions of job satisfaction included interpersonal relations and supervision. Floyd and Smith (1983) ranked the importance of the job satisfaction dimension with the top three items referencing nurse-manager interaction and collaborative behaviors. Nurse-physician collaborative behaviors were ranked lower than the nurse-manger dimensions. The findings in these studies were supported by the results of the current study. 
Post Hoc Analysis

Further examination of the Pearson-product moment correlation coefficients between demographic variables and the endogenous or outcome variables revealed several findings that supported previous research. The current study found significant but weak correlations between age of the respondent and job stress and anticipated turnover which supported the findings of Choi et al. (1989), but dici not support the findings of other research (McCranie, Lambert \& Lambert, 1987). Age was also noted to be significantly correlated with job satisfaction by other researchers (Blegen \& Mueller, 1987; Choi et al., 1989; Norbeck, 1985), but was not significantly correlated to job satisfaction in this study.

A significant but weak relationship was noted between unit assignment and job satisfaction in this study which validated the findings of Blegen and Mueller (1987), Roedel and Nystrom (1988), Hinshaw et al. (1987), and Simpson (1985). When analyzed using oneway analysis of variance (ANOVA), there were no significant differences between units in job satisfaction or anticipated turnover.

A significant relationship between shift and job satisfaction was also reported by Blegen and Mueller (1987) and Norbeck (1985), and shift was a significant predictor of job satisfaction for the Critical Care and Baccalaureate path nurses described by Hinshaw et al. (1987). These findings were substantiated with a significant correlation 
between shift and job satisfaction found in this study. A significant correlation between the same variables was not substantiated by Choi et al. (1989), demonstrating the instability of the demographic variables with variables such as job satisfaction or anticipated turnover. The oneway ANOVA in this study validated significant differences in mean satisfaction scores between nurses working night shift as compared to nurses working the evening shift. Surprisingly, the night shift nurses were the most satisfied as compared to eveninç, day, or rotating shift nurses. Group differences in pay $(\underline{p} \leq .06)$ and professional status ( $\underline{\underline{p}} \leq .02)$, dimensions of job satisfaction, were seen among nurses working the day, evening, night, and rotating shifts. Nurses working the night shift had higher mean scores for these dimensions than compared to the other three shifts which may have explained the increased job satisfaction. Unit assignment was significantly correlated with job satisfaction and anticipated turnover in this study which was also reported by Hinshaw et al. (1987) . Significant unit differences in job satisfaction and anticipated turnover was not confirmed in this study by the oneway ANOVA.

An analysis of the correlation coefficients between the demographic variables and the exogenous variables also revealed findings that were consistent with other researchers. Years of experience, years in the present position, and shift were weakly but significantly correlated 
with nurse-physician collaborative behavior. Interestingly, Alt-White, Charns and strayer (1983) demonstrated an inverse and significant relationship, although extremely weak $(\underline{\underline{x}}=-.09, \underline{\mathrm{p}}<.05)$, between nurse-physician collaboration and length of employment at the hospital. The oneway ANOVA confirmed significant differences in nurses with differing levels of seniority in their position. Nurses with one year or less scored lower in nurse-physician collaboration than nurses with nine or more years of seniority. This finding was not surprising, since the interpersonal valuing and reciprocal sharing of expertise that occurs in collaborative relationships (Stichler, 1989) is more likely to occur with a more experienced nurse. Shift assignment was also determined to affect nurse-physician collaboration with day nurses demonstrating higher collaborative scores than their evening or night colleagues. Nurses working the day shift may have more exposure to physicians than nurses working other shifts allowing collaborative relationships to develop. It was expected that differences in the educational level of nurses would effect nurse-physician collaborative behavior, but this was not noted. Similar findings were also reported by Alt-White et al. (1983). These findings suggested that educational preparation alone does not effect nurse-physician collaboration, confirming again the importance of expertise which can be shared reciprocally in the collaborative relationship. 
The nurse's position and unit were significantly correlated with nurse-manager collaboration in this study, although there were no significant group differences among units or positions noted by the oneway ANOViss; however, significant group differences were noted for nurse-manager collaboration between age groups. Subjects in the 41 to 50 year old group had significantly higher mean scores for nurse-manager collaboration than the 31 to 40 year old or 51 to 60 year old groups. The effect of age as a variable on nurse-manager collaboration may have been influenced by other unnamed variables; therefore, it is difficult to interpret this finding without information pertaining to the average experience level, educational level, or position on the clinical ladder of each of age groups.

oneway analyses of variances demonstrated differences in Baccalaureate and Diploma prepared nurses in perceptions of organizational climate and in the individual autonomy subscale of the instrument measuring organizational climate. It was also interesting to note that clinical specialists reported the lowest scores for individual autonomy as compared to nurses in other positions. These findings are assumed to be artifact of these particular group samples, since the overall correlations between the organizational Climate Scale and the inherent subscales were not significantly correlated with the demographic variables measuring education preparation, highest degree earned, nor position. 
Significant group differences in organizational climate were expected and found between nurses working full-time, part-time, or perdiem. It was surprising, however, to note that perdiem nurses had higher mean scores for consideration (a subdimension of organizational climate) than the other two groups. However, the correlation coefficients between consideration and job status and between organizational climate and job status were not significant. The correlation between individual autonomy (a subdimension of organizational climate) and job status were significantly correlated, although weak $1 y$, but significant group differences were not revealed in the ANOVA. These findings are difficult to interpret, because of the inconsistency in the correlational coefficients and the ANOVA results. Further validation of these findings in other research would be merited before serious interpretation should be offered. Age, unit assignment, years in the present position, and job status were all significantly correlated with job stress. While there were no significant age group differences in the total stress scores, significant differences were revealed for physician-nurse conflict (a subdimension of stress). The older age group (51 to 60) differed significantly from all other age groups and had the lowest stress scores for this subdimension. This finding substantiated the findings of other researchers who also reported significant and inverse correlations between age and years of experience with job stress (Bartz \& Maloney, 
1986; McCranie at al., 1987). In this study, significant differences were noted between labor and delivery nurses and medical-surgical nurses in job stress specifically related to inadequate preparation. Medical-surgical nurses reported higher stress scores related to this subdimension of job stress than their counterparts in labor and delivery and higher overall stress scores than postpartum nurses. While this finding was not discussed by other researchers, it is not surprising that nurses working in a generalized area with multiple patient diagnoses could feel the stress of being inadequately prepared as compared to nurses working in a specialized area of practice. While not significantly correlated with job stress, significant group differences in job stress were seen among the different shift assignments in this study. Evening nurses reported significantly higher stress related to workload than night nurses. similarly, McCranie et al. (1987) reported that nurses on a rotating schedule exhibited higher stress and burnout scores than nurses working straight shifts. The importance of these findings are that nurses working off-shifts may be experiencing more job stress related to workload, less resource availability, or diminished support as compared to their counterparts on the day shift. clinical specialists reported lower mean stress scores than nurses in other positions (staff nurses, charge nurses, clinical educators) for stress related to death situations or inadequate preparation. Conversely, charge nurses reported higher 
scores for these same dimensions as compared to all other groups.

The complexity of the charge nurse role cannot be overestimated, nor is it surprising that charge nurses would report stress related to inadequate preparation. Some charge nurses may be ill-prepared for their quasisuperviscrial role, and role ambiguity and role confusion may result from the overlapping responsibilities in both the administrative and clinical realms of nursing. In caring for the extremely moribund patient, the charge nurse role often incorporates both clinical, administrative, and coordinating responsibilities which may add to her/his stress level.

While the demographic variables should be considered in developing further path analytic models to predict job satisfaction and anticipated turnover, the instability of these variables from study to study should be considered. organizational differences, employee satisfying options, or managerial supports that are either present or absent within the study site could effect the demographic variables' predictive stability. Interpretation of demographic variables interrelatedness with the exogenous or endogenous variables in this study was done cautiously. Only two of the demographic variables, unit assignment and age, were significantly related to the outcome variables, and therefore, were entered into the regression analysis. only age significantly predicted anticipated turnover, but this 
finding also must be interpreted cautiously. Since there were no significant age group differences in anticipated turnover, it would be difficult to determine from this demographic variable alone, the true nature of this relationship or the predictive validity of this variable other than statistical significance.

In summary, the study results indicated that anticipated turnover is directly influenced by job satisfaction and nurse-collaborative behavior with job satisfaction having the greatest effect. Nurse-manager collaboration, organizational climate, and job stress indirectly effect anticipated turnover through job satisfaction. These antecedent variables accounted for $31 \%$ of the explained variance in anticipated turnover. Nursephysician collaborative behavior, nurse-manager collaborative behavior, organizational climate, and job stress directly influenced job satisfaction with organizational climate having the greatest effect. These antecedent variables accounted for $41 \%$ of the explained variance in job satisfaction. The explained variance of the outcome variables in this model were within ranges reported by other researchers. It is plausible that the remaining unexplained variance may be related to unidentified or unmeasured variables not included in the theoretical model for this study. The results of this study were consistent with the findings of other researchers, and yet the study 
provided additional knowledge related to predictors of job satisfaction and anticipated turnover.

\section{Limitations}

Using Krathwohl's (1985) methodology, the design and methodology of the study were assessed for potential threats and limitations. Krathwohl (1985) stated that internal validity (LP) refers to the strength of the linking power of the proposed relationships among the variables, and the validity that the linkages among variables are the only appropriate interpretations of the data. The external validity (GF) denotes the generalizability of the relationships among variables beyond the parameters of the current study.

\section{Internal Validity (LP)}

Translation fidelity. Instruments with known psychometric properties were used to quantify the variables, and all instruments were appropriate to the population and to the specific variables in the causal model. It is not known how other instruments measuring the same constructs would alter the effects seen on the study variables which could have minimal threat to the translation fidelity of the study.

Rival explanations. Other unknown influences in the respondents' background or in the organization could have 
effected outcome variables. No attempt was made to iäentify or control for extraneous variables.

External Validity (GP)

Explanation generality. The generality of the study was ilmilea to live rieid or nursing. winile it is reasonable to infer the same relationships for other fields, a literature review supporting the relationships among the studied variables was not included in the scope of this research. Multiple hospital sites for data coliection extend the generalizability of the findings, although the interpretation is limited to one geographical area.

Rival explanations. Multiple treatment interference may have occurred with the subjects taking multiple instruments measuring concepts that were thought to be related. The subjects may also have had experience with the instruments used in the study. The test environment could have been a Iimitation. The researcher did not attempt to control for distractions or interruptions, since the instruments were self-administered by the subject.

\section{Implications and Recommendations}

Three areas of for nursing were used to identify implications and recommendations for the study. These areas included research, service/management, and education. 
Nursing Research

The results of this study confirmed those reported by other researchers regarding the correlations and predictive validity of the significant variables influencing job satisfaction and anticipated turnover. While the amount of explained variance for the simplified model in this study was similar to that reported by others, additional research is necessary to identify other variables which may be significantly influencing job satisfaction and anticipated turnover. A strong pattern of relationships between the demographic variables and the study variabies has not been clearly identified in previous research nor in this study. Further research in diverse settings is needed to investigate the impact of personal and organizational characteristics on job satisfaction and anticipated turnover or the predictor variables in this study. Such knowledge allows resources aimed at retention to be focused more on personal or organizational variables that are more strongly effecting collaborative behavior, organizational climate, job stress, job satisfaction, or anticipated turnover. Perhaps most importantly, it is recommended that the impact of these study variables on the quality of patient care be investigated. Logically, there would seem to be a relationship between nurse/physician collaborative behavior, the climate of the organization, the level of stress perceived by the nurses, the nurses' job satisfaction, and organizational effectiveness measured by anticipated 
turnover, actual turnover, or other related indicators with the quality of patient care. Since the quality of patient care is the primary focus of the nursing profession, investigation of these proposed relationships is recommended.

Although this research was conducted in six different hospitals, all of the sites were within the same geographical area. It would be important to replicate the stuicy in other populations and sites in order to enhance the generalitability of the study. Using other research methods, such as qualitative or longitudinal designs, to study the relationships between the study variables or similar influencing variables would enhance nursing's understanding of these variables and their interrelatedness.

It is also recommended that other instruments designed to measure the same variables be used to confirm the findings and to validate the simplified model reported in this study. The newly developed Collaborative Behavior Scales used in this study demonstrated adequate psychometric properties and predictive validity with the outcome variables; however, further validation of the construct validity and reliability of these scales in other research and with other samples is recommended.

Because of the impact of the study variables on organizational effectiveness, studies measuring specific interventions to enhance the collaborative behavior, organizational climate, and job satisfaction, or reduce job 
stress and anticipated turnover are strongly recommended. Understanding the effectiveness of specific interventions would provide useful and important knowledge to nursing service.

\section{Nursing servicejääministration}

This study and others have demonstrated a number of variables that effect job satisfaction and anticipated turnover. The predictive effect of the variables cited in this study on job satisfaction and anticipated turnover is of interest to nursing administration. Since recruitment and retention resources are scarce, interventions that will make the most impact must be carefully identified and initiated. Recommenations for the enhancement of collaborative behavior and organizational climate and the reduction of job stress in order to effect job satisfaction and anticipated turnover are delineated.

Nurse-physician collaborative behavior. Enhancement of nurse-physician collaborative behavior in a hospital is complex, and multiple strategies can be implemented. Theoretically, collaboration is a reciprocal relationship characterized by sharing expertise, interpersonal valuing, and acknowledging an interdependency or recognizing a common goal (Stichler, 1989). Because of the inherent reciprocal nature of collaboration, the nurse may be desirous of a collaborative relationship when the physician is not. Helping both parties to understand and appreciate 
their common goal and their interrelatedness as care providers will enhance the collaborative process. Assuring the nurse's knowledge base, clinical expertise, and sizill with technological equipment will enhance the physician's appreciation of the nurse's expertise and will enhance the nurse's job satisfaction by reducing job stress related to inadequate preparation. Reciprocally, the nurse values the physician who demonstrates expertise and appreciates the physician's sharing of his/her expertise in a manner that enhances the nurse's sense of self-esteem. Interdisciplinary conferences, committees, and meetings provide opportunities for sharing of expertise and opinions which promote collaborative interactions. Personal interactions related to the patient's condition, progress, or plan which are based in theoretical and empirical knowledge and are characterized by a sharing or exchange of information will promote interpersonal valuing. Increased exposure to one another's knowledge base and expertise enhances interpersonal valuing and trust and will enhance the sense of interdependence that is essential to collaborative behavior. Nurses must be provided the time and opportunity to engage in collaborative interaction. Delegation of duties that are not essential for the professional nurse to perform will allow time for appropriate collaborative interaction. It is recommended that physicians and nurses who exhibit collaborative behavior be rewarded or recognized. Recognition for 
collaborative behavior will establish the expectation that such behavior is the norm.

Nurse-manager collaborative behavior. Interventions specific to enhancing nurse-manager collaborative behavior will positively influence job satisfaction and will negatively influence anticipated turnover. Nurse managers can have a strong influence on anticipated turnover and possibly avert actual turnover from occurring. The process of collaboration is characterized by interpersonal valuing, integration of ideas, opinions, expertise, and a balancing of unequal power (Stichler, 1989). The collaborative manager will promote an environment or culture that demonstrates a valuing of the professional nurse and a recognition that the goals of the hospital/unit could not be realized without the professional nurse. The clinical practice of nursing and the administrative practice of nursing have, in common, the goal of providing quality patient care. It is recommended that the manager involve the clinical nurse in decisions that affect the professional practice of clinical nursing and/or in decisions that affect the delivery of patient care to enhance the development of collaborative behaviors. Implementing systems such as Shared Governance, Participative Management, Joint Practice models or other similar programs will enhance staff involvement and/or participation in decision making. These systems also provide for increased nurse-manager interaction, planning, and coordination of patient care 
which integrates the expert opinions of administrative and clinical nurses. A balancing of power occurs in the council model of Shared Governance which fosters nurse-manager collaborative behaviors. Nurse managers generally serve on the clinical councils as consultants without voting privileges which helps to balance the power in patient care decision making between clinical and administrative nurses. Additionally, the chairpersons of each of the councils in the Shared Governance system, meet with an administrative director to coordinate the activities of patient care and the professional practice of nursing.

It is also recommended that career advancement programs be developed which allow those who choose to practice clinical nursing at advanced levels to be rewarded financially and with recognition of their power by expertise. Open communication between management and nurses that allows freedom of expression of concerns, criticisms, creativity, and opinions are recommended to enhance nursemanager collaboration. Encouraging clinical nurses to be active participants in strategic planning and program implementation, quality assurance activities, scheduling on duty time, and providing educational offerings will promote nurse-manager collaboration in domains that were traditionally recognized as management. It is recommended that nurse managers move from the more traditional leadership styles and roles of management to contemporary and collaborative roles which include facilitation of 
patienc care, integration of ideas, opinions, and expertise, and the coordination of resources including manpower, and finances.

The simplified model in this study indicated that anticipated turnover is inversely related to job satisfaction. Nurse-manager collaborative behavior was the only exogenous variable to significantly influenced both job satisfaction and anticipated turnover making it an important variable for consideration.

organizational climate. The strongest predictor of joi satisfaction in this study was organizational climate. The climate of the organization characterizes the generalized "feeling" of the organization and reflects the structure and processes of the organization. Although organizational climate is relatively stable over time, the manager can influence the climate by her/his style of management. For this study, organizational climate was conceptualized as a balance of individual autonomy, position structure, consideration, and reward. In order to enhance a positive organizational climate, it is recommended that the manager recognize the nurse's expertise as a clinician and empower her/him to participate in decisions, actions, and planning that effect patient care or the professional practice of nursing. Minimizing bureaucracy and traditional lines of communication facilitates the development of autonomy in the professional nurse and will minimize the formal structure of the organization. Position structure can inhibit the 
natural creativity of a nurse who wishes to risk individual participation in changes to unit functioning or patient care. Reward and recognition by the manager of the clinical nurse's contributions to quality patient care would facilitate the perception of a positive organizational climate. Leaders who demonstrate warmth, concern, and consideration will effect increased job satisfaction among the workforce. It is recommended that managers maximize positive changes in the organizational climate by facilitating nurses' participation in all aspects of operations and by empowering nurses to seek creative solutions to day-to-day problems. In developing a true partnership relationship with the nursing staff rather than the traditional bureaucratic relationship, the manager can positively effect the ciimate of the organization and ultimately the job satisfaction of the individual nurse.

Job stress. Job stress was the second strongest predictor of job satisfaction in the simplified model and was inversely related to job satisfaction. Workload and lack of support were the two dimensions of job stress that constituted the greatest amount of explained variance in job satisfaction. Numerous studies have validated that an unrealistic workload has a tremendous influence on the stress level of nurses and is directly related to burnout, job dissatisfaction, and anticipated or actual turnover. Because of the importance of this variable in job satisfaction and retention, it is strongly recommended that 
the nurse manager pay particular attention to assuring realistic workloads and preserving the same in times when hospitals are facing severe economic challenges and nursing shortages. Clinical nurses and administrative nurses must. work together to redefine patient care delivery systems that realistically have professional nurses performing responsibilities that must be performed by the professional and delegating palliative, comfort, or general hygiene functions to other support personnel.

Lack of support was significantly correlated to the total job stress concept and was predictive of job satisfaction. support is a little understood construct and can be defined differently depending on each individual's perspective. It is recommended that the manager talk with staff to better understand from their perspective what support means to them. In doing so, the manager can be better equipped to meet the employee's expectation of supervisor support and minimize the stress incurred when expectations are not met.

other dimensions of stress in this study were inadequate preparation for the job expectations or responsibilities; interactional conflicts with physicians or other nurses; and caring for dying patients and their families. It is recommended that managers work with staff to identify learning needs or skill deficiencies in order to provide appropriate continuing or inservice education to reduce the inherent fear and stress from being inadequately 
prepared. Fostering a learning environment where it is safe to request assistance, advice, or preceptoring from more experienced or knowledgeable nurses is one strategy for reducing stress related to inadequate preparation. Working through interactional conflicts with the involved persons to resolve issues and teaching conflict resolution and assertiveness skills to nurses and physicians can minimize work related stress. Using the resources of social services or others who are skilled in resolving interactional conflicts or working with staff through difficult patient or employee situations such as unexpected patient death, abortion, traumatic incidents should be encouraged. It is recommended that managers recognize and acknowledge the negative impact of work-related stress on the individual and on job satisfaction. Swift and immediate action must be taken by the manager to support the employee through situational crises such patient death, interpersonal conflicts, unplanned intensity in patient acuity or workload with long term interventions taken to minimize chronic stressors in the work environment.

\section{Implications and Recommendations for Nursing Education}

This study has important implications for nursing education. New trends in professional nursing are emerging which nursing educators must recognize, value, and subsequently adapt or modify for curricula. Baccalaureate education will need to include theoretical knowledge and 
experience in leadership to prepare clinical nurses to assume the leadership of supportive personnel who share in patient care responsibilities. The contemporary role of the professional nurse includes total patient management in a continuum of care that spans from pre-hospitalization preparation to post-hospitalization home care. The nurse must be adequately prepared to assume multiple roles or the coordina'ion of the patient's experience through multiple stages.

As the professional nurse assumes increased responsibilities in patient care management, enhanced interactional techniques, conflict resolution, and negotiation skills become more important. It will be important for nursing education to enhance the clinical nurses' ability to work with other nurses or health professionals in a partnership or collaborative manner. These same skills are necessary for the professional nurse to assume roles in shared governance systems in which nurses are active participants in decisions effecting patient care or the professional practice of nursing. Education related to the accountability of the professional to assure that quality standards are maintained will be important as the nurse assumes new roles in peer review and evaluation, development of interdisciplinary patient care standards, and promotion of continuing professional education.

Increased educational emphasis must be placed on organizational theory, group psychology, and role theory as 
nurses learn to work more in collaborative or partnership ralationships with physicians and management. The essence of creativity and entrepreneurship must be cultivated in educational settings and fostered in young graduates as the nursing profession seeks innovative and cost-effective methods of delivery patient care.

Graduate education should emphasize problem identification and problem solving with clinical residencies arranged with adrninistrative and advanced clinical nurses who have demonstrated leadership in collaborative management strategies and entrepreneurial skills. Contemporary management roles of integration, facilitation, and coordination should be taught in the educational setting and role modeled in practice in order for nurse managers to implement strategies which enhance job satisfaction of the workforce. A greater understanding and personal identification with concepts of power and authority, risk taking, creativity, and innovation will be essential for managing nurses who are more autonomous, interdependent, and fully vested participants in decision making.

Joint appointments between nursing education and nursing service will enhance the theoretical knowledge base of nurses practicing clinical. or administrative nursing and will enhance the empirical knowledge base of nurse educators. Sharing expertise will maximize the use of scare resources in both academia and service. Nurse managers must be helped to realize that they are accountable for the 
development of positive organizational climates which foster collaborative behavior, minimizes stressors, and empowers the professional nurse to enhance job satisfaction and reduce anticipated or actual turnover. Clinical nurses must assume power over their professional practice and leadership of others and develop collaborative behaviors with other profossionals in vider to be satisfied in role.

\section{Summary}

This study used path analytic techniques to examine the interrelatedness and influence of collaborative behavior, organizational climate, and job stress as predictor variables for job satisfaction and anticipated turnover in nursing. The relationships between the predictor and outcome variables were credible since they were supported by previous research and a theoretical framework delineating a causal effect of personal and organizational characteristics on affective reactions and organizational effectiveness. The results of the study supported the precedence of cause in the predictor variables and the presence of effect in the outcome variables. This research met criteria established by Krathwohl (1985) for internal and external validity. The findings contributed further understanding of variables effecting job satisfaction and anticipated turnover in nursing. Since these variables can be manipulated, enhanced, or minimized by nurse managers, positive effects on job satisfaction and effective interventions to prevent anticipated turnover could be realized. 
REFERENCES

124

Reproduced with permission of the copyright owner. Further reproduction prohibited without permission. 
REFERENCES

Alexander, C. S., Weisman, C. S., \& Chase, G. A. (1981).

Evalutating primary nursing in hospitals: Examination of effects on nursing staff. Medical Care, 14(1), 8089.

Alt-White, A. C., Charns, M., \& Strayer, R. (1983). Personal, organizational and managerial factors related to nurse-physician collaboration. Nursing Administration Quarterly, $\underline{8}, 8-16$.

Asher, H. B. (1983) - Causal modeling. Beverly Hills, CA: Sage Publications.

Bartz, C. \& \& Maloney, J. P. (1986). Burnout among intensive care nurses. Research in Nursing \& Health, 9, 147153.

Blegen, M. A., \& Mueller, C. W. (1987). Nurses' job satisfaction: A longitudinal analysis. Research in Nursing \& Health, 10, 227-237.

Blenkarn, H. D'Amico, M., \& Virtue, E. (1988). Primary nursing and job satisfaction. Nursing Management. 19 4, 41-42.

Bream T., \& Schapiro, A. (1989). Nurse-physician networks: A focus for retention. Nursing Management, 20 (5), 74-77. Buccheri, R. C. (1986). Nursing supervision: A new look at an old role. Nursing Administration Quarterly, 11, 1125. 
Campbell, J. P., Dunnette, M. D., Lawler, E. E., \& फ़eick, K. E. (1970). Managerial behavior, performance, and effectiveness. New York: McGraw-Hill. Campbell, J. P. (1977). On the nature of organizational effectiveness. In P. S. Goodman, \& J. M. Pennings (Eds.), New perspectives on organizational effectiveness. San Francisco: Jossey-Bass. Carlsen, R. F., \& irulley, J. D. (1981). Job satisfaction of staff registered nurses in primary and team nursing delivery systems. Research in Nursing and Health, 4 , $251-260$.

Choi, T., Jameson, 느., Brekke, M. L., Anderson, J. G., \& Podratz, R. O. (1989). Schedule related effects on nurse retention. Western Journal of Nursing Research, $11(1), 92-107$.

Clark, N. M., \& Lenburg, C. B. (1980). Knowledge-informed behavior and the nursing culture: f preliminary study. Nursing Research, 29, 244-249.

Coburn, M. S. (1988a). One hospital's experience with guidelines for improved collaboration between emergency medical technicians, nurses, and physicians. Journal of Emergency Nursing, 14 (1), 19-22.

Cohen, J. (1988b). Statistical power analysis for the behavioral sciences (2nd ed.). New Jersey: Lawrence Erlbaum Associates, Publishers.

Cohen, J., \& Cohen, P. (1983) . Applied multiple regression/correlation analysis for the behavior 
sciences (2nd ed.). New Jersey: Lawrence Erlbaum Associates, Publishers.

Cook, C. B., \& Mandrillo, M. (1982). Perceived stress and situational supports. Nursing Management, 13(9), 3133.

Department of Health \& Human Services (1988). Secretary's commission on nursing (vol. 1). Washington, D.C.

Deutsch, M. (1973). The resolution of conflict. New Haven, CT: Yale University Press.

Dieterly, D. L., \& Schneider, B. (1974). The effect of organizational environment on perceived power and climate: A laboratory study. Organizational Behavior and Human Periormance, 11, 316-337.

Dolan, N. (1987). The relationship between burnout and job satisfaction in nurses. Journal of Advanced Nursing, $12,3-12$.

Donohue, J. D. (1986). Faculty perceptions of organizational climate and expressed job satisfaction in selected baccalaureate schools of nursing. Journal of Professional Nursing, $\underline{2}, 373-379$.

Duxbury, M. I., Henly, G. A., \& Armstrong, G. D. (1982). Mesurement of the nurse organizational climate or neonatal intensive care units. Nursing Research, 31. 83-88.

Fain, J. A. (1987). Perceived role conflict, role ambiquity, and job satisfaction among nurse educators. Journal of Nursing Education, 26(6), 233-238. 
Feltham, M. A. (1983). A study of role stress conflict, role stress ambiguity, participation in decisionmaking, and social support in relation to job satisfaction and to organizational comitment among professional nurses. Dissertation Abstracts International, 20, 8329820, (University Microfilms International).

Floyd, G. J., \& Smith, B. D. (1983). Job enrichment. Nursing Management, 14(5), 22-25.

Forehand, G. A., \& Gilmer, B. (1964). Environmental Variation in studies of organizational Behavior, 62 . $361-382$.

Gibson, J. L., Ivancevich, J. M., \& Donnelly, J. H., Jr. (1979) - organizations, behavior, structure, processes. Dallas, TX: Business Publications. Godfrey, M. A. (1978). Job satisfaction: or should that be dissatisfaction? How nurses feel about nursing (Part II). Nursing 78, $\underline{8}(5), 105-120$. Gray, H. (1985). Conditions facilitating interorganizational collaboration. Human Relations, 38. $911-936$. Gray-Toft, P., \& Anderson, J. G. (1981). The nursing stress scale: Development of an instrument. Journal of Behavioral Assessment, $\underline{3}(1), 11-23$.

Harnett, D. L. (1982). Statistical methods (3rd ed.). Reading, MA: Addison-Wesley Publishing Co. Hart, D. H. (1989). Reducting nurse turnover. Healthcare Forum Journal, $\underline{32}(3), 37-41$. 
Herzberg, F. (1968), One more time: How do you motivate employees? Harvard Business Review, 46, 53-62.

Hinkle, D. E., Wiersma, W., \& Jurs, S. G. (1979) . Applied statistics for the behavioral sciences. Boston, MA: Houghton Mifrilin.

Hinshaw, A. S., \& Atwood, J. R. (1982). Anticipated turnover: A pilot stage instrument. Communicating Nursing Research, 13, 56.

Hinshaw, A. S., \& Atwood, J. R. (1984). Nursing staff turnover, stress, and satisfaction: Models, measures, and management. In H. H. Werley, \& J. J. Fitzpatrick (Eds.). Annual Review of Nursing, 1, 133-153.

Hinshaw, A. S, Smeltzer, C. H., \& Atwood, J. R. (1987). Innovative retention strategies for nursing staff. Journal of Nursing Administration, 17(6), 8-16.

Homans, G. C. (1950). The human group. New York: Harcourt, Brace \& Co.

Jacobson, S. F. (1988). Nurse retention on high stress clinical specialty units. In Nursing resources and the delivery of patient care. Washington, CD: U.S. Department of Health and Human Services. Kerlinger, F. N. (1986). Foundations of behavioral research (3rd. ed.). New York: Holt, Rinehart \& Winston. Kilmann, R. H., \& Thomas, K. W. (1977). Developing a forced-choice measure of conflict handling behavior: The "mode" instrument. Educational and Psychological Measurement, 37, 309-325. 
Rosmoski, ㄱ. A., \& Calkin, J. D. (1986). Critical care nurses'intent to stay in their positions. Research in Nursing \& Health, $9,3-10$.

Krathwohl, D. R. (1985). Social and behavioral science research. San Francisco: Jossey-Bass Publishers. Lawler, E. E., \& Porter, L. W. (1971). The effect of performance in job satisfaction. In J. H. Connelly, Jr., J. L. Gibson, \& J. M. Ivanevick (Eds.), Fundamentals of management selected readings (pp. 110150). Austin, TX: Business Publications.

Lawler, E. E., Hall, D. T., \& Oldham. G. R. (1974). Organizational climate: Relationship to organizational structure, process, and performance. organizational Behavior and Human Performance, 2, 139-155.

Lawler, E. E., Nadler, D. A., \& Cammann, C. (1980). Organizational assessment. New York: John Wiley \& Sons.

Lysaught, J. P. (1970). An abstract for action. New York: McGraw-Hill Book Company.

Lyon, H. L., \& Ivancevich, J. M. (1974). An exploratory investigation of organizational climate and job satisfaction in a hospital. Academy of Management Journal, $17,635-647$.

Marram, G, Barrett, M. W., \& Bevis, E. O. (1979). Primary nursing: A model for individual care. St. Louis: C.V. Mosby.

Maslow, A. H. (1954). Motivation and personality. New York: Harper \& Row. 
McCranie, E. W., Lambert, V. A., Lamvert, C. E. (1987). Work stress, hardiness, and burnout among hospital staff nurses. Nursing Research, $\underline{36}(6), 374-378$. McKay, P. S. (1983, Summer). Interdependent decision making: Redefining professional autonomy. Nursing Administration Quarterly, pp. 21-30.

Miunro, B. H., Visintainer, M. A., \& Page, E. B. (1986). Statistical methods for health care research. Philadelphia: J.B. Lippincott Company. National Commission on Nursing (1981). Summary of public Hearings. Chicago, IL: American Hospital Association. National Commission on Nursing (1982). Nursing in transition: Models for successful organizational change. Chicago, IL: The Hospital Research and Education Trust.

National Joint Practice Commission. (1981). Guidelines for establishing joint or collaborative practice in hospitals. Chicago, II: National Joint Practice Commission.

Norbeck, J.S. (1985) . Perceived job stress, job satisfaction, and psychological symptoms in critical care nursing. Research in Nursing \& Health, 8 , 253259 .

Nursing Shortage Poll Report. (19) . Nursing 1988, 18(2), $33-41$.

Nunnally, J.C. (1978). Psychometric theory. New York: McGraw-Hill. 
Office of the Inspector General. (1989). Hospital best practices in nurse recruitment and retention. Nursing Economics, 7(2), 98-106.

Payne, R. L., Fineman, P, \& Wall, J. (1976). Organizational climate and job satisfaction: A conceptual synthesis. organizational Behavior and Human Performance, 16: 4562.

Pedhazur, E. J. (1982). Multiple regression in behavioral research (2nd ed.). New York: Holt, Rinehart and winston.

Polit, D. F., \& Hungler, B. P. (1987). Nursing research: principles and method (3rd.ed.). Philadelphia: J.B Lippincott Company.

Porter, L. W., Lawler, E. E., \& Hackman, I. R. (1975): Behavior in organizations. New York: MCGrar-Hill. Prestholdt, P. H., Lane, I. M., \& Mathews, R. C. (1987). Nurse turnover a reasoned action: Development of a process model. Journal of Applied Psychology, $\underline{72}$ (2), 221-227.

Prestholdt, P. H., Lane, I. M., \& Mathews, R. C. (1988). Predicting nurse turnover. Nursing Outlook, 36(3), 145-147.

Price J. L., \& Mueller, C. W. (1981). A causal model of turnover for nurses. Academy of Management Journal, $\underline{24}, 543-565$.

Roedel, R. R., \& Nystrom, P. C. (1988) . Nursing jobs and satisfaction. Nursing Management, $19(2), 34-38$. 
Ruble, T. L., \& Thomas, K. W. (1976). Support for a twodimensional model of conflict behavior. organizational Behavior and Human Performance, 16, 145.

Sellick, K. J., Russell, S., Beckman, J. L. (1983). Primary nursing: An evaluation of its effects on patient perception of care and staff satisfaction. International Journal of Nursing Studies, 20 (4), 265273 .

Schein, E. H. (1985). organizational culture and leadership. San Francisco: Josey-Bass Publishers. Simpson, K. (1985). Job satisfaction or dissatisfaction reported by registered nurses. Nursing Administrative Quarterly, $9(3), 64-73$.

Slavitt, D. B., Stamps, P. L., Piedmonte, E. B., \& Haase, A. B. (1978). Nurses satisfaction with their work situation. Nursing Research, 27, 114-120. Slavitt, D. B., Stamps, P. L., Piedmonte, E. B., \& Haase, A. B. (1979). Measuring the levels of satisfaction of hospital nurses. Hospital and Health Services Administration Journal, $\underline{24}(3), 62-77$. SPSS-X User's Guide (3rd. ed.). (1988). Chicago, IL: SPSS, Inc.

Stamps, P. L., \& Piedmonte, E. B. (1986). Nurses and work satisfaction. Ann Arbor, MI: Health Administration Press.

Stember, M. L., Ferguson, J., Conway, K., \& Yingling, M. (1978). Job satisfaction research-an aid in decision making. Nursing Administrative Quarterly, 2, 95-105. 
Stephen, S., \& Bailey, J. (1979). Sources of stress and satisfaction in ICU nursing. Focus, $\underline{6}(6), 26-32$. Stichler, J. F. (1989). Development and psychometric testing of a collaborative behavior scale. Unpublished manuscript, University of San Diego, Philip Y. Hahn School of Nursing.

Stogdill, R. M. (1974) - Handbook of leadership. New York:

The Free Press.

Taylor, F. W. (1911). Principles of management. New York:

Harper and Brothers.

Taunton, R. I. , Krampitz, S. D., \& Woods, C. Q. (1989).

Managers impact on retention of hospital staff (Part

2). Journal of Nursing Administration, 19(4), 15-19.

Tauskey, C. (1978). Work organization: Major theoretical

perspectus (2nd ed.). Itasca, IL: Peacock Press.

Thompson, B. (1989). Canonical correlation analysis.

Newbury Park, CA: Sage Publishing.

Vandersiice, V. J., Rice, R. W., \& Julian, J. W. (1987).

The effects of participation in decision-making on worker satisfaction and productivity. Journal of

Applied Psychology, 17(2), 158-170.

Verran, J. A., \& Ferketich, S. (1987). Testing linear model assumptions: Residual analysis. Nursing research, $\underline{36}$, $127-130$.

Volicer, B. J. (1984). Multivariate statistics for nursing research. New York: Grune \& Stratton.

Vroom, V. H. (1964). Work and motivation. New York: John Wiley \& Sons. 
Vroom, V. H., \& Yetton, P. W. (1973). Leadership and decision-making. Pittsburg, PA: University of Pittsburg Press.

Waltz, C. F., \& Bausell, R. B. (1981). Nursing research: Design, statistics and computer analysis. Philadelphia, PA: F.A. Davis Company. Waltz, C. F., Strickland, O. L., \& Ienz, E. R. (1984). Measurement in nursing research. Fhiladelphia: F.A. Davis. Weiss, S. J., \& Davis, H. P. (1983). The health role expectaitions index: A neasure of aligninent, disparity and change. Journal of Behavioral ijeaicine, $\underline{6}(1), 63-$ 76 .

Weiss, S. J., \& Davis, H. P. (1985). Validity and reliability of the collaborative practice scales. Nursing Research, 34, 299-305.

Wolf, G. A. (1981). Nursing turnover: Some causes and solutions. Nursing outlook, 29(4), 233-236. 


\section{APPENDICES}

136

Reproduced with permission of the copyright owner. Further reproduction prohibited without permission. 
APPENDIX A

COLIABORATIVE PRACTICE SCALE 


\section{PLEASE NOTE:}

Copyrighted materials ir, Afis document have not been filmed at the request of the author. They are available for consultation, however, in the author's university library.

These consist of pages:

138

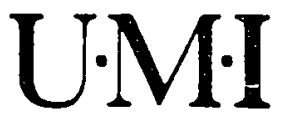

Reproduced with permission of the copyright owner. Further reproduction prohibited without permission. 


\section{APPENDIX B}

COLIAABORATIVE BEHAVIOR SCALE - A 


\section{Collaborative Behavior Scale - Part 1}

\section{Used willi permission}

Stichler, J. F. (1989). Derelopment and nsychometulc tegling of a collaboralive behavior scale. Unpublished manuscript, Unlversily of San Dlego, Philip Y. Hahn School of Nuroing.

Directions: The purpose of this scale is to determine the extent of collaboratlve behaviors which generally exdst between you and the physiclans with whom you worle. (For each statement check $(G)$ the one box that indicates how of statement occurs.) There are no right or wiong answers. Please answer each llem as best you can.

\begin{tabular}{|l|l|l|l|l|}
\cline { 2 - 5 } \multicolumn{1}{c|}{} & $\begin{array}{c}\text { Rarely } \\
1\end{array}$ & \begin{tabular}{c} 
Sometines \\
\multicolumn{1}{c|}{}
\end{tabular} & $\begin{array}{c}\text { Often } \\
3\end{array}$ & $\begin{array}{c}\text { Nearly } \\
\text { Always } \\
4\end{array}$ \\
\hline $\begin{array}{l}\text { 1. We feel free to } \\
\text { share ideas wilh } \\
\text { one another. }\end{array}$ & & & & \\
\hline $\begin{array}{l}\text { We acknowiedge } \\
\text { one another's } \\
\text { competence. }\end{array}$ & & & & \\
\hline $\begin{array}{l}\text { 3. We support cach } \\
\text { other as team } \\
\text { members. }\end{array}$ & & & & \\
\hline $\begin{array}{l}\text { 4. We work as part- } \\
\text { ners. }\end{array}$ & & & & \\
\hline $\begin{array}{l}\text { 5e are commit- } \\
\text { led to working } \\
\text { log'ther as a } \\
\text { teim. }\end{array}$ & & & & \\
\hline
\end{tabular}

\begin{tabular}{|c|c|c|c|c|}
\hline & $\begin{array}{c}\text { Rarely } \\
1 \\
\end{array}$ & $\begin{array}{c}\text { Somelimes } \\
\mathbf{2}\end{array}$ & $\begin{array}{c}\text { Orten } \\
3 \\
\end{array}$ & $\begin{array}{c}\text { Nearly } \\
\text { Always } \\
4\end{array}$ \\
\hline $\begin{array}{l}\text { 6. We trust one an- } \\
\text { other. }\end{array}$ & & & & \\
\hline $\begin{array}{l}\text { 7.There is a sharing } \\
\text { of expertise and } \\
\text { talents between } \\
\text { us. }\end{array}$ & & & & \\
\hline $\begin{array}{l}\text { 8. We work as } \\
\text { "equals" or "part- } \\
\text { ners" for the } \\
\text { accomplishment } \\
\text { of some goals. }\end{array}$ & & & & \\
\hline $\begin{array}{l}\text { 9. We work together } \\
\text { as a team. }\end{array}$ & & & & \\
\hline $\begin{array}{l}\text { 10. My oplnions are } \\
\text { listened to. }\end{array}$ & & & & \\
\hline $\begin{array}{l}11.1 \text { feel that my in- } \\
\text { put is truly } \\
\text { valued. }\end{array}$ & & & & \\
\hline $\begin{array}{l}\text { 12. We work together } \\
\text { as assoclates. }\end{array}$ & & & & \\
\hline $\begin{array}{l}\text { 13.There is a feeling } \\
\text { of mutual regard } \\
\text { and respect. }\end{array}$ & & & & \\
\hline $\begin{array}{l}\text { 14. We make an effort } \\
\text { to resolve any con- } \\
\text { ficts which arise } \\
\text { to our mut ual } \\
\text { satusfaction. }\end{array}$ & & & & \\
\hline
\end{tabular}




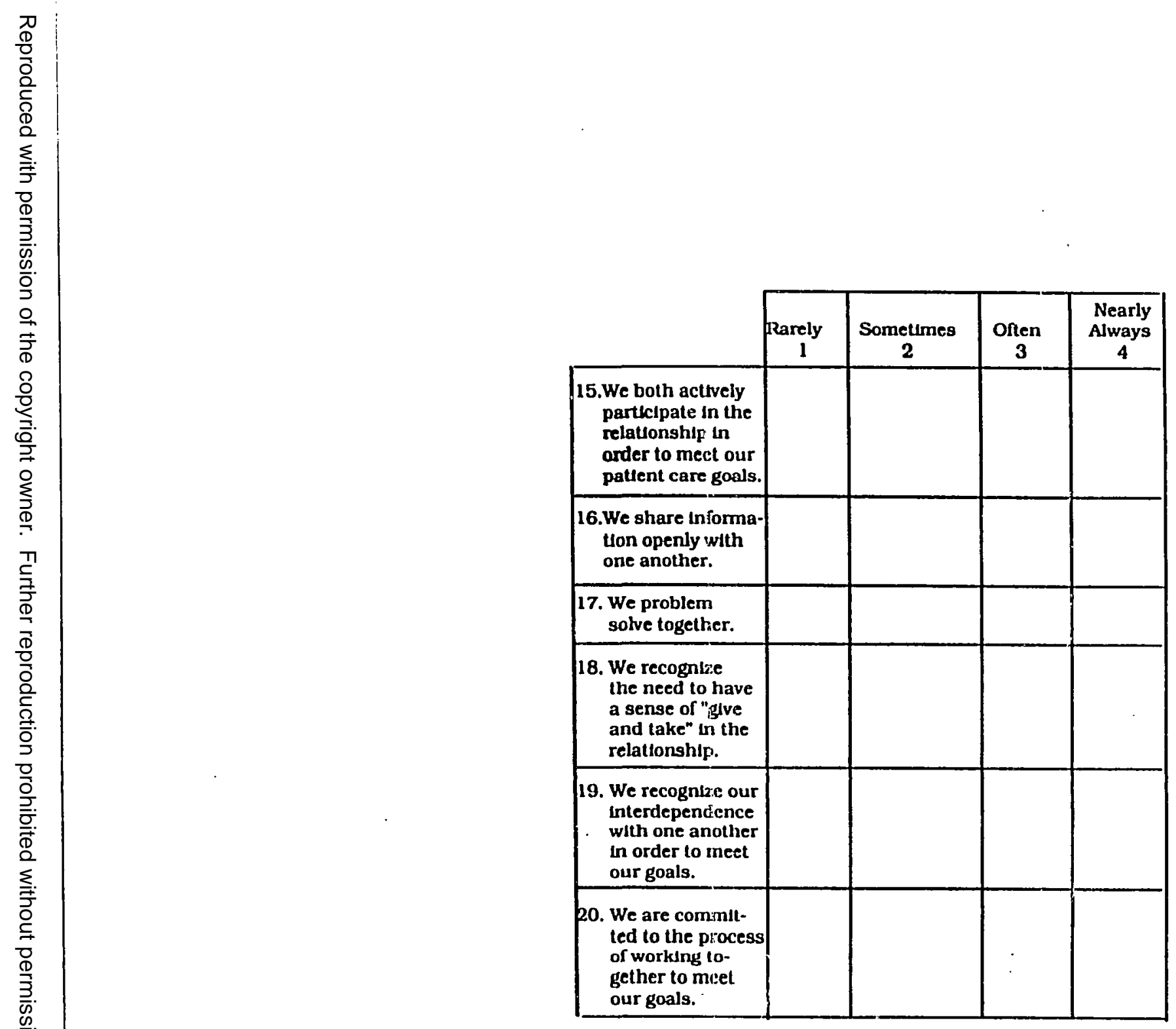




\section{APPENDIX C}

COLLABORATIVE BEHAVIOR SCALE - B 


\section{Collaivorative Behavior Scale - Part 2}

Directions: The purpose of this scale is to determine the extent of collaborattve behaviors which generally exdst between you and the manacers with whom you work. (For each statement check $(n$ ) the one box that indicates how often you believe that each behaviorlal statement occurs.) There are no rtght or wrong answers. Please answer each item as best you can.

\begin{tabular}{|c|c|c|c|c|}
\hline & $\begin{array}{c}\text { Rarely } \\
1\end{array}$ & $\begin{array}{c}\text { Sometimes } \\
2\end{array}$ & $\begin{array}{c}\text { Often } \\
3\end{array}$ & $\begin{array}{c}\text { Nearly } \\
\text { Always } \\
4\end{array}$ \\
\hline $\begin{array}{l}\text { 1. We feel free to } \\
\text { share icleas with } \\
\text { one ancther. }\end{array}$ & & & & \\
\hline $\begin{array}{l}\text { 2. We acknowledge } \\
\text { one another. }\end{array}$ & & & & \\
\hline $\begin{array}{l}\text { 3. We support cach } \\
\text { other as team } \\
\text { members. }\end{array}$ & & & & \\
\hline $\begin{array}{l}\text { 4. We work as part- } \\
\text { ners. }\end{array}$ & & & & \\
\hline $\begin{array}{l}\text { 5. We are commutted } \\
\text { lo working to- } \\
\text { gether as a team. }\end{array}$ & 1. & & & \\
\hline $\begin{array}{l}\text { 6. We trust one an- } \\
\text { other. }\end{array}$ & & & & \\
\hline $\begin{array}{l}\text { 7. There is a sharing } \\
\text { of expertise and } \\
\text { talents between } \\
\text { us. }\end{array}$ & & & & \\
\hline
\end{tabular}

\begin{tabular}{|c|c|c|c|c|}
\hline & $\begin{array}{l}\text { Rarely } \\
1\end{array}$ & $\begin{array}{l}\text { Sometumes } \\
2\end{array}$ & $\begin{array}{c}\text { Offen } \\
3\end{array}$ & $\begin{array}{c}\text { Nearly } \\
\text { Always } \\
4\end{array}$ \\
\hline $\begin{array}{l}\text { 8. We work as } \\
\text { "equals" or "part- } \\
\text { ners" for the } \\
\text { accomplishment } \\
\text { of some goals. }\end{array}$ & & & & \\
\hline $\begin{array}{l}\text { 9. We work together } \\
\text { as a team. }\end{array}$ & & & & \\
\hline $\begin{array}{l}\text { 10. My opinions are } \\
\text { IIstened to. }\end{array}$ & & & & \\
\hline $\begin{array}{l}\text { 11.I feel that my in- } \\
\text { put is truly } \\
\text { valued. }\end{array}$ & & & & \\
\hline $\begin{array}{l}\text { 12. We work together } \\
\text { as assoclates. }\end{array}$ & & & & \\
\hline $\begin{array}{l}\text { 13.There is a feeling } \\
\text { of mutual regard } \\
\text { and respect. }\end{array}$ & & & & \\
\hline $\begin{array}{l}\text { 14. We make an effort } \\
\text { to resolve any con } \\
\text { ficts which artse } \\
\text { to our mutual } \\
\text { satlsfaction. }\end{array}$ & & & . & \\
\hline $\begin{array}{l}\text { 15. We both actively } \\
\text { participate in ihe } \\
\text { relationship in } \\
\text { order to meet our } \\
\text { pattent care goals. }\end{array}$ & & & & \\
\hline $\begin{array}{l}\text { 16. We share informa- } \\
\text { Uon openly wilh } \\
\text { one anolher. }\end{array}$ & & & & \\
\hline
\end{tabular}




\section{APPENDIX D \\ ORGANIZATIONAI CLIMATE MEASURE}




\section{PLEASE NOTE:}

Copyrighted materials in this document have not been filmed at the request of the author. They are available for consultation, however, in the author's university library.

These consist of pages:

$146-147$

$149-150$

$152-154$

156

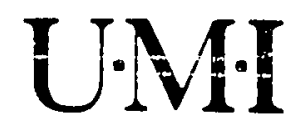


APPENDIX E

\section{NURSING STRESS SCALE}


APPENDIX F

INDEX OF WORK SATISFACTION

Reproduced with permission of the copyright owner. Further reproduction prohibited without permission. 
APPENDIX G ANTICIPATED TURNOVER SURVEY 
APPENDIX H

DEMOGRAPHIC QUESTIONNAIRE 


\section{Demographlc Information}

To waist me In the otatlotlcal ennlyols of tho data for thle study. (ollowng Informatlon about you. Plensio To assure the conldenllallity of your regponses, please list the last four numbers of your Soclal Security Number _- - - licuse sulkate the hospital where you are enployed.

\section{Sharp Mernorial}

Sharp Cabrilo _

Malser-

Seripps Mennortal_

Grossmont_-

Tr.Clly

Palomar

Other

(please specl[y)

1. Sex: Male __ Fenral:

2. Marilal Slatus: — Never Mantied

$$
\text { 二 Curro:nly Marred }
$$

3. Your age in yeara ls:

4. instlal preparation in nursing: - Diploma 二Associate Degree

5. Year that tuttal educatlonul preparation in nuralng completed: 10

6. Ilypiest degree canicd:

$$
\begin{aligned}
& \text {--Diploona in Nursing } \\
& \text { - Bachelors Degree iNursing } \\
& \text { Bachelors Degree (Other) piease } \\
& \text { Masiera Degree (Nursing) } \\
& \text { - Mastera Degree (Other) please } \\
& \text { pecify } \\
& \text { Dacloral Degree (Nuralnes } \\
& \text { - Doctural Degree (OLher) please }
\end{aligned}
$$

7. Nussber of years you liave worked as a nurse: -

8. Number of years you lave been comployed in current husphttul.

9. Type of postion you currenty hold at this thospttal: —Clinlcal uurse (stafl nurse) assistant manage sial educalor

$$
\text { Oller (please apreclíy: }
$$

10. Number of years you lave been employed in your preseit

11. Type of postlfon you currently work: - Full IIme (72 hours or greater)
- Part Uime (less than 72 hours! - Parl lime lless than

$$
\text { - Per-diern or canual }
$$

12. Number of hours you work each week tis llits hospllal. -

13. Whuch slth ts your prtmary stun assignment:

$$
\text { — days — }
$$

14. On which clinkeal unt do you premially work?

$$
\begin{aligned}
& \text { Med/Surg Postpartuin Melual, } \\
& \text { _Nursery _Emerg. Depl. _ L. } \\
& \text { _on _ Mecovery Rum. _ _ CCU } \\
& \text { MICU _ SiCU Neouatal ICI }
\end{aligned}
$$


ADPENDIX I

DISCLAIMER LETTER 
14322 Blue Sage Rd.

Poway, CA 92064

October 1989

Dear Colleague,

I am a Doctorate of Nursing Science candidate at the University of San Diego School of Nursing. For a number of years I have been interested in the effect of collaborative behavior between nurses and physicians and nurses and managers on job satisfaction and anticipated turnover. such a study is important, since job dissatisfaction and turnover among murses can adversely affect the quality of patient care and contribute significantiy to the cost of health care.

I an requesting your assistance in a study to determine the effect of collaboration, stress, and organizational climate on job satisfaction and anticipated turnover in nursing organizations. The study specifically focuses on your perception of collaborative behaviors between you and most physicians and managers with whom you work; the stressors you face in your work; your perception of the climate of your organization; your degree of satisfaction with your job; and your intent to leave your position.

Your name has been selected at random from thie iist of all staff nurses (Registered Nurses) employed at Hospital. I would appreciate your willingmess to participate in the study which will take approximately 20 mimutes of your time to complete a packet of questionnaires. You wili not incur any costs during the study.

All of your answers will kept in strict confidence. Your personal identity will not be divulged in any manner, since you will be entering the last four digits of your social security number rather than your name in the questionnaire booklet. Only grouped data will be discussed or published.

There are no other agreements, written or verbal, related to this study beyond that expressed in this letter. I have attached a copy of "The Experimental subject's Bill of Rights" for your consideration. Please complete questionnaires and return them to me by Date. Just drop your completed questionnaire in the enclosed envelope in your nursing office. Your completion of the questionnaires implies your voluntary consent.

Should you have any questions, plsase feel free to phone me at the numbers provided below. Thank you for your support in this important research project.

Sincerely,

Jaynelle F. Stichler, R.N., D.N.Sc. (candidate)

$619 \quad 541-3470$ 
161

APPENDIX J

RESEARCH BILL OF RIGHTS

Reproduced with permission of the copyright owner. Further reproduction prohibited without permission. 


\section{EXPERTIMENIAL SUBJECT'S BILL OF RIGFIS}

Any person who is requested to consent to participate as a subject in a research study involving a medical experiment, or who is requiested to consent on behalf of another, has the right to:

1. Be informed of the nature and purpose of the experiment.

2. Be given an explanation of the procedures to be followed in the medical experiment, and any drug or device to be used.

3. Be given a description of any attendant discomforts and risks reasonably to be expected from the experiment.

4. Be given ain explanation of any benefit; to the subject reasonably to be expected from the experiment, if applicable.

5. Be given a disclosure of any appropriate alternative procedures, drugs or devices that might be advantageous to the subject, and their relative risks and benefits.

6. Be informed of the avemues of medical treatment, ir any, availabie to the subject after the experiment if complications should arise.

7. Be given an opportunity to ask any questions concerning the experiment or the procedures involved.

8. Be instructed that consent to participate in the medical experiment may be withdrawn at any time, and the subject may discontinue participation in the medical experiment without prejuaice.

9. Be given a copy of a signed and dated written consent form when one is required.

10. Be given the opportunity to decide to consent or not to consent to a medical experiment without the intervention of any element of force, fraud, deceit. duress, coercion or undue influence on the subject's decision.

Ir you have any questions regarding a research study, the researcher will be glad to answer them.

I acknowledge that I have received, dated and signed a copy of this Experimental Subject's Bill of Rights before consent to participate in any medical experiment has been given.

Dated: 
APPENDIX L

INDIRECT EFFECTS OF NURSE-PHYSICIAN COLLABORATIVE BEHAVIOR ON ANTICIPATED TURNOVER 
APPENDIX I

INDIRECT EFFECTS OF NURSE-PHYSICIAN COLIABORATIVE BEHAVIOR ON ANTICIPATED TURNOVER
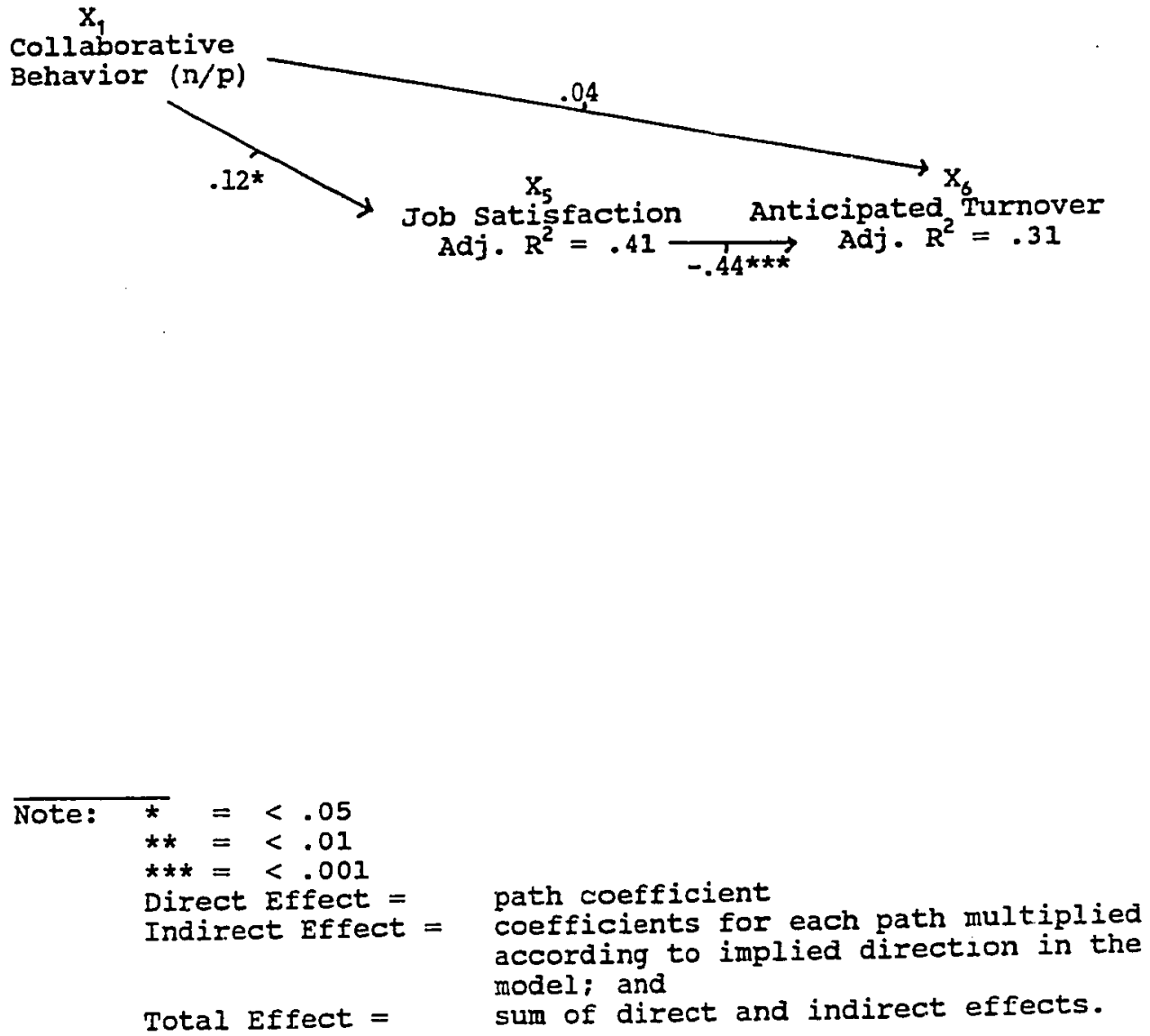


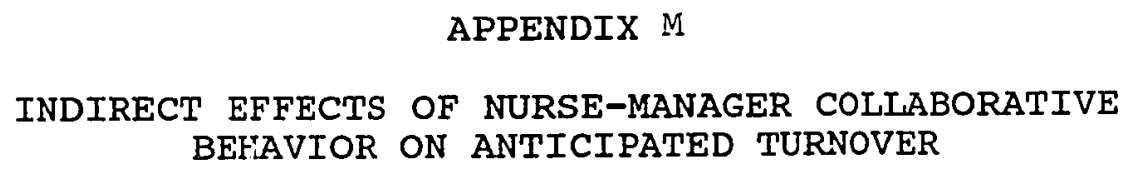

Reproduced with permission of the copyright owner. Further reproduction prohibited without permission. 
APPENDIX M

INDIRECT EFFECTS OF NURSE-MANAGER COLLABORATIVE BEHAVIOR ON ANTICIPATED TURNOVER
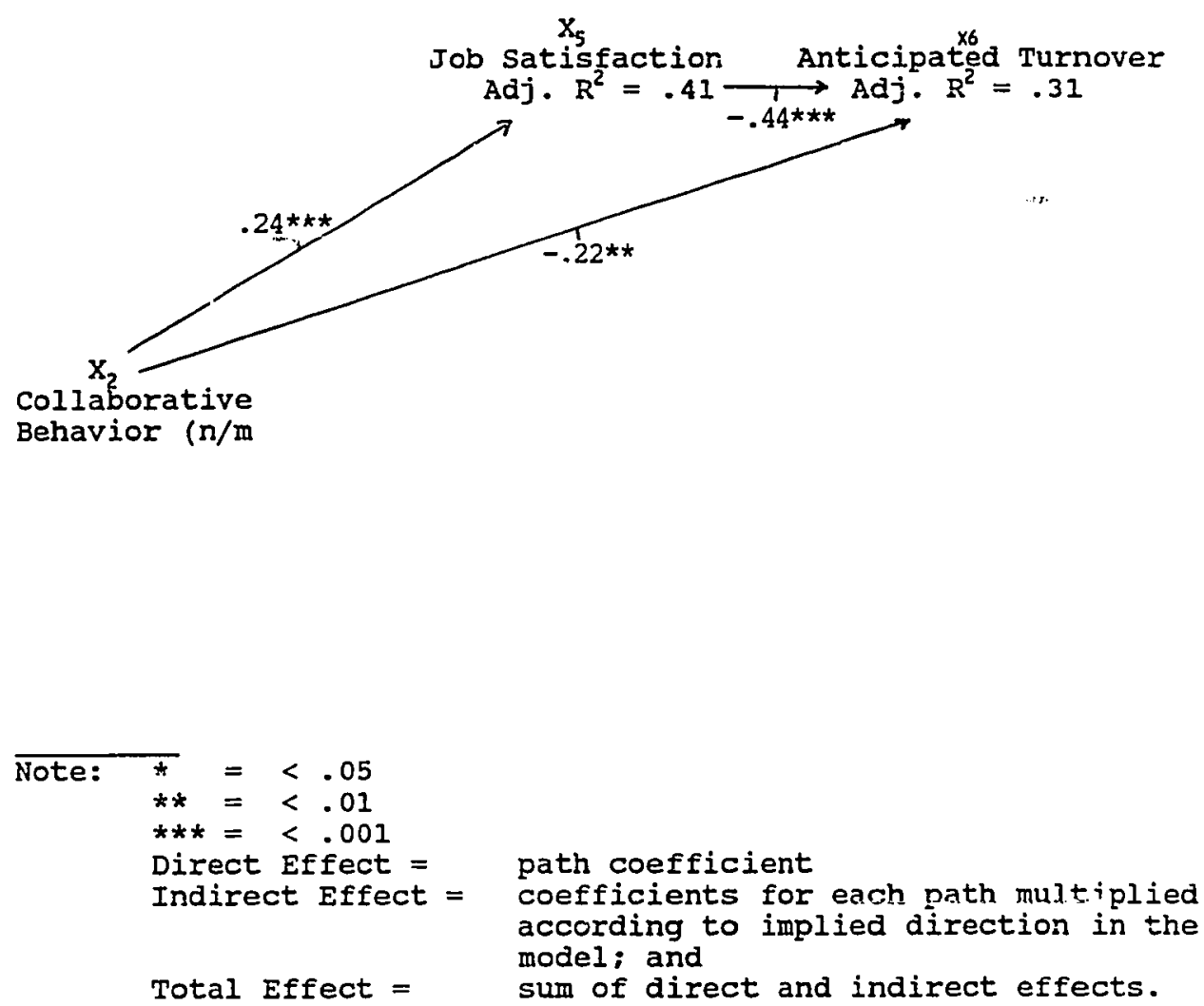


\section{APPENDIX N \\ INDIRECT EFFECTS OF ORGANIZATIONAL CLIMATE ON ANTICIPATED TURNOVER}




\section{APPENDIX N}

\section{INDIRECT EFFECTS OF ORGANIZATIONAL CLIMATE} ON ANTICIPATED TURNOVER

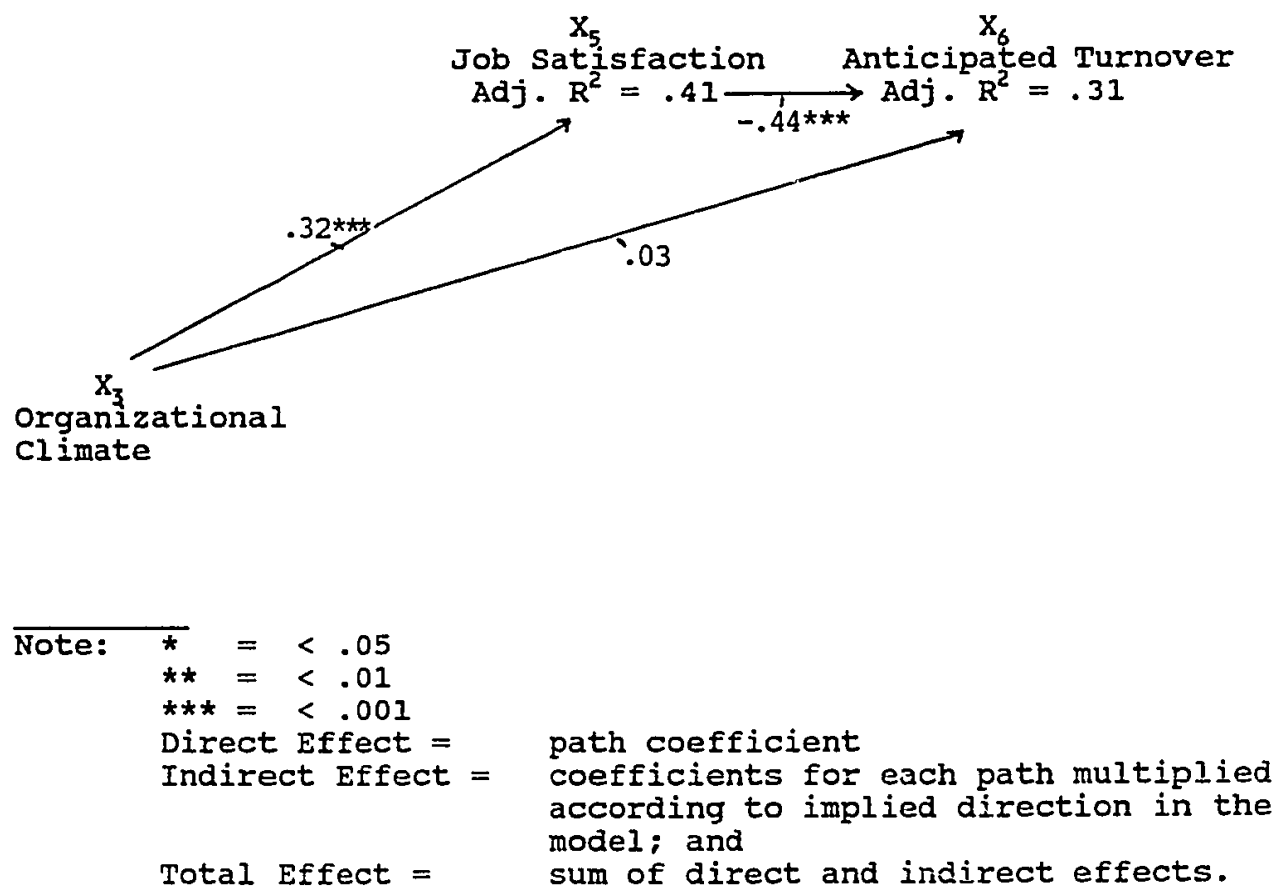




\section{APPENDIX 0 \\ INDIRECT EFFECTS OF JOB STRESS \\ ON ANTICIPATED TURNOVER}


APPENDIX 0

INDIRECT EFFECTS OF JOB STRESS

ON ANTICIPATED TURNOVER
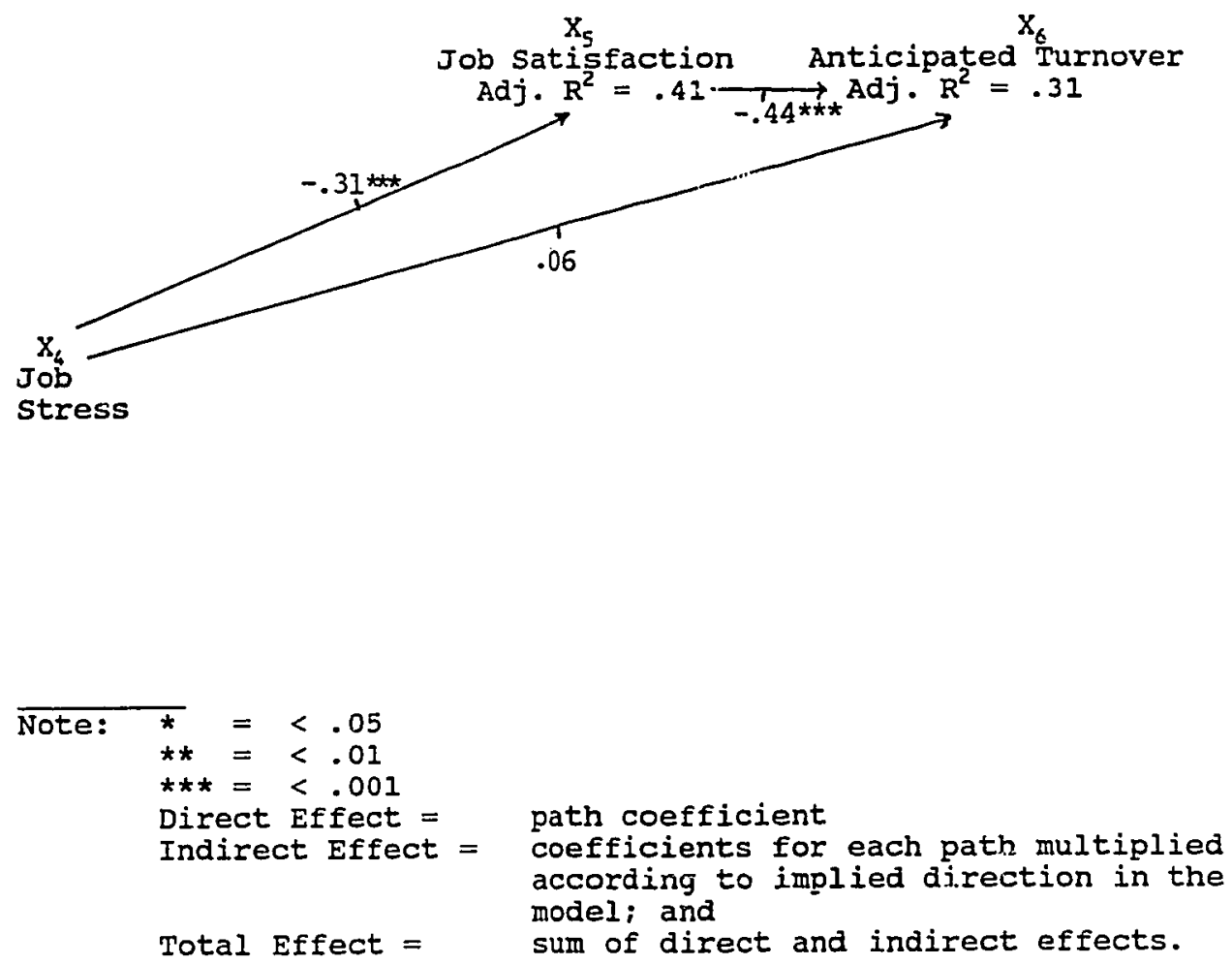


\section{APPENDIX F}

TABLE

ANALYSIS OF VARIANCE SUMMARY TABLE COMPARING DEMOGRAPHIC

VARIABLES ON STUDY VARIABLES AND RESPECTIVE DIMENSIONS 
Appendix $P$

ANALYSIS IF VARIANCE SUMMARY TABLES COMPARING VARIABLES ON STUDY VARIABLES AND RESPECTIVE DIMENSIONS

AGE

\begin{tabular}{llcccc}
\hline $\begin{array}{l}\text { Study } \\
\text { Variable }\end{array}$ & $\begin{array}{l}\text { Source of } \\
\text { Variance }\end{array}$ & df & SS & MS & F \\
\hline $\begin{array}{l}\text { Nurse-Manager } \\
\text { Collaborative } \\
\text { Behavior }\end{array}$ & $\begin{array}{l}\text { Between Groups } \\
\text { Within Grips } \\
\text { Total }\end{array}$ & $\begin{aligned} 183 \\
186\end{aligned}$ & $\begin{array}{r}2782 \\
41337\end{array}$ & $\begin{array}{l}42120 \\
226\end{array}$ & $4.11 * \star *$ \\
\hline
\end{tabular}

CLINICAL UNIT

\begin{tabular}{|c|c|c|c|c|c|}
\hline $\begin{array}{l}\text { Study } \\
\text { Variable }\end{array}$ & $\begin{array}{l}\text { Source of } \\
\text { variance }\end{array}$ & df & ss & MS & F \\
\hline $\begin{array}{l}\text { Nurse-Physiclan } \\
\text { Collaborative } \\
\text { Behavior (CBS-A) }\end{array}$ & $\begin{array}{l}\text { Between Groups } \\
\text { within Groups } \\
\text { Total }\end{array}$ & $\begin{array}{r}13 \\
165 \\
178\end{array}$ & $\begin{array}{r}6128 \\
32618 \\
38746\end{array}$ & $\begin{array}{l}471 \\
198\end{array}$ & $2.38 * \hbar$ \\
\hline MD Conflict (NSS) & $\begin{array}{l}\text { Between Groups } \\
\text { W1thin Groups } \\
\text { Total }\end{array}$ & $\begin{array}{r}13 \\
164 \\
177\end{array}$ & $\begin{array}{l}128 \\
874 \\
1003\end{array}$ & $\begin{array}{r}10 \\
5\end{array}$ & $1.85 *$ \\
\hline $\begin{array}{l}\text { Inadequate Prep- } \\
\text { aration (NSS) }\end{array}$ & $\begin{array}{l}\text { Between Groups } \\
\text { Within Groups } \\
\text { Total }\end{array}$ & $\begin{array}{r}13 \\
164 \\
176\end{array}$ & $\begin{array}{r}73 \\
351 \\
424\end{array}$ & $\begin{array}{l}6 \\
2\end{array}$ & $2.59 \star \star$ \\
\hline $\begin{array}{l}\text { Job Stress } \\
\text { Total (NSS) }\end{array}$ & $\begin{array}{l}\text { Between Groups } \\
\text { Within Groups } \\
\text { Total }\end{array}$ & $\begin{array}{r}13 \\
164 \\
177\end{array}$ & $\begin{array}{r}5717 \\
34538 \\
40254\end{array}$ & $\begin{array}{l}440 \\
211\end{array}$ & $2.09 *$ \\
\hline
\end{tabular}

Key: $\quad \leq .05 \quad$ CBSA = Collaborative Behavior Scale - Nurse-Physician

** $\leq .01 \quad$ IWS $=$ Index of Work Satiafaction

$+\leq .06 \quad$ OCS $=$ Organizational climate Measure 


\begin{tabular}{|c|c|c|c|c|c|}
\hline \multicolumn{6}{|c|}{ DEGREE } \\
\hline $\begin{array}{l}\text { study } \\
\text { Variable }\end{array}$ & $\begin{array}{l}\text { Source of } \\
\text { variance }\end{array}$ & af & ss & MS & $\mathbf{F}$ \\
\hline $\begin{array}{l}\text { Independent } \\
\text { Autonomy (OCS) }\end{array}$ & $\begin{array}{l}\text { Between Groups } \\
\text { Within Groups } \\
\text { Total }\end{array}$ & $\begin{array}{r}4 \\
121 \\
125\end{array}$ & $\begin{array}{r}305 \\
2402 \\
2708\end{array}$ & $\begin{array}{l}76 \\
20\end{array}$ & $3.85 k \hbar$ \\
\hline $\begin{array}{l}\text { Position } \\
\text { structure (ocs) }\end{array}$ & $\begin{array}{l}\text { Between Groups } \\
\text { Within Groupg } \\
\text { Total }\end{array}$ & $\begin{array}{c}4 \\
121 \\
125\end{array}$ & $\begin{array}{r}43 \\
536 \\
576\end{array}$ & 11 & $2.42 *$ \\
\hline $\begin{array}{l}\text { Organizational } \\
\text { cl imate (Total } \\
\text { ocs) }\end{array}$ & $\begin{array}{l}\text { Between Groups } \\
\text { Within Groups } \\
\text { Total }\end{array}$ & $\begin{array}{c}4 \\
121 \\
125\end{array}$ & $\begin{array}{r}563 \\
6705 \\
7267\end{array}$ & $\begin{array}{r}141 \\
55\end{array}$ & $2.54 *$ \\
\hline \multicolumn{6}{|c|}{ POSITION } \\
\hline $\begin{array}{l}\text { study } \\
\text { variable }\end{array}$ & $\begin{array}{l}\text { Source of } \\
\text { Variance }\end{array}$ & de & ss & MS & F \\
\hline $\begin{array}{l}\text { Independent } \\
\text { Autonomy (רes) }\end{array}$ & $\begin{array}{l}\text { Between Groups } \\
\text { Within Groups } \\
\text { Total }\end{array}$ & $\begin{array}{r}4 \\
182 \\
186\end{array}$ & $\begin{array}{r}187 \\
3574 \\
3762\end{array}$ & $\begin{array}{l}47 \\
20\end{array}$ & $2.38 *$ \\
\hline Death (HSS) & $\begin{array}{l}\text { Between Groups } \\
\text { Within Groups } \\
\text { Total }\end{array}$ & $\begin{array}{r}4 \\
181 \\
185\end{array}$ & $\begin{array}{r}147 \\
2557 \\
2704\end{array}$ & $\begin{array}{l}37 \\
14\end{array}$ & $2.61) *$ \\
\hline $\begin{array}{l}\text { Inadequate } \\
\text { Preparation (nSS) }\end{array}$ & $\begin{array}{l}\text { Between Groups } \\
\text { Within Groups } \\
\text { Total }\end{array}$ & $\begin{array}{r}4 \\
\mathbf{1 8 0} \\
: 184\end{array}$ & $\begin{array}{r}43 \\
427 \\
470\end{array}$ & $\begin{array}{r}11 \\
2\end{array}$ & $4.5: 1 * \hbar$ \\
\hline $\begin{array}{l}\text { Nurse/Physician } \\
\text { Interaction (IWS) }\end{array}$ & $\begin{array}{l}\text { Between Groups } \\
\text { within Groups } \\
\text { Total }\end{array}$ & $\begin{array}{r}4 \\
280 \\
184\end{array}$ & $\begin{array}{r}379 \\
6293 \\
7262\end{array}$ & $\begin{array}{l}95 \\
38\end{array}$ & $2.48 *$ \\
\hline
\end{tabular}

Key: $\star \leq .05 \quad$ CBSA $=$ Collaborative Behavior scale - Nurse-physician

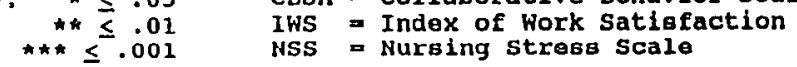


YEAKS IN THE POSITION

\begin{tabular}{|c|c|c|c|c|c|}
\hline $\begin{array}{l}\text { Study } \\
\text { Variable }\end{array}$ & $\begin{array}{l}\text { Source of } \\
\text { Variance }\end{array}$ & dit & ss & MS & $F$ \\
\hline $\begin{array}{l}\text { Nurse-Physician } \\
\text { Collaborative } \\
\text { Behavior }\end{array}$ & $\begin{array}{l}\text { Between Groups } \\
\text { within Groups } \\
\text { Total }\end{array}$ & $\begin{array}{r}3 \\
184 \\
187\end{array}$ & $\begin{array}{r}1908 \\
39150 \\
42059\end{array}$ & $\begin{array}{l}636 \\
212\end{array}$ & $2.99 x$ \\
\hline Pay (IWS) & $\begin{array}{l}\text { Between Groups } \\
\text { Within Groups } \\
\text { Total }\end{array}$ & $\begin{array}{r}3 \\
182 \\
185\end{array}$ & $\begin{array}{r}515 \\
10272 \\
10787\end{array}$ & $\begin{array}{r}172 \\
56\end{array}$ & $3.04 *$ \\
\hline $\begin{array}{l}\text { Nurse-Physician } \\
\text { Interaction (IWS) }\end{array}$ & $\begin{array}{l}\text { Between Groups } \\
\text { Within Groups } \\
\text { Total }\end{array}$ & $\begin{array}{r}3 \\
2.82 \\
185\end{array}$ & $\begin{array}{r}342 \\
6924 \\
7266\end{array}$ & $\begin{array}{r}114 \\
38\end{array}$ & $2.99 *$ \\
\hline \multicolumn{6}{|c|}{ JOB STATUS } \\
\hline $\begin{array}{l}\text { Study } \\
\text { variable }\end{array}$ & $\begin{array}{l}\text { Source of } \\
\text { varlance }\end{array}$ & def & ss & MS & $\boldsymbol{F}$ \\
\hline $\begin{array}{l}\text { Considertion } \\
\text { (Ocs) }\end{array}$ & $\begin{array}{l}\text { Between Groups } \\
\text { Within Groups } \\
\text { Total }\end{array}$ & $\begin{array}{r}3 \\
183 \\
186\end{array}$ & $\begin{array}{r}72 \\
980 \\
1053\end{array}$ & $\begin{array}{r}24 \\
5\end{array}$ & $4.48 *$ \\
\hline $\begin{array}{l}\text { organizational } \\
\text { climate (Total } \\
\text { ocs) }\end{array}$ & $\begin{array}{l}\text { Between Groups } \\
\text { Within Groupg } \\
\text { Total }\end{array}$ & $\begin{array}{r}3 \\
184 \\
286\end{array}$ & $\begin{array}{r}9.79 \\
9873 \\
20353\end{array}$ & $\begin{array}{r}160 \\
54\end{array}$ & $2.96 *$ \\
\hline Key: $\begin{array}{r}\star \leq \leq .05 \\
\star \star \leq \\
* \star \star 01 \\
+\leq .001 \\
\leq .06\end{array}$ & $\begin{array}{l}\text { CBSA }=\text { Collabo } \\
\text { IWS = Index } \\
\text { NSS : Nursing } \\
\text { OCS }=\text { Organiz }\end{array}$ & $\begin{array}{l}\text { e Beh } \\
\text { k Sat } \\
\text { as Sc } \\
\text { al c1 }\end{array}$ & $\begin{array}{l}\text { or scale } \\
\text { action } \\
\text { te seasur }\end{array}$ & Nurse-Phy & ian \\
\hline
\end{tabular}


